UNIVERSIDADE DE SÃO PAULO

ESCOLA POLITÉCNICA

JOÃO UMBIRUÇU CAMPOS MUNDIM

\title{
USO DE SIMULAÇÃO DE EVENTOS DISCRETOS PARA O DIMENSIONAMENTO DE FROTA PARA COLHEITA E TRANSPORTE DE CANA-DE-AÇÚCAR
}

São Paulo

2009 
JOÃO UMBIRUÇU CAMPOS MUNDIM

\section{USO DE SIMULAÇÃO DE EVENTOS DISCRETOS PARA O DIMENSIONAMENTO DE FROTA PARA COLHEITA E TRANSPORTE DE CANA-DE-AÇÚCAR}

Dissertação apresentada à Escola Politécnica da Universidade de São Paulo para obtenção do título de Mestre em Engenharia de Sistemas Logísticos.

Área de Concentração: Engenharia de Sistemas Logísticos

Orientador: Prof. Dr. Rui Carlos Botter 
Este exemplar foi revisado e alterado em relação à versão original, sob responsabilidade única do autor e com a anuência de seu orientador.

São Paulo, de abril de 2009.

Assinatura do autor

Assinatura do orientador

FICHA CATALOGRÁFICA

Mundim, João Umbiruçu Campos

Uso de simulação de eventos discretos para o dimensionamento de frota para colheita e transporte de cana-de-açúcar /

J.U.C. Mundim. -- ed.rev. -- São Paulo, 2009.

$104 \mathrm{p}$.

Dissertação (Mestrado) - Escola Politécnica da Universidade de São Paulo. Departamento de Engenharia de Transportes.

1. Sistemas discretos (Simulação) 2. Logística 3. Transportes 4. Cana-de-açúcar I. Universidade de São Paulo. Escola Politécnica. Departamento de Engenharia de Transportes II. t. 


\section{FOLHA DE APROVAÇÃO}

João Umbiruçu Campos Mundim

Uso de Simulação de Eventos Discretos para o dimensionamento de frota para colheita e transporte de cana-de-açúcar

Dissertação apresentada à Escola Politécnica da Universidade de São Paulo para obtenção do título de Mestre em Engenharia de Sistemas Logísticos

Área de concentração: Sistemas Logísticos

Aprovado em:

\section{Banca Examinadora}

Prof. Dr.

Instituição:

Assinatura:

Prof. Dr.

Instituição: Assinatura:

Prof. Dr.

Instituição: Assinatura: 


\section{DEDICATÓRIA}

Este trabalho é dedicado a três Marias que têm sido fundamentais na minha vida:

À Maria, minha mãe, que me deu à luz, ensinou-me as primeiras letras e passos e continua a me ensinar com a sua simplicidade e amor infindável.

À Ângela Maria, minha esposa, fonte inesgotável de amor, paciência, carinho e a grande incentivadora para a minha melhoria como ser humano.

À Maria Cristina, minha sobrinha, que me ensina todos os dias o que é o amor verdadeiro e que me faz lembrar que a sapiência se revela nas coisas mais simples da vida.

Dedico ainda à memória de meu pai que, junto com minha mãe, ensinou-me o caminho da retidão e a importância do respeito ao próximo e à natureza. 


\section{AGRADECIMENTOS}

Agradeço a Deus, quem quer que seja Ele, por nos dar a luz e o pão de cada dia.

Ao estímulo, confiança e paciência inesgotáveis de minha esposa.

À Tegma Gestão Logística S.A., que me permitiu conciliar as atividades acadêmicas e profissionais.

Ao Luciano Gabas Stuchi, com quem passei por maus momentos e aprendi muito sobre o que é ter esperança de um futuro melhor.

Ao João Eduardo A. R. da Silva, cujos alunos invejo, pela revisão do texto e pelas dicas valiosas.

Às novas amizades formadas durante as aulas do mestrado, especialmente ao Bonassa, David e Marcelo Aragão, com os quais vejo o mundo por ângulos diferentes.

Aos colegas de trabalho da Tegma, especialmente à equipe de Projetos, que muito contribuem para meu aperfeiçoamento profissional e pessoal.

Aos meus professores da Politécnica, em especial ao Prof. Dr. Cláudio Barbieri da Cunha, mestre exemplar.

Ao Elizio Rodrigues da Silva e Eduardo Kimura, que mesmo sem perceber mudaram o curso de minha vida.

E um agradecimento especial ao meu orientador Prof. Dr. Rui Carlos Botter que, com seu jeito peculiar, nunca se furtou a uma palavra de incentivo e que esteve sempre pronto para a orientação deste trabalho e sem cuja confiança eu não teria alcançado esta posição. 
"Tudo que nós vividamente imaginamos, ardentemente desejamos, sinceramente acreditamos e entusiasticamente colocamos ação, inevitavelmente tornarse-á realidade!"

Autor desconhecido 


\section{RESUMO}

MUNDIM, J. U. C. Uso de simulação de eventos discretos para o dimensionamento de frota de colheita e transporte de cana-de-açúcar. 2009. 118 f. Dissertação (Mestrado) Escola Politécnica, Universidade de São Paulo, São Paulo, 2009.

A produção brasileira de cana-de-açúcar foi de cerca de 426 milhões de toneladas na safra 2006/2007, tendo o estado de São Paulo participado com aproximadamente 264 milhões desse total. Esses valores conferem ao país a posição de maior produtor mundial de cana-de-açúcar, comprovando a importância do setor sucroalcooleiro na economia brasileira. As paradas na indústria açucareira, caracterizadas pela interrupção da produção por falta de matéria-prima, podem afetar negativamente a qualidade do produto final. Para que o abastecimento de cana na moenda seja feito de forma contínua é importante que o dimensionamento da frota para execução das operações de corte, carregamento e transporte (CCT) da cana-de-açúcar, até a entrega dela na usina, seja realizado de forma criteriosa, sob pena de se incorrer em elevado custo operacional. Estas operações podem ser executadas de diversas maneiras, variando parâmetros desde o tipo de corte (corte manual ou mecanizado) como o tipo de equipamento utilizado (carregadoras, colhedoras, tratores-reboque, etc.). Devido à interdependência dos processos, é possível a ocorrência de tempos não produtivos (filas) nos locais de carregamento e descarga, justamente pela quantificação desbalanceada dos recursos ou devido à variabilidade dos tempos de processo. Este trabalho aborda o problema de dimensionamento da frota de equipamentos utilizados no CCT, utilizando-se a técnica de simulação de eventos discretos. Este problema consiste, basicamente, em determinar a quantidade de equipamentos necessários ao cumprimento das operações citadas, de forma a maximizar a produção do sistema como um todo, minimizando o custo operacional. Foi desenvolvido um modelo de simulação que representa com fidelidade as operações de uma usina de cana-de-açúcar com capacidade de moagem de $19.500 \mathrm{t} /$ dia. Investigou-se necessidade de equipamentos frente a diferentes políticas de despacho da frota de caminhões, comparando o despacho estático de conjuntos de caminhões por frente de corte versus despacho Dinâmico; avaliou-se também a adoção de sistema drop and hook (D\&H) para as composições de transporte. O modelo desenvolvido foi capaz de mostrar como as decisões logísticas afetam a produtividade da frota e, conseqüentemente, o custo do sistema. $\mathrm{O}$ cenário com despacho dinâmico e sem adoção de D\&H apresentou o melhor resultado de custo operacional. Os resultados indicaram também que a adoção de reboques reserva na lavoura é economicamente viável. Como o modelo é bastante flexível quanto às configurações de cenários, outras combinações de fatores podem ser avaliadas.

Palavras-chave: Sistemas Discretos (Simulação), Transportes, Logística, Cana-de-açúcar. 


\begin{abstract}
MUNDIM, J. U. C. Use of discrete event simulation to the sizing of the harvest and transportation of sugar cane fleet f. 2009. 106 p. Essay (Master’s degree) - Escola Politécnica, Universidade de São Paulo, São Paulo, 2009.

The Brazilian production of cane sugar was around 426 million tonnes in the 2006/2007 season, the state of São Paulo participated in about 264 million from that sum. These figures give the country the position of the world's largest sugar cane producer, showing the importance of sugar-alcohol section in the Brazilian economy. The halts on the sugar industry, characterized by the interruption of production due to the lack of raw material, may adversely affect the quality of the final product. For the supply of cane in the milling to be done on a continuous way, it is important that the size of the fleet which runs the cutting, loading and transportation of sugar cane (CCT) operations up to its delivery in the mill- is carried out carefully, under penalty of incurring high operational costs. These operations might be implemented in different ways, ranging parameters from the kind of cut (manual or mechanical cutting) as the kind of equipment (loaders, harvesters, tractors, trailers, etc.). Due to the interdependence in the processes, it is possible the occurrence of non-productive time (queues) in place of loading and unloading, due to unbalanced quantifying of resources or due to the variability of time during the process. This paper approaches the problem of the equipment fleet sizing used in the $\mathrm{CCT}$, using the simulation of discrete events technique. This problem consists in determining the necessary amount of equipment to perform the above operations, in order to maximize the production of the system as a whole, minimizing the operational costs. We developed a simulation model that represents with accuracy the operations of a sugar cane plant with a milling capacity of 19,500 ton / day. The need for equipments facing different political dispatch from the fleet of trucks has been investigated, by comparing the dispatch of Static sets of trucks for each cutting front versus dynamic dispatch and the use of drop and hook system (D \& H) for the transportation setting. The developed model was able to show how the logistics decisions affect the fleet productivity and, consequently, the cost of the system. The scenario with dynamic dispatch and no D \& H use had the best results of operational costs. The results also indicated that the use of backup trailers in farming is economically viable. As the model is quite flexible concerning scenario settings, other combinations of factors can be evaluated.
\end{abstract}

Keywords: Discrete Systems (Simulation), Transport, Logistics, Sugar cane. 


\section{SUMÁRIO}

1. INTRODUÇÃ

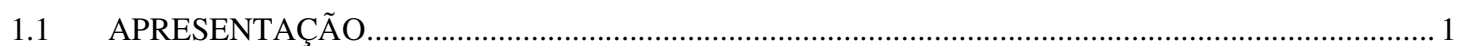

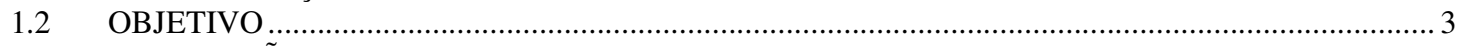

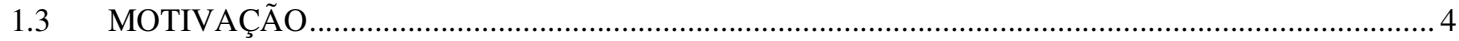

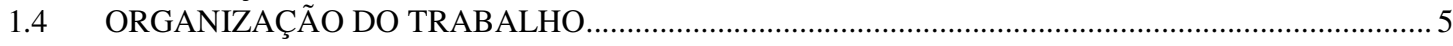

2. SISTEMAS DE CORTE, CARREGAMENTO E TRANSPORTE DE CANA-DE-AÇÚCAR .............. 7

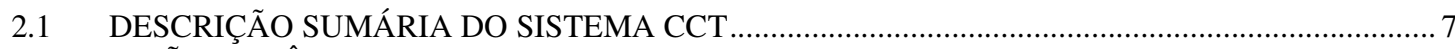

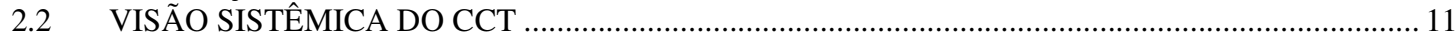

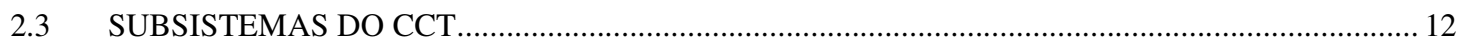

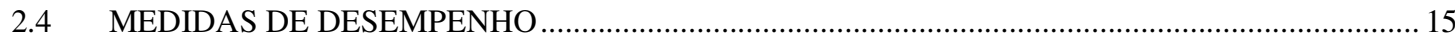

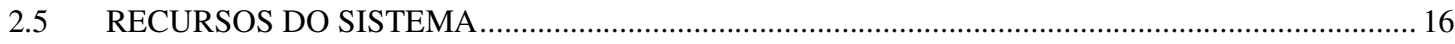

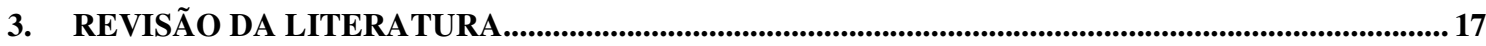

4. O QUE É SIMULAÇÃ

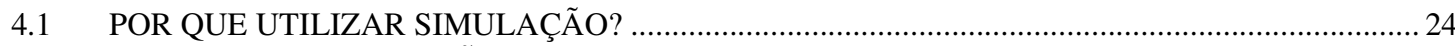

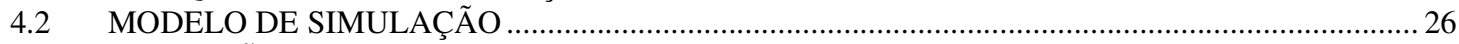

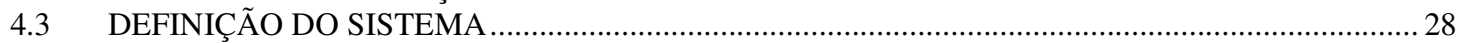

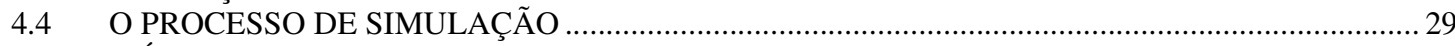

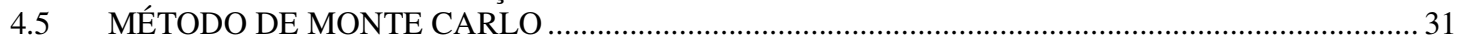

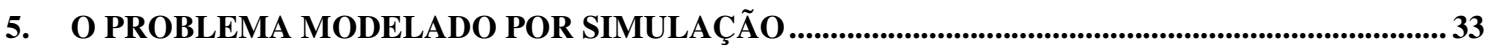

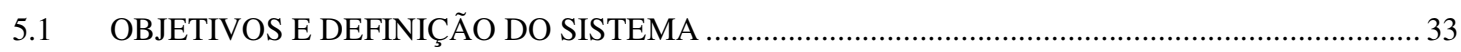

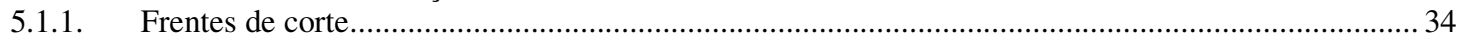

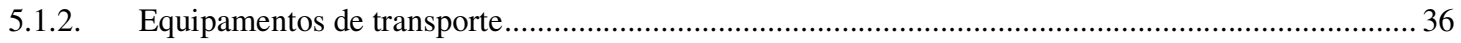

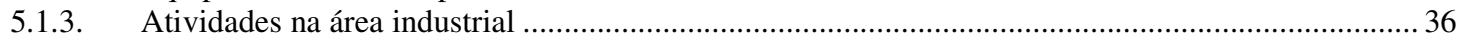

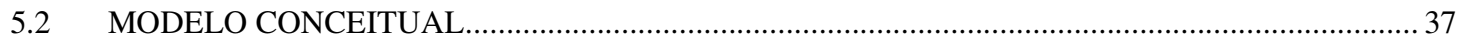

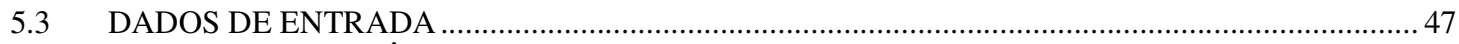

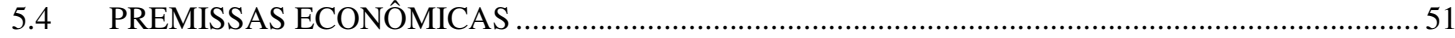

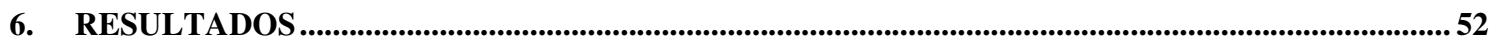

$6.1 \quad$ PROJETO EXPERIMENTAL

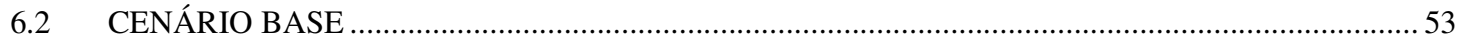

6.3 AVALIAÇÃO DE CENÁRIOS SEM ADOÇÃO DE BATE-VOLTA................................................56

6.4 AVALIAÇÃO DE CENÁRIOS COM ADOÇÃO DE BATE-VOLTA .......................................... 71

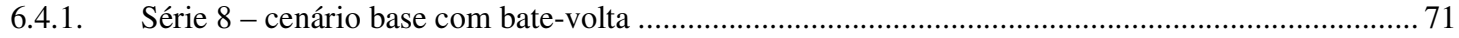

6.4.2. Série 9 - 32 rodotrens com bate-volta e despacho estático..................................................... 72

6.4.3. Série $10-27$ rodotrens com bate-volta e despacho dinâmico .................................................. 72

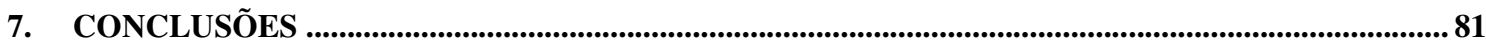

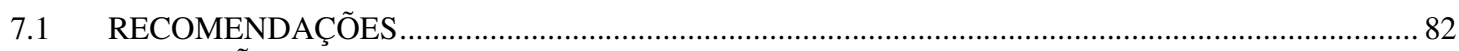

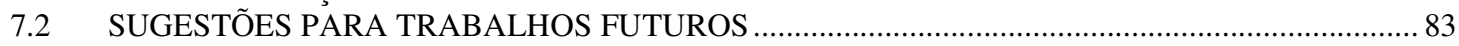

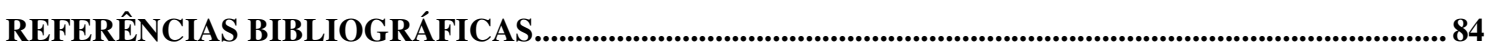

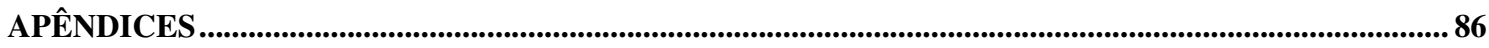




\section{LISTA DE FIGURAS}

Figura 1 - Representação esquemática das operações de CCT …......................................... 8

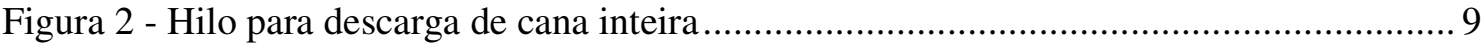

Figura 3 - Descarregamento de cana picada por báscula lateral ........................................... 10

Figura 5 - Etapas de desenvolvimento de um modelo de simulação ................................... 31

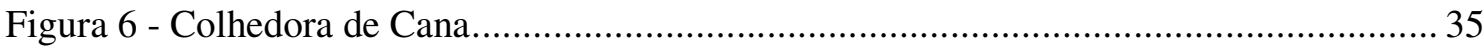

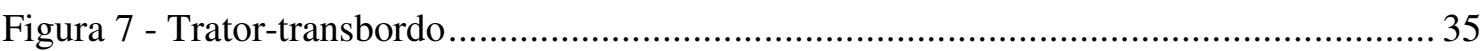

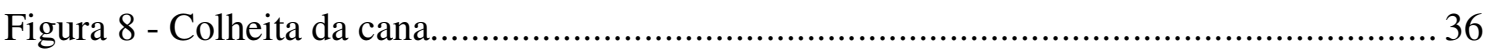

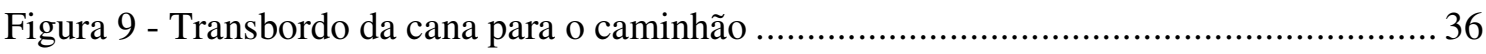

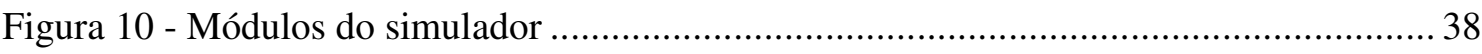

Figura 11 - Modelo conceitual do simulador de CCT …..................................................... 39

Figura 12 - Módulos da rotina de cálculo de vazão............................................................ 40

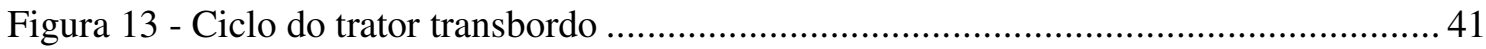

Figura 14 - Lógica para o cálculo da capacidade de carregamento da frente de corte ............ 45

Figura 15 - Fluxograma conceitual da frente de corte ........................................................... 46 


\section{LISTA DE GRÁFICOS}

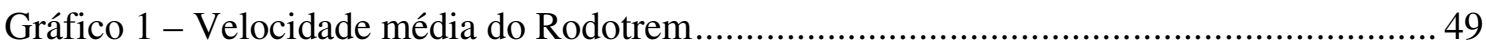

Gráfico 2- Série 1:Produção e tempo de campo ............................................................... 57

Gráfico 3 - Série 2: 27 rodotrens com reboque reserva na lavoura.................................... 59

Gráfico 4- Série 3: 32 rodotrens com reboque reserva na lavoura...................................... 60

Gráfico 5 - Série 4: 27 rodotrens sem reboque reserva na lavoura, despacho dinâmico ......... 61

Gráfico 6 - Série 5: 27 rodotrens com reboque reserva na lavoura, despacho dinâmico......... 63

Gráfico 7 - Série 6: 32 rodotrens com reboque reserva na lavoura, despacho dinâmico......... 64

Gráfico 8 -Série 7: custo da produção vs frota de caminhões vs frota de reboques reserva.... 68

Gráfico 9 - Série 7: produção diária vs frota de caminhões vs frota de reboques reserva....... 68

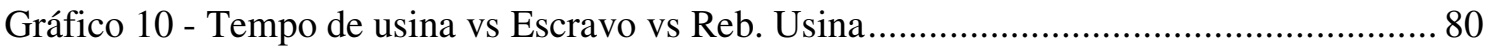




\section{LISTA DE QUADROS}

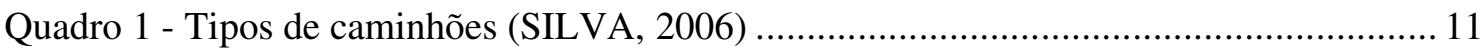

Quadro 2 - Medidas de efetividade do sistema CCT .................................................... 15

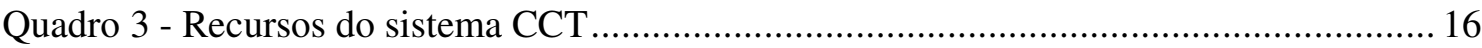

Quadro 4 - Variável auxiliar para cálculo da vazão............................................................. 44

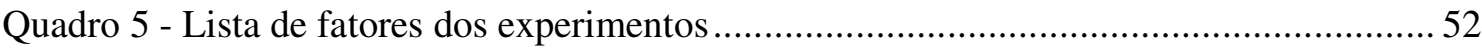

Quadro 6 - Valores associados a níveis de cada fator ....................................................... 53

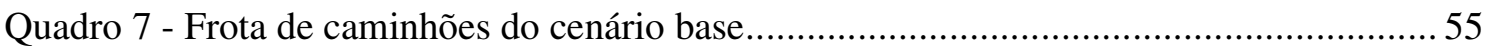

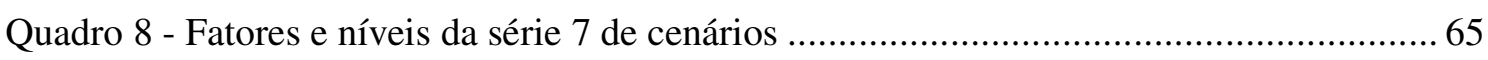




\section{LISTA DE TABELAS}

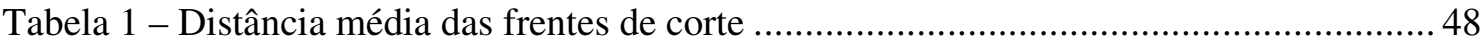

Tabela 2 - Relação de itens de manutenção considerados no modelo de simulação ...............50

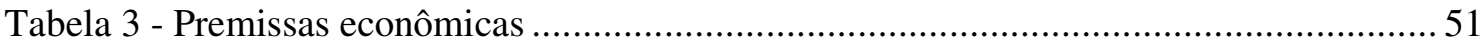

Tabela 4 - Série 1: 27 rodotrens sem reboque reserva na lavoura, despacho estático ........... 57

Tabela 5 - Série 2 - 27 rodotrens, com reboque reserva na lavoura, despacho estático ........ 58

Tabela 6 - Série 3: 32 rodotrens, com reboque reserva na lavoura, despacho estático........... 60

Tabela 7 - Série 4: 27 rodotrens sem reboque reserva na lavoura, despacho dinâmico......... 61

Tabela 8 - Série 5: 27 rodotrens com reboque reserva na lavoura, despacho dinâmico ........ 62

Tabela 9 - Série 6: 32 rodotrens com reboque reserva na lavoura, despacho dinâmico ........ 64

Tabela 10 - Série 7: 28 a 31 rodotrens, com reboque reserva e despacho dinâmico .............. 66

Tabela 11 - Melhores resultados de cada série sem bate-volta na usina ............................. 69

Tabela 12 - Melhores resultados de cada série sem bate-volta na usina ............................. 70

Tabela 13 - Série 8: 27 cenário base com bate-volta na usina............................................ 73

Tabela 14 - Série 9: 32 rodotrens com e bate-volta na usina.............................................. 73

Tabela 15 - Cenários com 27 rodotrens e diferentes quantidades de cavalo-escravo e reb.

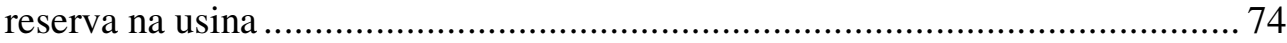




\section{Ca pít ulo}

\section{INTRODUÇÃ̃}

O presente trabalho foi redigido como parte dos requisitos para obtenção do título de Mestre na especialidade de Engenharia de Sistemas Logísticos, do curso multidisciplinar dos Departamentos de Engenharia Naval, Produção e Transportes da Escola Politécnica da Universidade de São Paulo.

\subsection{APRESENTAÇÃO}

A produção brasileira de cana-de-açúcar foi de cerca de 426 milhões de toneladas na safra 2006/2007, tendo o estado de São Paulo participado com aproximadamente 264 milhões desse total (UNICA, 2008). Esses valores conferem ao país a posição de maior produtor mundial de cana-de-açúcar, comprovando a importância do setor sucroalcooleiro na economia brasileira.

A safra de cana-de-açúcar na região centro-sul do Brasil tem início no mês de maio com término no mês de novembro, período que é caracterizado pela menor incidência de chuvas e pelos melhores índices de maturação da cana, em termos do teor de sacarose.

As paradas na indústria açucareira, caracterizadas pela interrupção da produção por falta de matéria-prima, são muito prejudiciais, uma vez que a qualidade da matéria-prima e do produto final pode ser negativamente afetada, razão pela qual a moagem nas usinas deve ser ininterrupta. Além disso, o custo de reinício de operação de uma usina é bastante elevado. Visando minimizar qualquer interrupção, é necessário um trabalho conjunto entre as áreas agrícola e industrial das usinas. Ações devem ser tomadas para programar as etapas de corte, a 
escolha de variedades adequadas com maiores teores de sacarose e o processamento quase que imediato da matéria-prima para evitar perdas e deterioração de açúcar.

Para que o abastecimento de cana na moenda seja feito adequadamente é importante que as operações de corte, carregamento e transporte (CCT) da cana-de-açúcar, até a entrega dela na usina, sejam feitas com eficiência. Estas operações podem ser executadas de diversas maneiras, variando parâmetros desde o tipo de corte (corte manual ou mecanizado) como o tipo de equipamento utilizado (carregadoras, colhedoras, tratores-reboque, etc.). Devido à interdependência dos processos, é possível a ocorrência de tempos não produtivos (filas) nos locais de carregamento e descarga, justamente pela quantificação desbalanceada dos recursos ou devido à variabilidade dos tempos de processo.

Outros procedimentos administrativos como trocas de turno, paradas para refeições e as paradas para manutenção automotiva também interferem no sistema produtivo, reduzindo a disponibilidade dos equipamentos para a plena operação.

Em muitas usinas a determinação do número de equipamentos necessários para a colheita (carregadoras, colhedoras e tratores) assim como a do número de caminhões necessários por frente de corte são feitas no início do dia pelo responsável do transporte, baseando-se geralmente no conhecimento prático, sem respaldo científico.

Embora o processo de CCT seja complexo, as operações são muito bem definidas, podendo ser detalhadas por meio de fluxogramas. SILVA (2006) afirma que outras abordagens diferentes da simulação não permitem analisar a dinâmica a interação entre os equipamentos de maneira adequada.

SILVA (2006) justificou assim a escolha de simulação para auxiliar o planejamento das operações de CCT: 
A escolha de simulação para auxiliar o planejamento das operações de CCT para abastecimento contínuo de cana para moagem foi devida à complexidade destas operações; não apenas pela interação entre os equipamentos, mas pela variabilidade associada às condições ambientais (topografia, umidade, configuração de talões) em que tais equipamentos operam. Tal variabilidade é relacionada não apenas às mudanças nas condições operacionais, como também à ocorrência de eventos não esperados, como a quebra de máquinas e veículos. A simulação contempla a interação entre os equipamentos e a variabilidade das operações tal qual ocorrem no sistema real. (SILVA, J. E. A. R., 2006, p. 7)

Através de um modelo de simulação, alterações nas configurações do sistema podem ser rapidamente avaliadas, evitando-se o dispêndio de testar esses sistemas na prática, ou tomar decisões sem qualquer critério. Uma vez construído o modelo, o planejamento estratégico da produção pode ser feito com maior segurança, visto que essa ferramenta pode ser utilizada facilmente para testar o impacto de novos cenários propostos.

Face à importância do setor sucroalcooleiro na economia nacional, é de grande relevância o desenvolvimento de ferramentas de suporte à tomada de decisão que possibilitem alcançar uma redução dos custos de produção do açúcar e do álcool. Mediante análise adequada, a tecnologia de simulação permite identificar as restrições do processo de produção e auxilia na tomada de decisão sobre as ações de melhoria que devem ser implementadas. No caso específico da cana-de-açúcar, dada a dimensão do setor, comprovada pelo volume de material trabalhado ou pela quantidade de equipamentos envolvidos, qualquer alteração proposta no sentido de redução de custo representa um potencial de economia muito significativo.

\subsection{OBJETIVO}

Esta dissertação aborda o uso de simulação de eventos discretos para o dimensionamento de recursos para o sistema de corte, carregamento e transporte de cana-deaçúcar, necessários para a realização da safra. 
O objetivo principal deste trabalho é desenvolver uma ferramenta computacional, baseada em simulação estocástica, capaz de representar o despacho de caminhões para o transporte de cana-de-açúcar tanto pelo método de despacho estático quanto pelo método de despacho dinâmico.

A simulação poderá ser utilizada pelos gerentes agrícolas para os planejamentos estratégicos (dimensionamento da frota, definição de modelo de equipamentos), bem como para o planejamento tático, auxiliando na definição da localização das frentes de corte.

Como objetivo secundário buscou-se comparar duas diferentes abordagens para a administração da frota de caminhões, sendo uma delas a adoção do desengate de composições na usina e outra, com a descarga direta das composições de carga tal como foram montadas na lavoura.

\subsection{MOTIVAÇÃO}

Conforme cita Marcos Sawaya Jank, presidente da ÚNICA:

A cana-de-açúcar tem quase 500 anos de história neste país, sendo que nos últimos 30 anos, graças aos empreendedores do setor sucroalcooleiro, a atividade tomou o leme da eficiência no universo da agroenergia, deixando de ser apenas uma planta alimentícia para se tornar um novo paradigma da energia limpa e renovável, na área dos combustíveis e da eletricidade.

As novas gerações de gestores das usinas de açúcar, atentos a esse movimento evolutivo, têm reconhecido que somente terão um lugar garantido nesse novo cenário se adotarem técnicas modernas de gestão e planejamento. A logística de CCT enquadra-se na categoria das atividades que requerem a adoção dessas técnicas, e é um campo no qual se percebe facilmente as vantagens da aplicação das modernas técnicas da pesquisa operacional. 
Neste sentido, o uso de técnicas de modelagem matemática contribui de maneira incisiva e positiva, como ferramentas de apoio à decisão, aos executivos e gestores destas empresas.

Então, com o intuito de contribuir com a difusão de técnicas de modelagem, adotouse esta linha de pesquisa, reforçada pelo fato de não terem sido encontrados na literatura pesquisada trabalhos relativos a dimensionamento de frota, em que estejam presentes, concomitantemente, as técnicas de simulação e rotinas de despacho de frota de composições rodoviárias.

\section{ORGANIZAÇÃO DO TRABALHO}

A dissertação está organizada em 7 capítulos. O capítulo 1 apresenta o tema, sua importância dentro do contexto brasileiro, o objetivo e a motivação para o seu desenvolvimento.

O capítulo 2 trata da descrição das operações de corte, carregamento e transporte da cana-de-açúcar.

No capítulo 3 apresenta-se a revisão bibliográfica do tema, com apresentação de aplicações de simulação computacional no setor sucroalcooleiro.

O capítulo 4 conceitua a simulação de sistemas, apresentando as terminologias utilizadas, vantagens e desvantagens de sua aplicação e a estrutura de desenvolvimento de um projeto de simulação.

No capítulo 5 são descritos o modelo de simulação de CCT desenvolvido e os parâmetros gerais de configuração de cenários. 
O capítulo 6 contempla os cenários analisados e os resultados obtidos.

Por fim, no capítulo 7 encontra-se a conclusão do trabalho e as considerações finais. 


\section{C a p ít u lo}

2

\section{SISTEMAS DE CORTE, CARREGAMENTO E TRANSPORTE DE CANA-DE-AÇÚCAR}

\subsection{DESCRIÇÃO SUMÁRIA DO SISTEMA CCT}

As operações de corte, carregamento e transporte (CCT) da cana-de-açúcar podem ser executadas de diversas maneiras, variando-se os parâmetros, desde o tipo de corte (corte manual ou mecanizado) como o tipo de equipamento utilizado (carregadoras, colhedoras, tratores-reboque, etc.).

O corte da cana pode ser manual ou mecanizado. No sistema de corte manual, a prática mais comum é o corte da cana inteira e disposição em linhas, que é realizada após a queima do canavial, e posterior carregamento mecânico em caminhões ou carretas tracionadas por tratores. No corte mecanizado, colhedoras automotrizes executam o corte, a limpeza, a picação em toletes, e a descarga da cana em um veículo, que pode ser um caminhão ou uma carreta tracionada por um trator. Para a colheita mecânica, uma prática mais recente é a utilização de transbordos (caçambas tracionadas por tratores). Neste sistema os caminhões não entram na área de colheita e os transbordos executam um transporte intermediário: recebem a cana picada das colhedoras e transferem a carga para os caminhões que permanecem fora do talhão.

O transporte da cana é predominantemente do tipo rodoviário, com o emprego de caminhões que carregam cana inteira (colheita manual) ou cana picada em toletes de 20 a 25 cm (colheita mecânica). Há vários tipos de composições de conjuntos de transporte, sendo os 
mais comuns o caminhão com um reboque (Romeu e Julieta), o caminhão com dois reboques (Treminhão) e o cavalo-mecânico com dois semi-reboques (Rodotrem). Dependendo do tipo de configuração da frota, no campo e/ou na usina, podem ser adotadas carretas-reserva como estratégias para dinamizar a produção, que potencializa o uso do cavalo-mecânico ou caminhão.

Na Figura 1 encontra-se a representação esquemática do sistema CCT.

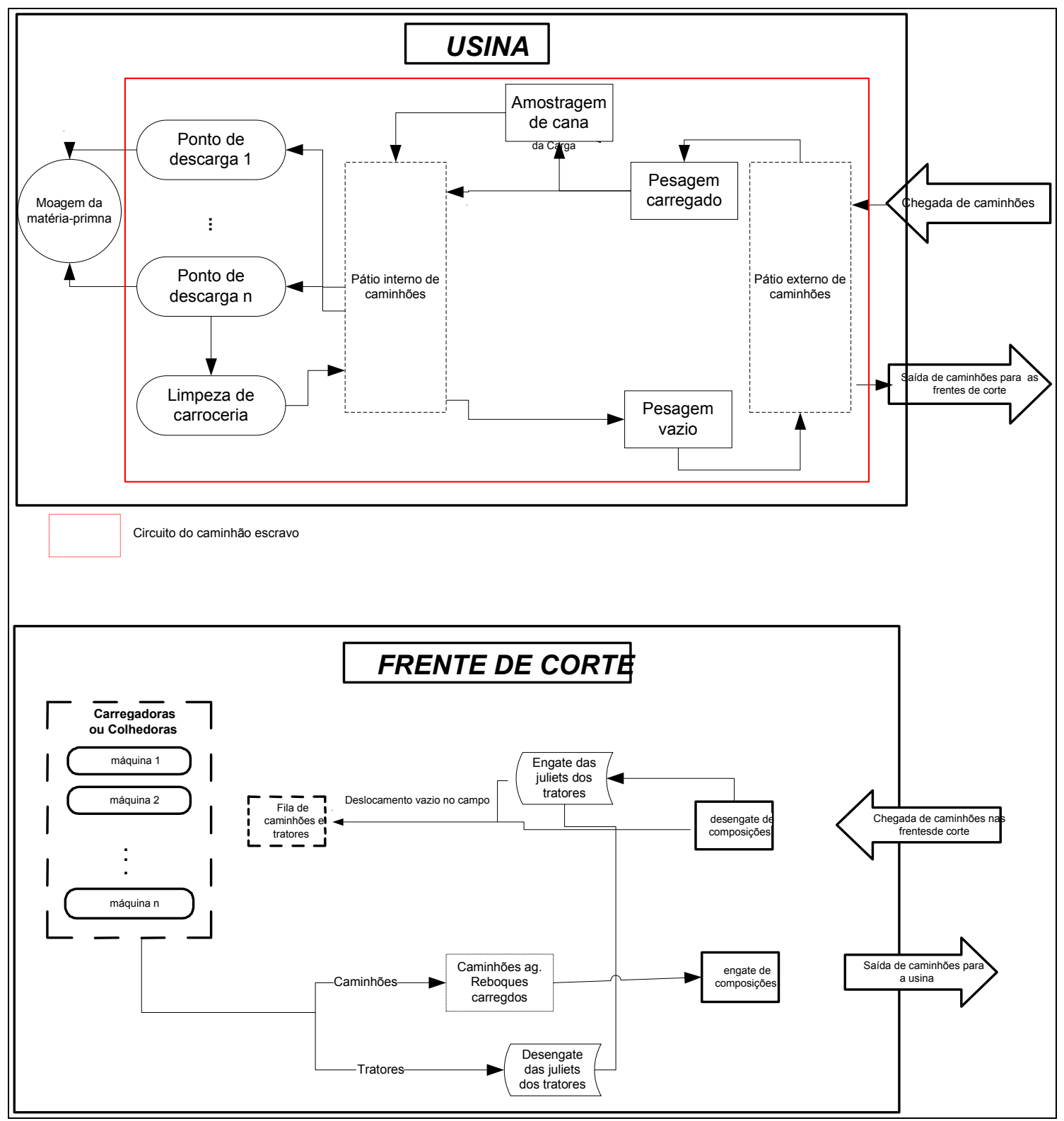

Figura 1 - Representação esquemática das operações de CCT (Hahn (1994)) 
Na usina, os veículos são pesados antes e após o descarregamento, obtendo-se assim o peso real da cana pela diferença entre as duas medidas. Algumas cargas são aleatoriamente selecionadas e amostradas para posterior determinação, em laboratório, do teor de sacarose na matéria-prima.

A cana pode ser descarregada e permanecer em pátio próprio para estocagem. É possível, também, ser estocada nas próprias composições que realizaram o transporte desde a lavoura (pátio sobre rodas) ou, ainda, ser enviada para alimentação direta nas moendas. No primeiro caso, o descarregamento se dá através de pontes rolantes equipadas com garras hidráulicas ou guindaste do tipo hilo, em pátio aberto ou em um barracão. Tratando-se de cana picada, o estoque só pode ser feito sobre rodas.

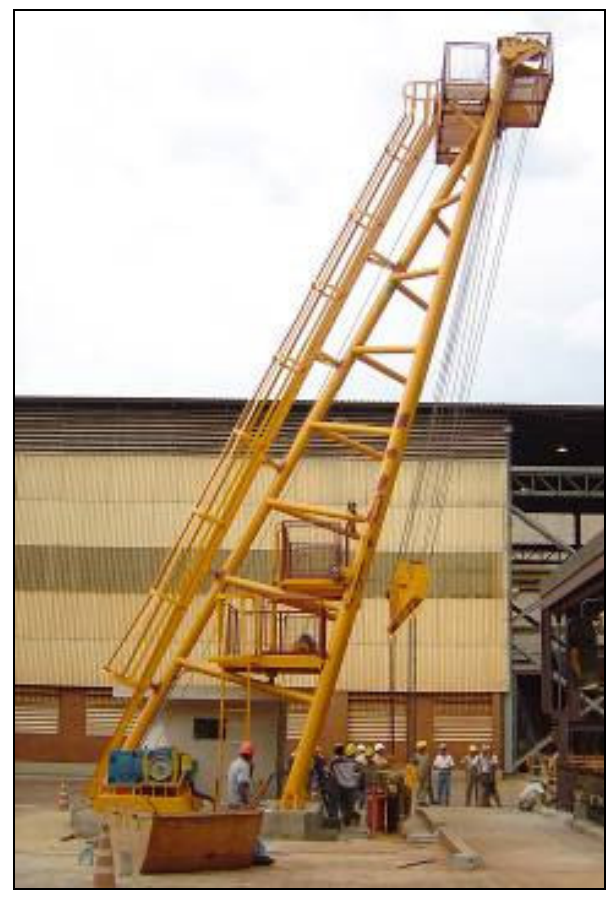

Figura 2 - Hilo para descarga de cana inteira (Fonte: Silva (2006))

O descarregamento da cana picada é realizado com o uso de pontes rolantes, guindastes do tipo hilo e também através de um tombador hidráulico para basculamento lateral dos caminhões, ou ainda por pivotamento lateral de caçambas fechadas. 


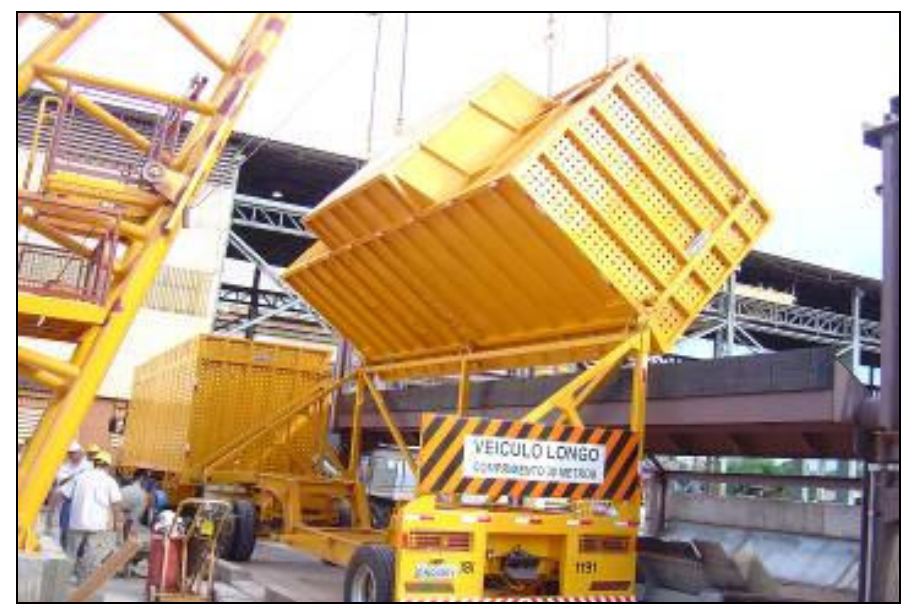

Figura 3 - Descarregamento de cana picada por báscula lateral (Fonte: Silva (2006))

Segundo Hahn (1994), os caminhões canavieiros podem ser classificados nas seguintes categorias:

a) Caminhões simples (também chamado "Truck", "Plataforma" ou "Solteiro") caminhão com uma carroceria própria.

b) "Romeu e Julieta" - caminhão plataforma rebocando uma carreta, que no jargão das usinas chama-se "Julieta".

c) "Treminhão" - caminhão plataforma rebocando duas carretas ou julietas.

d) Caminhões do tipo Cavalo-mecânico (também chamados "Bate Volta" ou dropand-hook), que não possuem carroceria própria.

Segundo Hahn (1994), o número de frentes de corte trabalhadas diariamente varia de três até mais de 12, de acordo com a quantidade de cana estimada em cada frente e a capacidade de moagem diária da usina. Estas frentes encontram-se a diferentes distâncias da usina, fazendo com que a quantidade de caminhões em direção a uma frente de corte seja diferente de outra frente com o mesmo potencial de colheita.

No Quadro 1 estão ilustrados os diferentes tipos de caminhões. 


\begin{tabular}{llc}
\hline \multicolumn{1}{c}{ Descrição } & Esquema & Nome popular \\
\hline Caminhão plataforma & & "Truck" \\
\hline Caminhão plataforma com & & "Romeu e Julieta" \\
um reboque acoplado & & \\
\hline Caminhão plataforma com & & \\
dois reboques acoplados & & \\
\hline Cavalo-mecânico com & & \\
dois semi-reboques & &
\end{tabular}

Quadro 1 - Tipos de caminhões (SILVA, 2006)

\subsection{VISÃO SISTÊMICA DO CCT}

Segundo Merdith, Wong, Woodhead e Wortman, citados por GUALDA (1995), um sistema pode ser definido como uma coleção de componentes, conectados por algum tipo de interação ou relacionamento, sendo capaz de responder a estímulos ou demandas, e de realizar algum propósito ou função. Cada componente responde ao estímulo de acordo com a sua natureza, porém o estímulo recebido, assim como o comportamento do componente, é condicionado pela sua interação com os demais componentes.

Dentro deste contexto o Sistema CCT abordado aqui pode ser considerado um subsistema dentro do sistema maior que é a Produção de Açúcar.

Para identificar um sistema pelo método do enfoque sistêmico devem ser considerados seus componentes (entidades) e as características (atributos) destes componentes. As entidades são os elementos do sistema que podem ser identificados e processados individualmente. Exemplos de entidades no Sistema CCT incluem os caminhões, 
as carregadoras, as colhedoras, os transbordos e os tratores, enfim, todos os elementos que mudam de estado durante a execução das operações.

\subsection{SUBSISTEMAS DO CCT}

O sistema de produção de cana-de-açúcar pode-ser subdivido em três grandes subsistemas:

- O sistema de produção de cana, responsável pelo trato da terra e pela produção da cana-de-açúcar;

- O sistema de corte, carregamento e transporte de cana (CCT), responsável pela colheita e transporte da cana-de-açúcar;

- O sistema industrial de produção de açúcar, álcool e energia, responsável pela industrialização da cana-de-açúcar.

Neste trabalho o foco é o subsistema CCT, identificado na Figura 4, que representa a relação sistêmica entre o sistema CCT e seu ambiente.

Pela Figura 4 verifica-se que o subsistema CCT está também subdividido em outros subsistemas:

- Subsistema Carregamento: voltado para o carregamento de cana inteira e circulação de tratores dentro do talhão;

- Subsistema Corte Mecânico: relacionado ao corte mecânico da cana-de-açúcar e à circulação de tratores dentro do talhão, sendo que este último componente, embora tenha o mesmo nome de um componente do Subsistema Carregamento, apresenta característica e entidades diferentes. As entidades diferentes são as caixas de transbordo e as características são o fato de que o conjunto tratortransbordo não é desengatado; 
- Subsistema Pátio de Engate: associado à formação das cargas e das composições rodoviárias de transporte;

- Subsistema Rodoviário: diz respeito às vias de circulação e às atividades de manutenção dos caminhões e julietas;

- Subsistema Recepção de Cana: representa os equipamentos presentes na indústria propriamente dita, limitando-se à parte externa da unidade industrial, ou seja, desde a balança de pesagem até a mesa alimentadora.

$\mathrm{Na}$ interligação destes subsistemas podem-se identificar as entidades que circulam entre eles e que passam por algum tipo de processamento ao longo do Sistema CCT. 
SITEMA DE PRODUÇÃO DE AÇÚCAR

SISTEMA AGRÍCOLA

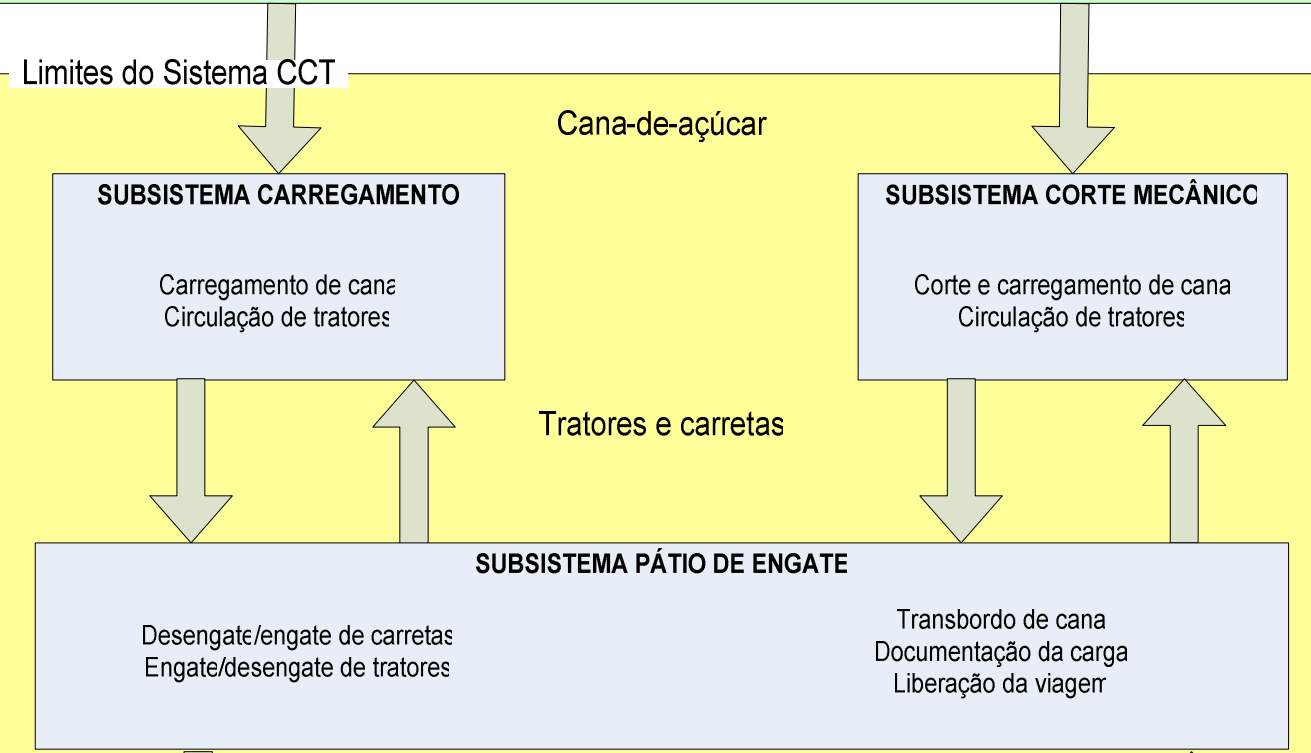

Caminhões carretas e cana

SUBSISTEMA RODOVIÁRIO

Transporte da cana-de-açúcar

Abastecimento $\epsilon$ manutenção de

Vias de circulação

equipamentos

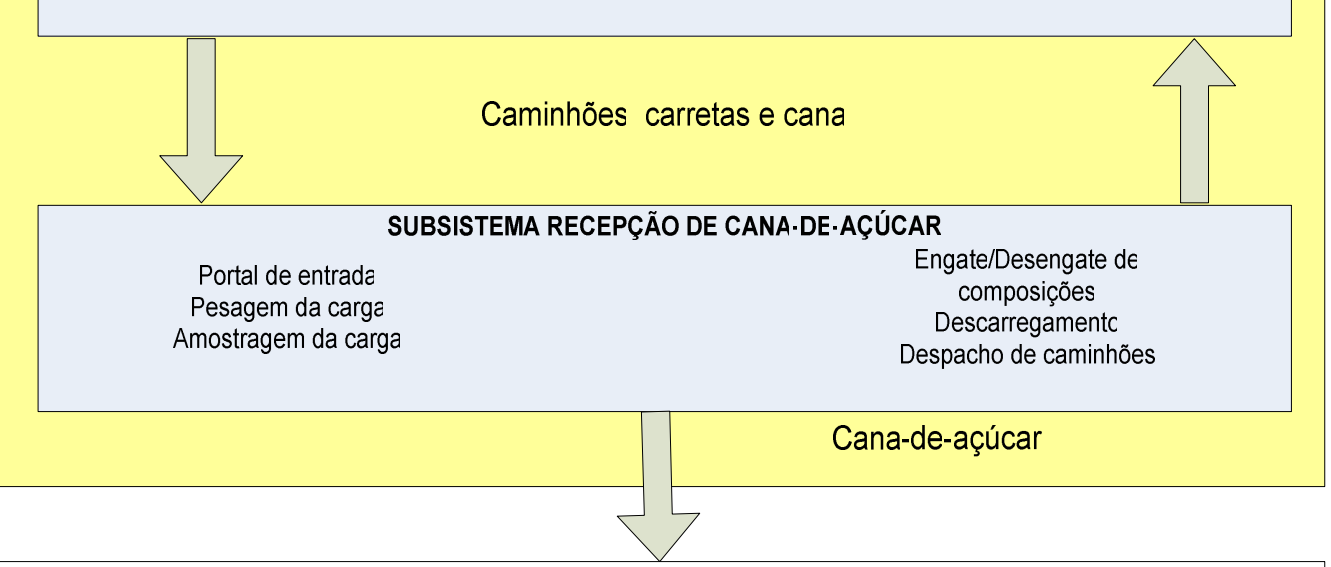

SISTEMA INDUSTRIAL

Figura 4 - Subsistemas e componentes do sistema CCT (adaptado de Gualda (1995)) 


\subsection{MEDIDAS DE DESEMPENHO}

A modelagem de um processo tem como função básica o auxílio à tomada de decisão. Assim, torna-se necessário identificar a capacidade operacional dos equipamentos do sistema em estudo, bem como os níveis de serviço.

Nível de serviço pode ser entendido, conforme GUALDA (1995), como sendo a qualidade do serviço oferecido e, no caso deste trabalho, pode ser exemplificado pelo comprimento de uma fila de caminhões aguardando por descarga.

Já a capacidade operacional de máquinas agrícolas (para efeitos de simplificação consideram-se os caminhões como sendo máquinas agrícolas neste trabalho), conforme metodologia apresentada por Mialhe citada por SILVA (2006), representa a quantidade de trabalho capaz de se executar por unidade de tempo, podendo ser representada pela equação 1 .

$$
C O=\frac{Q T}{T} \quad \text { (Equação 1) }
$$

Onde:

$$
\begin{aligned}
& \text { CO = Capacidade Operacional } \\
& \text { QT = Quantidade de trabalho executado ou "produção" } \\
& \text { T = Unidade de Tempo }
\end{aligned}
$$

As medidas de desempenho do Sistema CCT adotadas neste trabalho, e seus índices de avaliação, estão listados no Quadro 2.

\begin{tabular}{lc}
\hline \multicolumn{1}{c}{ Medida } & Índice de análise \\
\hline Custo da operação & $\mathrm{R} \$ / \mathrm{t}$ \\
\hline Produtividade dos caminhões & $\mathrm{t} . c a m /$ dia \\
\hline Produção diária & t total transportada/dia \\
\hline Quadro 2 - Medidas de efetividade do sistema CCT
\end{tabular}




\subsection{RECURSOS DO SISTEMA}

Os recursos do sistema CCT, e suas associações com os subsistemas, estão listados no Quadro 3.

\begin{tabular}{ll}
\hline Subsistema & Recursos \\
\hline Carregamento & Carregadoras \\
& Tratores de reboque \\
\hline Corte mecânico & Colhedoras \\
& Tratores de reboque \\
& Transbordos \\
\hline Pátio de engate & Reboques reservas \\
\hline Rodoviário & Engatadores \\
& Caminhões \\
& Reboques \\
Recepção de cana & Vias de acesso \\
& Balança \\
& Amostrador de cana \\
& Pátio de engate / desengate \\
& Mesas de descarga \\
Cabine de despacho & Engatadores \\
\hline
\end{tabular}

Quadro 3 - Recursos do sistema CCT 


\section{Ca pít u lo}

3

\section{REVISÃO DA LITERATURA}

Segundo SLACK (1997), a atividade de programação é uma das mais complexas tarefas no gerenciamento da produção. Os programadores têm que lidar com tipos diferentes de recursos simultaneamente. As máquinas têm diferentes capacidades e funções e os operadores terão diferentes habilidades. De maneira mais importante, o número de programações cresce rapidamente à medida que o número de atividades e processos aumenta. A tarefa de programação deve ser repetida freqüentemente para permitir respostas às variações de mercado e às mudanças do mix de produtos. Pequenas alterações no mix de produtos podem fazer com que os recursos limitadores de capacidade dentro das instalações mudem bastante em um tempo curto, assim, gargalos podem mover-se pela fábrica bastante rapidamente.

KELTON (1998) afirma que, embora simulação não seja a única ferramenta que se possa usar para estudar o sistema produtivo, é um método de escolha freqüentemente utilizado. A razão para isso é que um modelo de simulação pode se tornar complexo, se necessário, para representar o sistema fielmente. Outros métodos podem requerer simplificações demais do sistema para permitir a análise, o que pode questionar a validade do modelo.

O sucesso ou o fracasso de um estudo de simulação depende do estabelecimento de um escopo e do planejamento do projeto (SADOWSKI, 1999). A especificação do estudo deve ser focada na obtenção de resultados de acordo com o escopo estabelecido. Falhas na 
obtenção desses compromissos ou o estabelecimento de objetivos que são muito vagos podem levar o projeto ao fracasso.

Na visão de KELTON (1998), a maneira que a simulação é utilizada tem mudado. Ela está sendo empregada mais cedo, na fase de projeto, e está sendo freqüentemente atualizada na medida em que as mudanças estão ocorrendo nos sistemas em operação. Isto fornece um modelo de simulação vivo, que pode ser rapidamente utilizado para análise dos sistemas. A simulação também ocupou a indústria de serviços, na qual ela está sendo aplicada em muitas áreas não tradicionais, como, por exemplo, procedimentos administrativos.

KELTON (1998) também aponta que os fatores que dificultam a simulação de se tornar uma ferramenta universalmente aceita são o tempo de desenvolvimento dos modelos e o conhecimento requerido para o seu desenvolvimento. Com o objetivo de tornar a simulação mais simples de se usar por um número maior de pessoas, há a tendência de desenvolvimento de mais produtos verticais, ou seja, que podem ser customizados para um mesmo tipo de processo. Isso irá permitir aos analistas construir simulações facilmente, utilizando construções de modelagem projetadas para sua área de atuação, diretamente relacionadas com sua realidade. A primeira geração desse tipo de produto está em áreas de aplicação como comunicações, callcenters e processos de reengenharia.

HAHN (1994) assim definiu os métodos de despacho de caminhões:

Despacho estático é aquele onde cada caminhão é alocado a uma determinada frente de corte no início do dia. Neste caso o caminhão permanece viajando apenas para esta frente durante todo o dia. No caso de despacho dinâmico os caminhões ficam livres para viajar para qualquer frente. A decisão de qual frente o caminhão se dirigirá é tomada sempre no momento de sua saída da usina.

Abordando o assunto CCT, HAHN (1994) afirma que as usinas normalmente possuem uma frota mista com caminhões próprios e fretados. A frota pode ser homogênea ou ter várias categorias de caminhões com diferentes capacidades e características operacionais. 
O transporte é efetuado de forma cíclica entre a usina e os pontos de colheita do produto primário. As principais características deste sistema são que um caminhão, a cada viagem, visita apenas um ponto de suprimento, retornando em seguida à usina. Os pontos de suprimento não são permanentes, podendo variar diariamente em número e localização. Finalmente, uma das características mais importantes deste sistema é a formação de filas, que devem ser minimizadas, tanto nos pontos de fornecimento como na usina.

O problema abordado por HAHN (1994), era o de dimensionar todos os equipamentos para o dia seguinte, sendo a simulação o ferramental utilizado para resolução do problema. A simulação permite uma previsão do que pode acontecer, baseando-se em histórico anterior. Naturalmente, não necessariamente o que foi simulado acontece no dia seguinte. Dessa forma a simulação permite um planejamento tático ou estratégico, mas para o planejamento operacional, para o qual existe a necessidade de decisão rápida do local para onde o caminhão deve ser enviado, a simulação não seria o ferramental mais adequado, uma vez que ela não oferece, necessariamente, uma solução ótima.

Ainda segundo HAHN (1994), existe grande dificuldade no gerenciamento das atividades de carregamento e transporte pois, quando ocorrem mudanças em algumas variáveis envolvidas, é necessário um rápido replanejamento, a fim de se verificar a viabilidade ou não de determinadas mudanças. O objetivo final é manter um fluxo constante de entrega de matéria-prima para moagem, durante 24 horas do dia, ao longo de toda a safra. Como os fatores envolvidos são muitos e os erros muito onerosos, acaba-se tendo uma situação de superdimensionamento dos recursos.

Segundo LOPES (1995) as operações de CCT respondem por 30\% a 40\% do custo da cana entregue para moagem e, na seqüência desses custos, após a moagem, o transporte é a operação mais cara, seguida pelo carregamento. Assim, chega-se a uma situação em que a 
ociosidade no transporte é preferível a uma falta de cana para moagem, assim como a ociosidade de carregadoras e tratores é preferível à perda de tempo dos caminhões aguardando carregamento. Essa situação, segundo o mesmo autor, muda quando a frente de corte deixa de ter carregadoras e passa a ter colhedoras, com custo de capital e operacional bem mais elevados.

COCHRAN \& WHITNEY (1977) estudaram o planejamento de um sistema de transporte de cana-de-açúcar considerando os seguintes fatores:

- $\quad$ Capacidade de carregamento;

- $\quad$ Número de equipamentos de transporte;

- $\quad$ Capacidade de carga de cada equipamento de transporte;

- $\quad$ Distância do campo até a indústria;

- Velocidade média dos equipamentos de transporte;

- $\quad$ Tempo gasto para descarregamento na usina.

Para dimensionar a capacidade de abastecimento de cana de um determinado sistema de transporte, os autores tomaram por base a capacidade de carregamento. Se houvesse uma disponibilidade constante de veículos de transporte no campo, o fluxo de cana entregue à indústria $(D e)$ seria igual ao fluxo de carregamento $(R)$ :

$$
D e=R \quad \text { (Equação 2) }
$$

No entanto, existe uma probabilidade de que em parte do tempo, todos os veículos estejam na usina ou em trânsito. Assim, o fluxo de cana entregue (De) é:

$$
D e=R(1-P o) \quad(\text { Equação } 3)
$$

Em que (1- Po) é a probabilidade de, em um determinado momento, pelo menos um equipamento de transporte ou de carregamento estar ocioso (fila para carregamento e/ou espera de veículos). 
SEIXAS \& WIDMER (1993) aplicaram programação linear inteira para selecionar e dimensionar a frota de veículos para o transporte principal de madeira. Em seu estudo os autores não consideraram os equipamentos de campo, responsáveis pelo carregamento dos caminhões; neste aspecto o trabalho limitou-se a considerar o número de viagens de um veículo no período T; pelo método utilizado (programação linear) não foi possível agregar a variabilidade dos tempos dos processos ao modelo proposto.

WIDMER (1990) analisou a formação de filas nos eventos de carregamento e descarregamento de madeira e cítricos, demonstrando que técnicas de despacho estático contribuem para o baixo aproveitamento da frota. $\mathrm{O}$ artigo, entretanto, não indica nenhuma técnica para a análise e soluções de melhoria.

IANNONI (2000) utilizou simulação de sistemas para analisar o processo de descarga de caminhões na usina. O trabalho restringiu-se apenas ao processo de descarga, não considerando que alterações neste subprocesso do sistema CCT possam afetar o desempenho da frota de equipamentos envolvidos nesta atividade.

ARCE, GUARNIERI E MENDES (1999) desenvolveram um sistema de programação de transporte florestal objetivando a minimização de custos, utilizando programação Dinâmico composto de dois módulos sendo um deles o Algoritmo del Modelo de Transportes (AMT) e o outro o Algoritmo de Designación de los Camiones (ADC). O AMT otimiza a quantidade de madeira que deve ser transportada a partir de um determinado ponto e o ADC, por sua vez otimiza, para cada caminhão do sistema, a jornada de trabalho que se refere ao tempo de efetivo de transporte e o tempo ocioso em viagens sem carga e/ou em filas. O modelo matemático desenvolvido pelos autores considera os tempos de viagens como sendo médios, não sendo possível aplicar variabilidade a esta variável. 
RAICU E TAYLOR (2002) desenvolveram um Sistema Computadorizado de Suporte à Decisão para selecionar a estratégia ótima de despacho de caminhões, com o objetivo de maximizar a utilização dos caminhões canavieiros. O sistema foi desenvolvido em Visual Fox Pro e destina-se ao planejamento operacional; não considera as variabilidades dos tempos de carregamento e trabalha apenas com as informações de bins (julietas) disponíveis nos locais de carregamento. Esta simplificação ocorre em função das características operacionais da indústria sucroalcooleira da Austrália, onde, por regra, o fornecedor de cana é responsável pelo carregamento dos bins fornecidos pela usina; o transporte ocorre durante as 24 horas do dia, enquanto que a colheita ocorre durante o período diurno (14 horas/dia) (RAICU, 2000).

GAUCHER, LE GAL E SOLER (2003) desenvolveram dois modelos complementares para simular, semanalmente, o planejamento e a operação de uma usina ao longo da safra. O primeiro modelo compara a produção semanal e total da safra, enquanto que o segundo modelo trata da cadeia logística e permite avaliar diariamente os impactos das mudanças estruturais da capacidade de colheita e transporte. A exemplo do trabalho desenvolvido por RAICU E TAYLOR (2002), os modelos desenvolvidos aplicam-se ao sistema australiano e não contemplam o subprocesso de colheita propriamente dito.

YOSHIZAKI (1989) aplicou Modelos de Redes de Filas para avaliar o desempenho operacional de sistemas logísticos, tendo como foco principal a análise da formação de filas na entrada do pátio de uma usina. Para o estudo foi considerado um dia típico de operação da usina, considerando o sistema CCT como uma cadeia fechada (caminhões da frota própria), sendo parte do sistema considerada como uma cadeia aberta (caminhões de terceiros), tendo uma simplificação bastante expressiva ao considerar a capacidade de campo (veículos carregados / minuto) como sendo infinita. O autor conclui que os modelos analíticos de redes 
de fila podem ser usados para cálculos preliminares, sendo recomendada a aplicação de simulação para resultados mais precisos.

Assim, considerando a complexidade do Sistema CCT, sua natureza dinâmica aleatória e a forte correlação entre seus subsistemas, que dificilmente podem ser representadas por métodos determinísticos e por modelos de redes de fila, o autor optou por utilizar Simulação Estocástica para o desenvolvimento desta dissertação. 
C a p ít u lo

4

\section{O QUE É SIMULAÇÃO?}

Segundo o Dicionário Aurélio: s.f. “Ato ou efeito de simular. Experiência ou ensaio realizado com o auxílio de modelos”.

De acordo com PEGDEN (1990), “simulação é o processo de desenhar um modelo de um sistema real e conduzir experimentos com este modelo, com o propósito de compreender o comportamento do sistema e/ou avaliar várias estratégias para operação do sistema”.

\subsection{POR QUE UTILIZAR SIMULAÇÃO?}

Segundo RAVINDRAN (apud HAHN, 1994, p. 2.7) ${ }^{1}$, recentes avanços na técnica de simulação, disponibilidade de software e de computadores mais velozes têm feito da simulação uma das ferramentas mais amplamente utilizadas e aceitas na análise de sistemas e Pesquisa Operacional, sendo que os levantamentos mais recentes neste campo científico colocam este tipo de análise (simulação) junto com a programação linear nos dois primeiros lugares entre as mais utilizadas.

PEGDEN, SHANNON, SADOWSKI (1995), SALIBY (1989) e FREITAS FILHO (2001) enumeram algumas das principais vantagens que tornam a simulação uma ferramenta tão utilizada:

\footnotetext{
${ }^{1}$ RAVINDRAN, A., PHILIPS, D.T., SOLBERG, J.J: Operations Research Principles and Pratice, Jonn Wiley \& Sons, Second Edition, 1987.
} 
1) Modelos mais realistas - a simulação permite uma maior liberdade na construção do modelo, não obrigando a enquadrar um problema a um determinado molde para que se possa obter uma solução, como ocorre, por exemplo, no caso da programação linear.

2) Processo e modelagem evolutivos - uma importante vantagem no processo de modelagem em simulação é o seu caráter evolutivo. Assim, começando com um modelo relativamente simples, pode-se aos poucos ir identificando de maneira mais clara as peculiaridades do problema, e em função disso ir aperfeiçoando o modelo. Mesmo depois de pronto, o modelo pode ser acrescido de novas variáveis e/ou relações, sem que isso comprometa a estrutura original dele .

3) Facilidade de comunicação - um modelo de simulação é, em geral, muito mais fácil de ser compreendido do que um conjunto de complicadas equações matemáticas. Atualmente muitos esforços vêm sendo dedicados ao desenvolvimento da simulação visual, mostrando-se num vídeo uma imagem animada do problema.

4) Sistemas complexos - a simulação toma possível o estudo e experimento de sistema com interações internas complexas tais como uma firma, uma indústria, a economia ou um subsistema componente de um desses.

5) Facilidade de testar regras de operação - a simulação pode testar novas políticas e regras de decisão para operação de um sistema, antes de correr o risco de implementá-las no sistema real. 
6) Introdução de novos elementos - quando novos elementos são introduzidos no sistema, a simulação pode ser utilizada para antecipar os gargalos e outros problemas que possam surgir em seu comportamento.

\subsection{MODELO DE SIMULAÇÃO}

A simulação através de protótipos é, na maioria dos casos, inviável técnica ou economicamente, sendo adotada, sempre que possível, a simulação em computadores digitais por suas indiscutíveis vantagens em termos de tempo, economia e flexibilidade.

Modelo é uma representação simplificada de um sistema e modelo de simulação consiste em um conjunto de equações lógico-matemáticas capazes de descrever as principais ações e inter-relações existentes entre os diversos componentes de um sistema. Em experimentos com modelo de simulação deseja-se obter aspectos importantes do comportamento do sistema ao longo de um período de tempo.

\section{Conforme KELTON, SADOWSKI \& SADOWSKY (1998) uma determinada} simulação, de acordo com o modelo desenvolvido, pode ser classificada da seguinte maneira:

- $\quad$ Simulação Determinística ou Estocástica (ou Probabilística) - uma simulação é determinística quando todas as variáveis envolvidas são também determinísticas, o que significa que os seus valores podem ser determinados sem incertezas. Este tipo de simulação geralmente é justificado quando aplicado a um sistema muito complexo envolvendo grande número de variáveis ou de relações. No entanto, a simulação estocástica aplica-se quando a incerteza nos valores das variáveis é determinante no funcionamento do sistema. Neste caso, o modelo contém uma ou mais variáveis aleatórias, representadas por distribuições de probabilidade, com objetivo de reproduzir, 
da maneira mais apropriada possível, os valores reais representados por estas variáveis.

- Simulação Estática ou Dinâmica - simulação estática se aplica quando a dimensão tempo não é relevante dentro da simulação. As aplicações deste tipo de simulação são bastante raras. A grande maioria das aplicações em simulação refere-se ao estudo de sistema ao longo do tempo, o que caracteriza uma simulação dinâmica.

- $\quad$ Simulação Discreta ou Contínua - uma simulação pode ser classificada em discreta ou contínua, dependendo do processo de atualização das variáveis que descrevem o estado do sistema. Na simulação contínua, a passagem do tempo é vista como se fosse realmente contínua, muito embora ela seja feita em pequenos intervalos de tempo, por imposição do método empregado e do próprio computador. Este tipo de simulação é muito útil no estudo de sistemas discretos através de equações diferenciais como, por exemplo, a simulação de sistemas elétricos. Já na simulação discreta, a passagem do tempo é feita aos "pedaços" entre um evento ou outro. Neste caso as mudanças de estado do sistema são instantâneas e acontecem apenas durante a ocorrência de eventos.

Neste trabalho será abordada a Simulação de Eventos Discretos. Isto porque no sistema estudado existe um grande número de variáveis que apresentam variabilidade (modelo estocástico), atuando ao longo do tempo (modelo dinâmico) e com mudança pontual de suas variáveis de estado (modelo discreto). 


\subsection{DEFINIÇÃO DO SISTEMA}

Componentes são subsistemas que interagem entre si por meio de entidades que fluem de um componente para outro. Cada componente desenvolve a sua atividade absorvendo certas entidades, processando-as e liberando-as posteriormente. O nível em que cada uma dessas atividades é desenvolvida define uma variável do sistema e, em geral, está relacionada com a taxa de fluxo de entrada e saída das entidades nos respectivos componentes.

As entidades são os elementos do sistema que podem ser identificados e processados individualmente (KELTON, SADOWSKI \& SADOWSKY ,1998). Exemplos de entidades incluem os caminhões e os tratores, enfim, todos os elementos que mudam de estado durante a execução da simulação. As entidades que permanecem no sistema durante todo o período de simulação são denominadas entidades permanentes, e as entidades que somente passam pelo sistema são denominadas temporárias, pois deixam de ser analisadas no instante que saem do sistema. Exemplo de entidade temporária pode-se citar a cana moída na usina.

Quando diversas entidades possuem as mesmas características, elas formam uma classe de entidades (ex.: classe de caminhões, classe de tratores). As entidades de uma mesma classe apresentam características próprias que as diferenciam de outras classes; estas características são denominadas atributos (KELTON, SADOWSKI \& SADOWSKY, 1998). Um atributo pode ser importante para subdividir uma classe, como no caso da distinção entre várias categorias de caminhões que podem existir na usina (atributo: tipo de caminhão), ou então, ele pode controlar o comportamento de uma classe (atributo: velocidade do caminhão).

As entidades podem ficar esperando algo acontecer em filas (ex.: fila de caminhões esperando a liberação de uma carregadora), que geralmente são do tipo FIFO (first in, first out 
- primeiro a entrar, primeiro a sair). Neste modelo todas as filas são do tipo FIFO, exceto a fila de caminhões para descarga, para a qual os caminhões de cana picada têm prioridade mais alta que os de cana inteira.

\subsection{O PROCESSO DE SIMULAÇÃO}

De acordo com CHWIF \& MEDINA (2006), o desenvolvimento de um modelo de simulação pode ser dividido em três grandes etapas:

- Concepção ou formulação do modelo;

- $\quad$ Implementação do modelo;

- $\quad$ Análise dos resultados do modelo.

Cada uma destas etapas, por sua vez, é composta de outras subetapas, conforme descritas a seguir:

1) Definição de objetivos e definição do sistema: determinação das fronteiras e restrições a serem usadas na definição do sistema (ou processo) e investigação de como o sistema trabalha;

2) Elaboração do modelo abstrato: como o próprio nome diz, nesta etapa o analista cria mentalmente o modelo a ser construído;

3) Formulação do modelo conceitual: Desenvolvimento de um modelo preliminar, graficamente (por exemplo, diagrama de blocos) ou em pseudocódigo, para definir os componentes, descrever as variáveis e interações (lógicas) que constituem o sistema; 
4) Levantamento de dados de entrada: paralelamente à construção do modelo conceitual são definidos os dados a serem utilizados no modelo. Assim, a lista de dados a serem coletados é definida pelo modelo, e não o contrário, conforme citam CHWIF \& MEDINA (2006). Durante esta fase devem ser selecionadas as medidas de eficiência a serem usadas, os fatores a serem variados e os níveis desses fatores a serem investigados;

5) Elaboração do modelo computacional: nesta fase o modelo conceitual é convertido em um modelo computacional, sendo necessária a utilização de alguma ferramenta de programação (software) que neste trabalho será o software Arena, desenvolvido pela Rockwell. Desta fase fazem parte duas importantes etapas do desenvolvimento de um projeto de simulação:

- Verificação e validação: confirmação de que o modelo opera da forma que se pretende e a saída do modelo é acreditável e compatível com a saída do sistema real;

Modelo operacional: estando o modelo conceitual "escrito" em uma linguagem computacional apropriada e devidamente validado, tem-se o modelo operacional, com o qual podem ser conduzidos os experimentos ou "rodadas" de simulação;

6) Experimentação: corresponde à execução da simulação para gerar os dados desejados e executar a análise de resultados;

7) Análise e interpretação: refere-se à análise dos resultados gerados pelo modelo;

8) Implementação e documentação: colocação dos resultados em uso, registro das constatações e documentação do modelo e seu uso; 


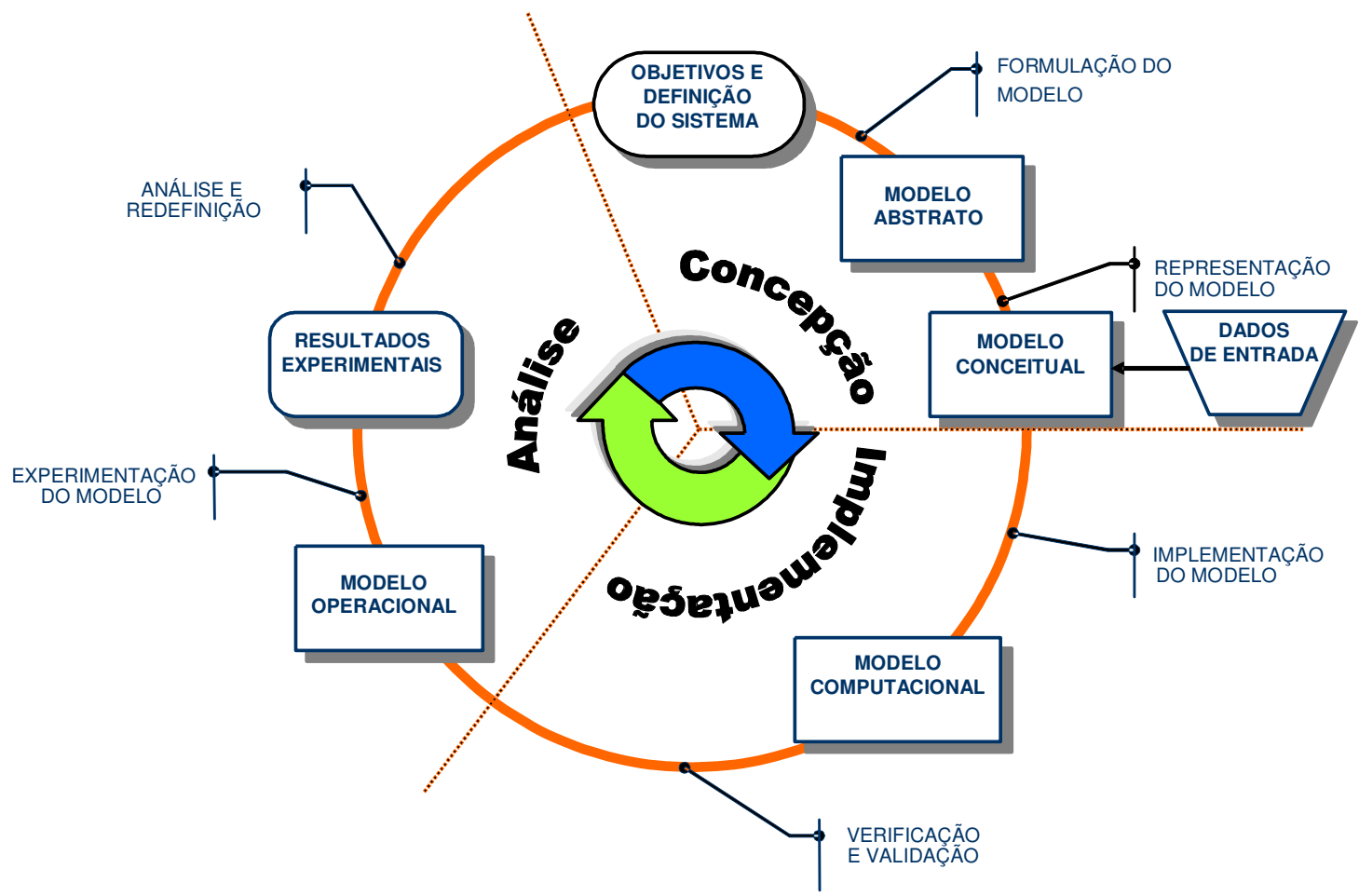

Figura 5 - Etapas de desenvolvimento de um modelo de simulação (CHWIF \& MEDINA, 2006)

CHWIF \& MEDINA (2006), citando Robinson, enfatizam que o processo de simulação não deve ser considerado estudo linear, devendo-se imaginar que seja um processo em espiral conforme sugere a Figura 5, sendo suas etapas repetidas até que não haja diferença nos resultados entre cada uma delas.

\subsection{MÉTODO DE MONTE CARLO}

PEGDEN, SHANNON, SADOWSKI (1995, p.11) afirmam que:

No coração de cada modelo de simulação estocástica repousa um mecanismo para geração dos valores daquelas variáveis aleatórias que influenciam o comportamento do sistema que está sendo analisado. Para modelos probabilísticos ou estocásticos, esse mecanismo é chamado de amostragem (ou método) de Monte Carlo. O método de Monte Carlo originou-se com o trabalho de Von Neumann e Ulam para o projeto da bomba atômica. A técnica matemática, conhecida por muitos anos, foi revivida para o projeto secreto em Los Alamos, EUA, recebendo após a sua divulgação o nome de "Método Monte Carlo". O termo tornou-se quase sinônimo de simulação. Embora, primeiramente, seja interessante o uso do método de Monte Carlo para simular eventos probabilísticos, ele também pode ser usado em certos problemas completamente determinísticos que não podem ser resolvidos analiticamente. 
Na técnica de Monte Carlo, dados artificiais são gerados através de um gerador de números aleatórios e uma distribuição cumulativa de interesse. Um gerador de números aleatórios aceitável deve ser capaz de gerar variáveis aleatórias que estejam uniformemente distribuídas no intervalo de 0 a 1. Uma vez que os números aleatórios são gerados pelo uso de um algoritmo, eles não são verdadeiramente aleatórios, sendo, então, chamamos de números pseudo-aleatórios - significando que a seqüência produzida é de fato reprodutível e daí não aleatória (FREITAS FILHO, 2001). Entretanto, se for comparado um conjunto de números derivados de um gerador digital de números aleatórios confiável com números que fossem verdadeiramente aleatórios, a distinção entre esses dois conjuntos não seria detectável, isto é, os dados gerados pelo computador passariam em todos os testes estatísticos para aleatoriedade.

A distribuição de probabilidade a ser amostrada pode ser uma distribuição teórica conhecida, por exemplo, normal ou exponencial, ou ela pode ser baseada em dados empíricos colhidos e/ou observados do sistema real. 


\section{Ca pít u lo}

\section{O PROBLEMA MODELADO POR SIMULAÇÃO}

\subsection{OBJETIVOS E DEFINIÇÃO DO SISTEMA}

O modelo de simulação desenvolvido nesta dissertação contempla a modelagem do sistema de corte, carregamento e transporte de cana-de-açúcar (CCT) de uma usina de porte médio (moagem de 20.000 t/dia).

Os limites do sistema avaliado, o escopo, contemplam as operações de colheita e transporte de cana-de-açúcar picada desde as áreas de produção até a mesa receptora de matéria-prima na usina; envolve os equipamentos de colheita mecânica, os conjuntos de tratores de transbordos, e as composições rodoviárias.

As operações envolvidas no processo produtivo foram determinadas em visita técnica a uma usina do interior do estado de São Paulo, sendo em seguida definido o tipo de dado a ser levantado. A coleta de dados foi realizada através de medições em campo com apontamento manual ou com base nos registros dos computadores de bordo instalados nos equipamentos (máquinas e veículos), no período da safra. Os dados de manutenção de equipamentos foram coletados nos sistemas de controle de manutenção automotiva, nos quais são registradas, rotineiramente, suas intervenções. Demais dados foram obtidos com a equipe técnica da usina. Todos estes dados foram processados para obter as distribuições estatísticas que representam cada processo, utilizando-se o software Input Analyzer, distribuído juntamente com o software Arena®. 


\subsubsection{Frentes de corte}

As frentes de corte, conforme definido por SILVA (2006), são pontos distintos fornecedores de cana-de-açúcar e trabalhadas por uma equipe autônoma de equipamentos e funcionários.

O modelo desenvolvido neste trabalho, conforme definido no escopo, contempla somente frentes de corte de cana picada, nas quais as atividades de corte, a limpeza e picação da cana são realizadas por um único equipamento, denominado colhedora de cana, que ainda transfere os toletes de cana para os equipamentos de transbordos. Em uma frente de corte a quantidade de colhedoras varia em função da meta de produção

Os equipamentos de transbordos são caçambas tracionadas por tratores agrícolas que se deslocam ao lado das colhedoras, recebendo a cana colhida em forma de toletes. Normalmente cada trator reboca duas caçambas, havendo arranjos operacionais em que o conjunto trator-transbordo é formado por até três caçambas; no modelo desenvolvido considerou-se o conjunto com duas caçambas. Após o enchimento das caçambas os tratores deslocam-se até o local reservado para a transferência da carga para as composições rodoviárias, este local é popularmente denominado de pátio de transbordo. Nas Figuras de números 6 à 9 estão ilustradas as atividades de colheita mecânica e transbordo.

As frentes de corte não permanecem o tempo todo em um mesmo local, o que quer dizer que, após colher certa quantia de cana, os equipamentos são transferidos para uma outra área, definida com base em uma programação para aproveitar a cana com maior retorno econômico. Neste trabalho, entretanto, há uma simplificação que não considera os tempos desta mudança de local de trabalho. 
Conforme descreve SILVA (2006), gargalos operacionais podem ser gerados pelo balanceamento entre os recursos mecanizados da frente de corte, o que ressalta a necessidade de abordagem do problema por uma visão holística, sendo o emprego da simulação uma melhor opção para abordar o problema, uma vez que este método trata a interação entre os recursos.

O ciclo operacional do trator transbordo está esquematizado na Figura 13.

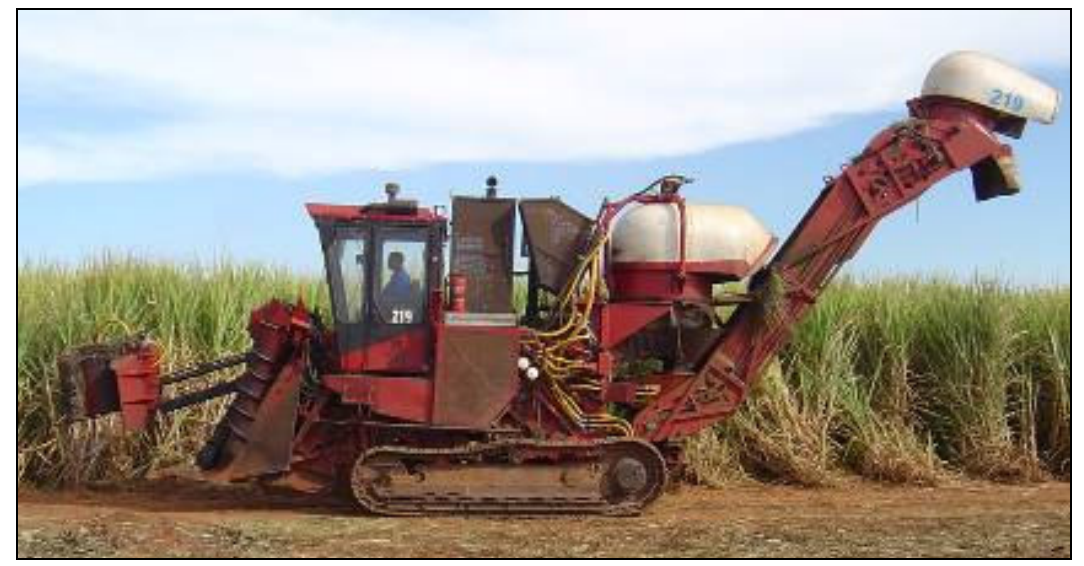

Figura 6 - Colhedora de Cana (SILVA, 2006)

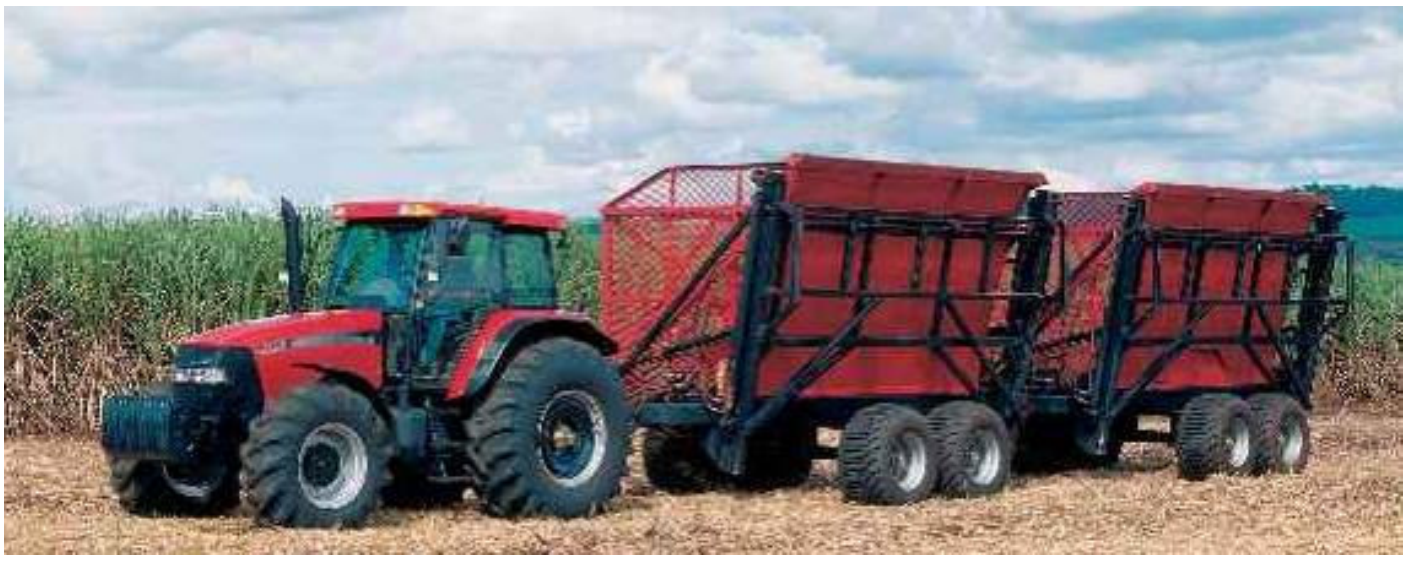

Figura 7 - Trator-transbordo (CASE IH, 2008) 


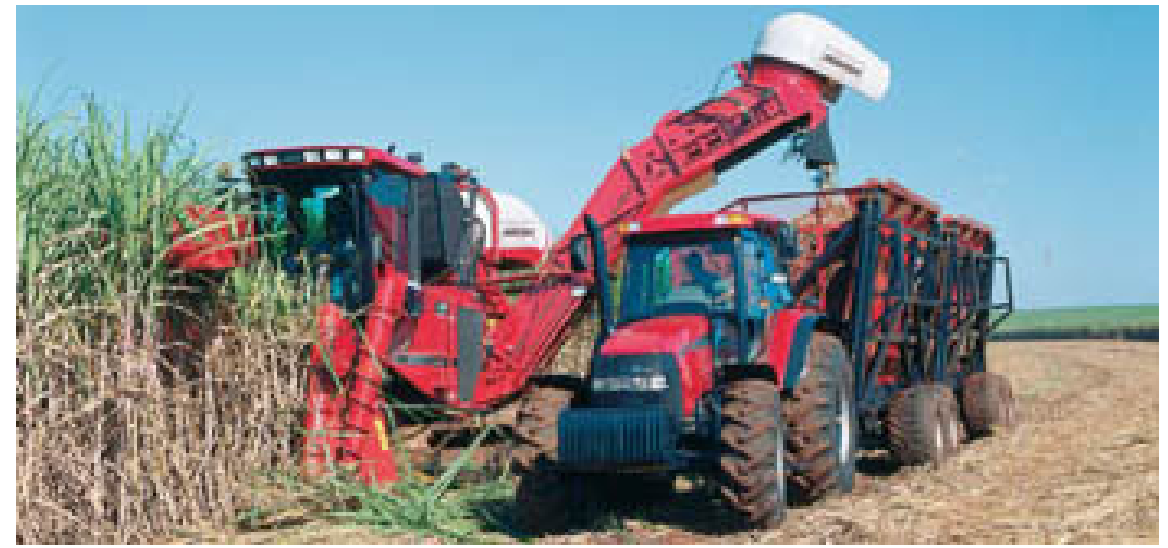

Figura 8 - Colheita da cana (CASE IH, 2008)

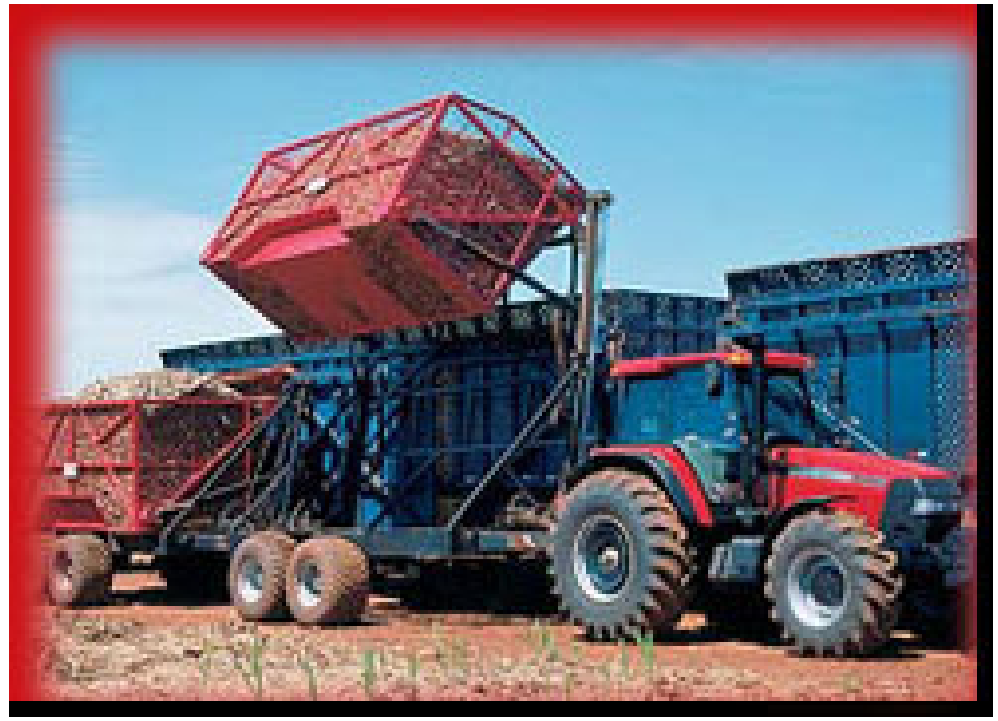

Figura 9 - Transbordo da cana para o caminhão (TRACAN, 2009)

\subsubsection{Equipamentos de transporte}

As composições rodoviárias para o transporte da cana estão listadas no Quadro 1, sendo que neste trabalho foram consideradas as composições do tipo rodotrem.

\subsubsection{Atividades na área industrial}

A área industrial corresponde à usina propriamente dita e dela fazem parte as atividades de pesagem, amostragem da cana-de-açúcar e descarregamento. Dependendo do arranjo logístico podem estar presentes também cavalo-escravos e reboques reservas. 
Os caminhões escravos são cavalos mecânicos dedicados exclusivamente à atividade de descarga e têm seu ciclo de deslocamento restrito à área industrial, conforme já destacado na Figura 1.

Os reboques reservas são conjuntos de reboques rodoviários que ficam na usina à espera de um cavalo-mecânico para serem levados à frente de corte. Tanto estes equipamentos quanto os cavalos-escravos são utilizados quando se adota o sistema de bate-volta (drop-andhook), que tem por objetivo diminuir o tempo de permanência do cavalo-mecânico na usina, minimizando a formação de fila e, conseqüentemente o melhor aproveitamento da frota.

No modelo de simulação desenvolvido para este trabalho não foi considerado o uso de pátio de estocagem de cana na usina, uma vez que só foi abordado o sistema de colheita de cana picada.

\subsection{MODELO CONCEITUAL}

$\mathrm{Na}$ Figura 10 encontram-se ilustrados os módulos que compõem o modelo de simulação, com destaque para o conjunto de módulos agrupados no subtítulo "Despachador de caminhões", que constituem a contribuição mais importante deste trabalho. Na Figura 11 encontra-se o modelo conceitual. 
Módulos do simulador
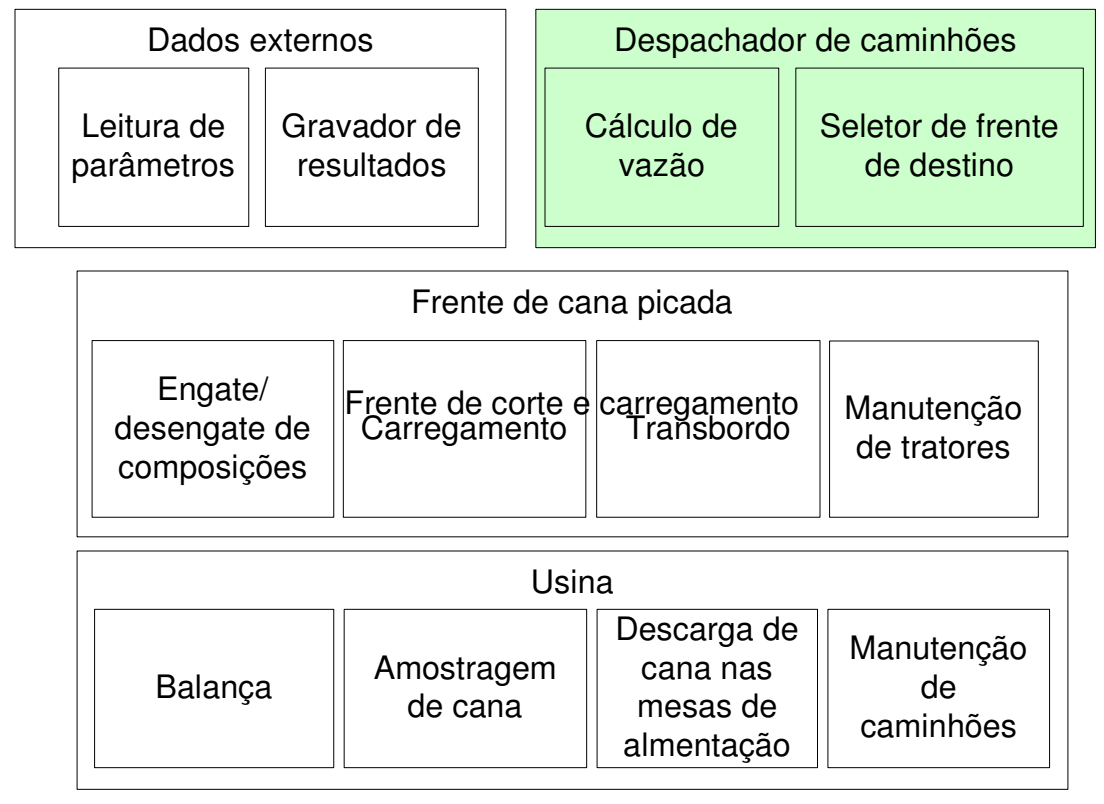

Figura 10 - Módulos do simulador 


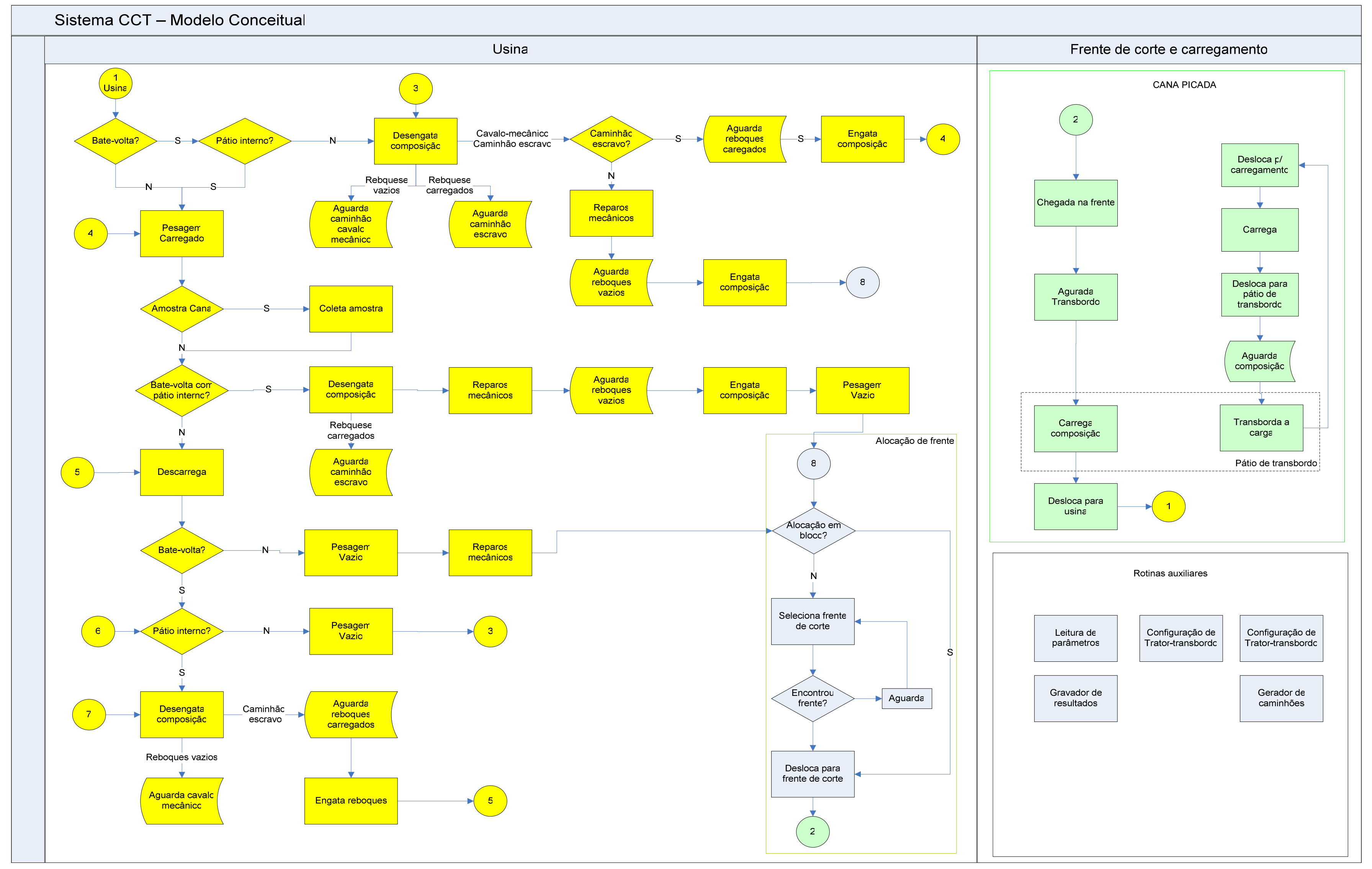

Figura 11 - Modelo conceitual do simulador de CCT 
Na Figura 12 estão representados os módulos da rotina de cálculo da capacidade de carregamento da frente de corte.

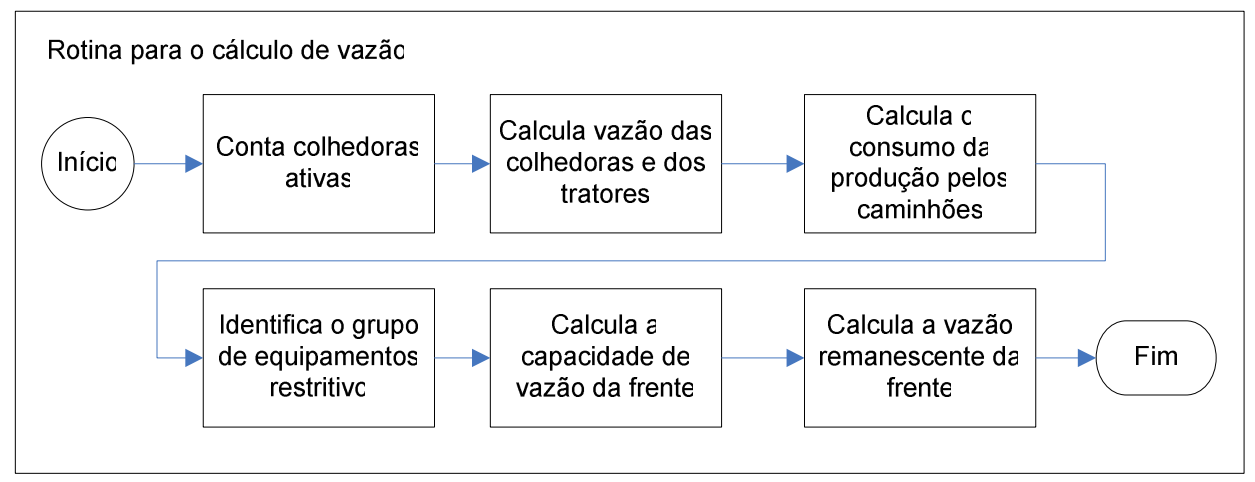

Figura 12 - Módulos da rotina de cálculo de vazão

- Conta colhedoras ativas: este módulo utiliza um função interna do Arena que faz uma varredura nos recursos do tipo colhedora a fim de identificar e contar os equipamentos que estão inoperantes. Ao final da varredura grava-se a quantidade de colhedoras ativas, que é obtida subtraindo-se a quantidade de colhedoras inativas do total de colhedoras alocadas na frente de corte.

- Cálculo da vazão das colhedoras e dos tratores: este módulo é responsável pela medição da capacidade de carregamento das colhedoras e dos tratores; o resultado é expresso em t/hora.

Para as colhedoras a capacidade de colheita, ou vazão, é dada pela equação 4 .

$$
C c=Q c a * \frac{P t b}{T c g}
$$

Onde

Qca = quantidade de colhedoras ativas (disponíveis para operação)

$\mathrm{Tcg}=$ tempo de carregamento do transbordo

$\mathrm{Ptb}=$ peso médio da carga do transbordo 
- Para os tratores que rebocam os transbordos a capacidade de reboque, ou vazão, é dada pela equação 5 .

$$
C r b=Q t a * \frac{P t b}{T c t}
$$

Onde

$\mathrm{Crb}=$ capacidade de reboque

Qta = quantidade de tratores ativos (disponíveis para operação)

Tct $=$ tempo de ciclo do trator

Ptb = peso médio da carga do transbordo

Na equação 5 o valor de Tct é obtido somando-se os tempos que compõem o ciclo do trator transbordo (deslocamento vazio, carregamento, deslocamento carregado e transbordo) e, que se encontra ilustrado na

Figura 13.

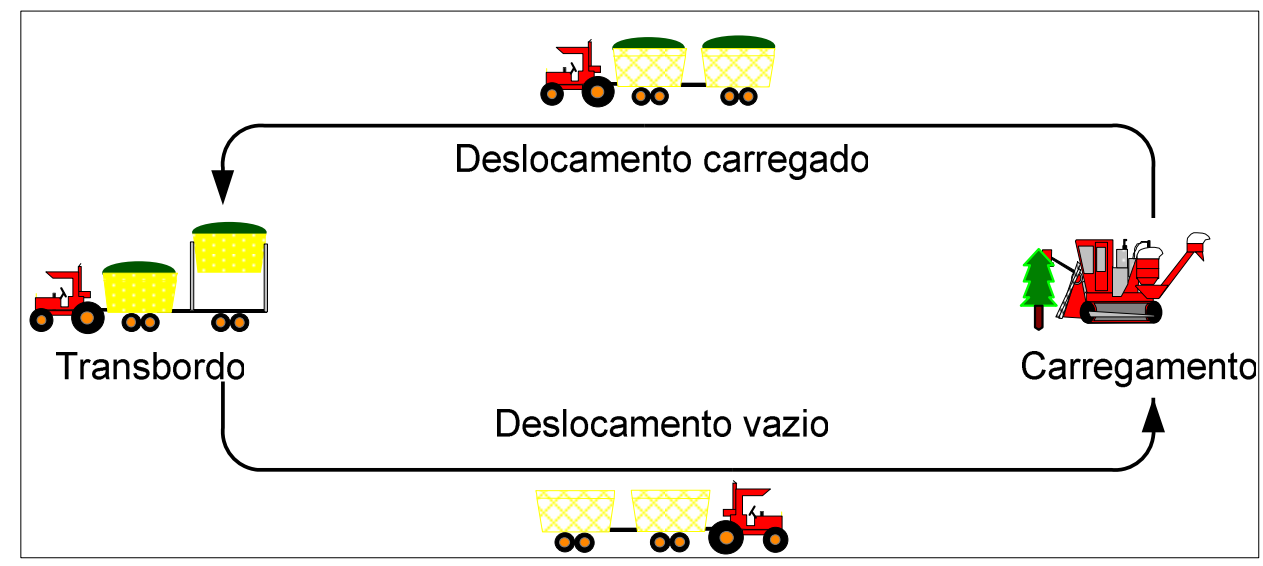

Figura 13 - Ciclo do trator transbordo (SILVA, 2006)

- $\quad$ O cálculo do consumo da produção pelos caminhões é obtido pela equação 6 .

$$
C c h=Q c t * \frac{P m}{T c h}
$$

Onde 


$$
\begin{aligned}
& \text { Cch = consumo da produção pelos caminhões } \\
& \text { Qct = quantidade de caminhões em trânsito } \\
& \text { Tch = tempo de ciclo do caminhão } \\
& \text { Pm = peso médio da carga do caminhão }
\end{aligned}
$$

A quantidade de caminhões em trânsito é obtida pela soma da quantidade de caminhões que estão se dirigindo a uma frente de corte e da quantidade de caminhões que estão sendo carregados ou aguardando carregamento.

O ciclo do caminhão equivale ao tempo decorrido entre o momento que ele deixa a usina e o momento em que ele retorna a ela. Para os cenários em que se adota bate-volta, o momento de retorno é aquele quando o caminhão chega ao pátio de desengate, se for utilizado pátio fora da usina, ou quando o caminhão é pesado carregado, se for utilizado pátio dentro da usina. Quando não se adota bate-volta o momento do retorno é caracterizado pela chegada à balança de entrada da usina Na Figura 1 encontra-se esquematizado o ciclo de um caminhão.

Identificação do grupo restritivo: a vazão, ou capacidade de carregamento da frente de corte, está diretamente relacionada à capacidade de carregamento das colhedoras e à capacidade de reboque dos tratores de transbordo, sendo limitada pela menor capacidade dentre esses dois grupos, pois tendo as colhedoras capacidade de colher um volume de cana maior do que os tratores são capazes de transportar, não há como colher um volume maior que a capacidade dos tratores, uma vez que não existe reservatório para cana colhida nas colhedoras. O inverso também é verdadeiro, uma vez que os tratores têm 
sua capacidade limitada por aquele volume que as colhedoras podem produzir, assim, o grupo restritivo é identificado pela equação 7 .

$$
G r t=\left\{\begin{array}{l}
1 \text { se } C c \leq C r b \\
2 \text { casocontrário }
\end{array}\right.
$$

Cálculo da capacidade de vazão da frente corte é obtido pela equação 8.

$$
V f=\left\{\begin{array}{l}
C c \text { se } G r t=1 \\
C r b, \text { casocontrário }
\end{array}\right.
$$

Cálculo da vazão remanescente da frente corte: a vazão remanescente da frente de corte representa o valor a ser utilizado pela rotina de seleção de destino de um caminhão quando este deixa a usina e está pronto para iniciar um novo ciclo, e é obtida pela diferença entre a capacidade de vazão e o consumo da produção pelos caminhões, conforme equação 9. Valores negativos neste cálculo indicam que há uma quantidade de caminhões em trânsito, para uma dada frente, maior do que a capacidade que esta tem para atendê-lo(s). Neste caso ocorrerá fila no carregamento. Esta situação ocorre quando, após o despacho do(s) caminhão(ões), houve redução da capacidade de vazão da frente, provocada pela parada de uma colhedora ou trator para manutenção.

$$
V r m=\left\{\begin{array}{l}
0 \text { se } C c h \geq V f \\
V f-C c h, \text { casocontrário }
\end{array}\right.
$$

Neste módulo são utilizadas variáveis matriciais e variáveis unidimensionais, descritas a seguir.

vCC: variável matricial de ordem 10 x 22. Nesta matriz cada linha representa uma frente de corte (embora o sistema estudado neste trabalho represente até cinco frentes 
de corte, o modelo pode ser configurado para até onze frentes), os valores registrados nas colunas estão relacionados no Quadro 4.

\begin{tabular}{|c|c|}
\hline Coluna & Dado armazenado \\
\hline 1 & Quantidade de carregadoras ou colhedoras inativas na frente de corte \\
\hline 2 & Capacidade de colheita de colheita da frente (t/hora) \\
\hline 3 & Quantidade de tratores inativos \\
\hline 4 & Capacidade de reboque de todos os tratores da frente (t/hora) \\
\hline 5 & Quantidade de truck em trânsito \\
\hline 6 & Quantidade de romeu \& julieta em trânsito \\
\hline 7 & Quantidade de treminhão em trânsito \\
\hline 8 & Quantidade de rodotrem em trânsito \\
\hline 9 & Tempo de ciclo do truck \\
\hline 10 & Tempo de ciclo do romeu \& julieta \\
\hline 11 & Tempo de ciclo do treminhão \\
\hline 12 & Tempo de ciclo do rodotrem \\
\hline 13 & Capacidade de transporte do Truck ( $\mathrm{t} / \mathrm{hora}$ ) \\
\hline 14 & Capacidade de transporte do romeu \& julieta (t/hora) \\
\hline 15 & Capacidade de transporte do treminhão (t/hora) \\
\hline 16 & Capacidade de transporte do rodotrem (t/hora) \\
\hline 17 & Capacidade de transporte de todos os caminhões alocados (t/hora) \\
\hline 18 & Constante 1 \\
\hline 19 & Capacidade de abastecimento da frente (t/hora) \\
\hline 20 & Restrição ( $1=$ colhedora, $2=$ trator $)$ \\
\hline 21 & Produção remanescente (t/hora) \\
\hline 22 & Vazão relativa da frente \\
\hline
\end{tabular}

Quadro 4 - Variável auxiliar para cálculo da vazão. 


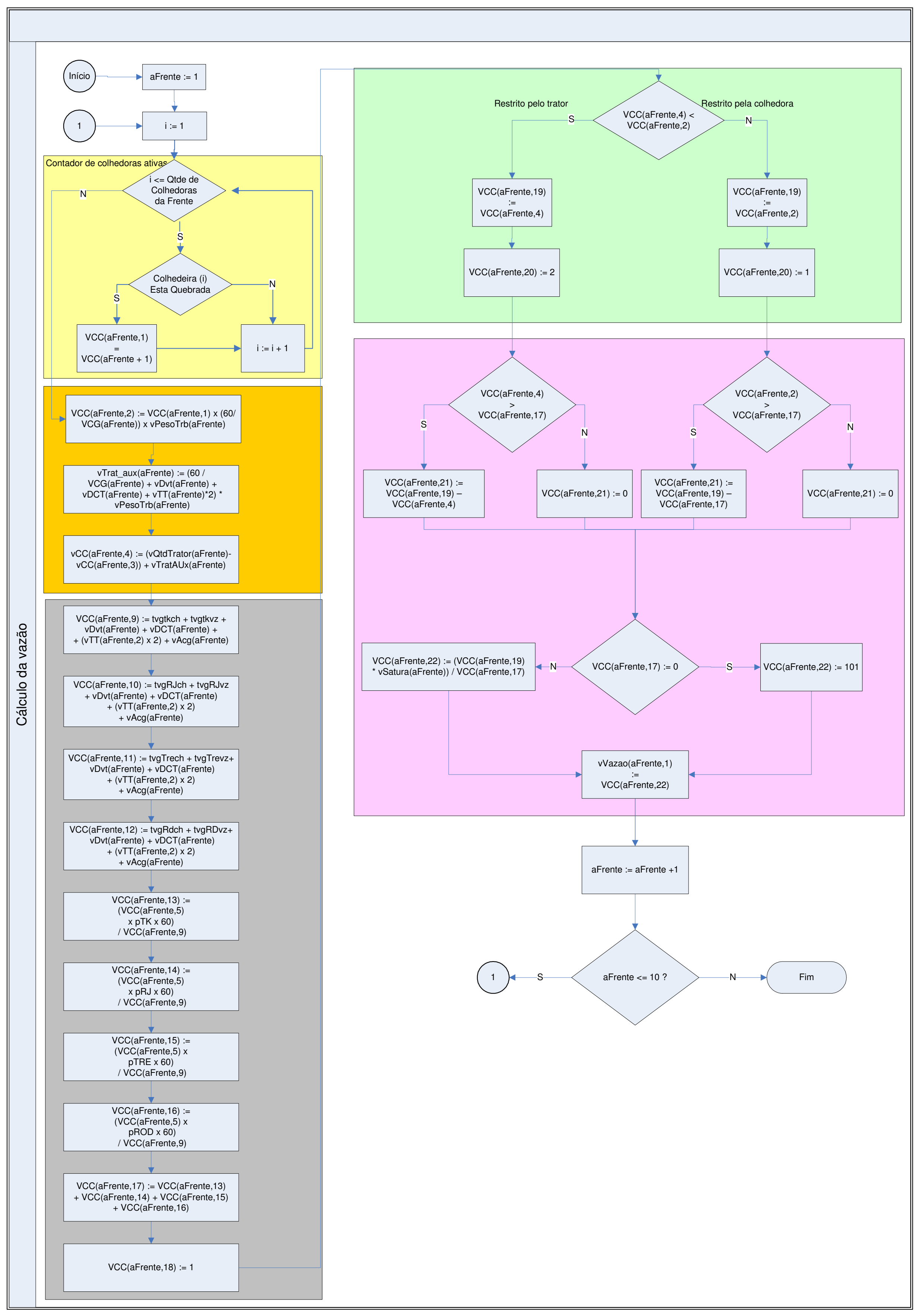

Figura 14 - Lógica para o cálculo da capacidade de carregamento da frente de corte 


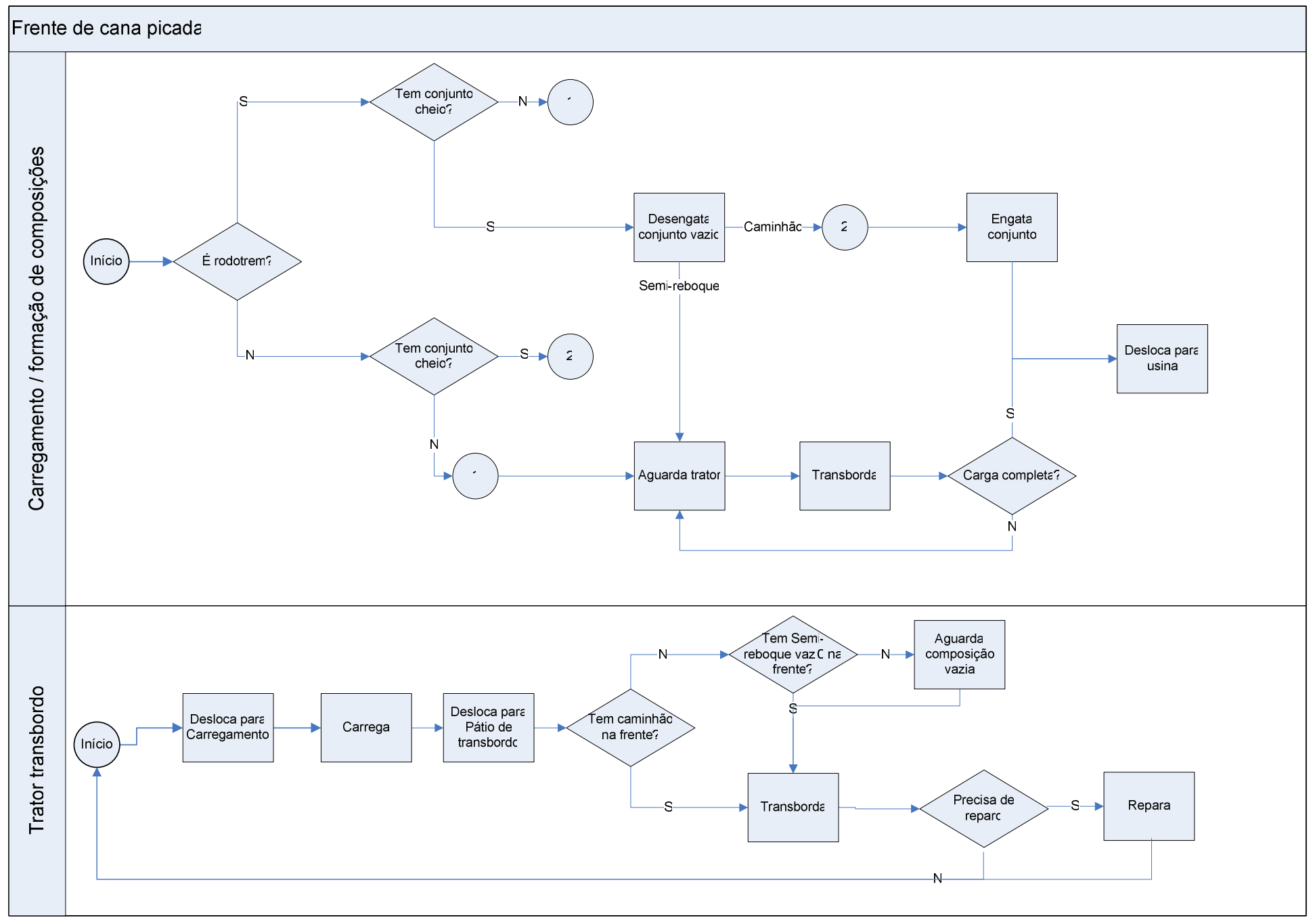

Figura 15 - Fluxograma conceitual da frente de corte 


\subsection{DADOS DE ENTRADA}

Os dados de entrada do modelo de simulação, que constituem os parâmetros dos cenários, são os descritos abaixo:

\subsubsection{Parâmetros Gerais}

- Amostragem da cana-de-açúcar: percentual para sorteio das cargas a serem amostradas - adotado $30 \%$;

- Horários de restrição ao tráfego de composições rodoviárias: em algumas regiões não é permitido o trânsito de composições maiores que $19,8 \mathrm{~m}$ em alguns horários do dia. Quando essa restrição ocorre as composições rodoviárias trafegam com apenas um semi-reboque atrelado. Nos cenários analisados não foi considerada esta restrição.

- Capacidade de moagem: corresponde à capacidade de processamento da usina. Nos cenários analisados a meta foi estabelecida em 19.500 t/dia.

- Frota de composições rodoviárias disponível, por tipo de composição. Nos cenários em que se adota o despacho dinâmico informa-se a quantidade total de rodotrens; quando se adota o despacho estático, informa-se a frota para cada frente de corte. Quando se adota a prática de bate-volta, informa-se a quantidade de cavalos escravos e a quantidade de semi-reboques reserva na usina.

- Turnos de trabalho: a jornada de trabalho em usinas de açúcar é de 24 horas/dia. Os turnos de trabalhos dos operadores e motoristas são estabelecidos levando-se em conta as restrições legais, sendo prática corrente a adoção de três turnos, com 
oito horas de duração cada um. No modelo analisado, a cada reinício de ciclo do caminhão verifica-se se houve mudança de turno em relação à viagem anterior. Tendo havido, o caminhão é retido na usina durante 40 (quarenta) minutos, sendo em seguida liberado.

\subsubsection{Parâmetros das Frentes de Corte}

- Quantidade de colhedoras disponíveis;

- Quantidade de tratores de reboque disponíveis;

- Distância entre a usina e a frente de corte;

Para desenvolvimento do modelo considerou-se cinco frentes de corte e transporte de cana picada, cujas distâncias até a usina estão destacadas na Tabela 1.

Tabela 1 - Distância média das frentes de corte

\begin{tabular}{ccc}
\hline Frente & Tipo de corte da cana & Distância $(\mathbf{k m})$ \\
\hline 1 & Picada & 27,0 \\
2 & Picada & 35,0 \\
3 & Picada & 11,0 \\
4 & Picada & 18,0 \\
5 & Picada & 5,0 \\
\hline
\end{tabular}

- Velocidade dos rodotrens: velocidade média geral, para as composições vazias e carregadas. Na lógica do modelo está gravada uma função que representa a velocidade média do rodotrem. Esta função foi obtida a partir de dados de campo coletados na safra 2003/2004, tendo sido observado que a velocidade média modifica-se em função da distância percorrida, conforme demonstra o Gráfico 1. 


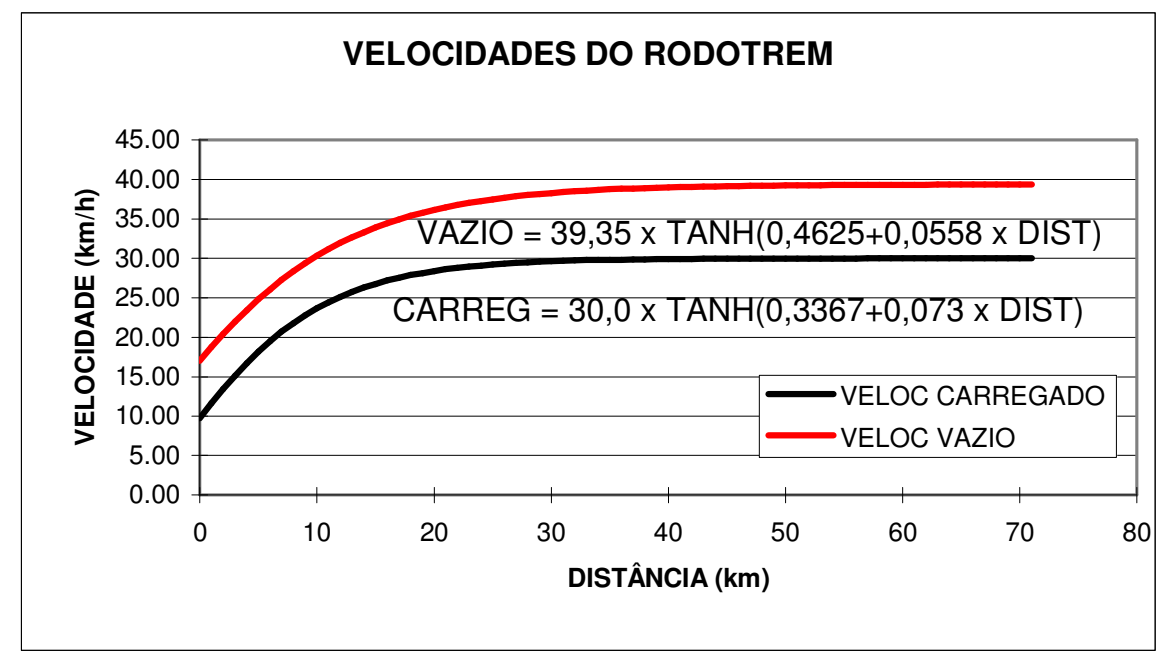

Gráfico 1 - Velocidade média do Rodotrem

- Tempo de carregamento: tempo médio para carregamento do conjunto de transbordo;

- Tempo de transbordo: tempo médio para transbordar a carga do transbordo para o rodotrem;

- Indicador de restrição ao tráfego de composição de grande porte: quando esta opção é habilitada, as composições são desmembradas e o cavalo trafega com apenas um semi-reboque; habilitando esta funcionalidade, deve-se indicar o período em que ocorre a restrição. Nos cenários analisados não se considerou esta característica;

- Quantidade de semi-reboques reservas: estes equipamentos são utilizados para permitir que se realize o bate-volta na lavoura.

- Peso médio da carga, por tipo de composição: utilizou-se histórico da safra 2003/2004 quando o peso médio foi de 62,0 t/viagem para a composição do tipo rodotrem com cana picada. 
- Prioridade para despacho de caminhão: o modelo está preparado para que se configure composições do tipo rodotrem e treminhão. Esta opção de configuração permite que se priorize um determinado tipo de composição para uma frente, ou até mesmo pode bloquear o acesso de um tipo de composição. Nos cenários analisados, como foi considerado apenas o uso de rodotrem esta função não foi utilizada.

\subsubsection{Parâmetros de Manutenção}

Os parâmetros de manutenção das carregadoras, tratores reboque e caminhões foram obtidos através da pesquisa em base de dados da usina, bem como em levantamentos de campo.

$\mathrm{Na}$ Tabela 2 encontra-se a relação de eventos de manutenção considerados. Os detalhes do levantamento encontram-se nos Apêndices. Para cada um destes eventos foram analisadas a duração e o intervalo entre ocorrências.

Tabela 2 - Relação de itens de manutenção considerados no modelo de simulação

\begin{tabular}{ll}
\hline Equipamento & Manutenção \\
\hline Caminhões & Abastecimento de combustível \\
& Reparos de borracharia \\
& Reparos de elétrica \\
& Reparos de funilaria \\
& Reparos de geral \\
& Reparos de motor \\
\hline Trator de reboque & Abastecimento de combustível \\
& Manutenção mecânica na lavoura \\
& Manutenção mecânica na oficina \\
& - continua -
\end{tabular}


- continuação -

\begin{tabular}{ll}
\hline Equipamento & Manutenção \\
\hline Colhedora & Abastecimento de combustível \\
& Manutenção elétrica \\
& Manutenção geral \\
& Manutenção do elevador \\
& Reparos com solda \\
& Troca de faca \\
& Manutenção de mangueiras \\
& Lavagem
\end{tabular}

\subsection{PREMISSAS ECONÔMICAS}

Para a determinação do custo total de CCT foram utilizados dados de custos fixos e variáveis dos equipamentos descritos na da Tabela 3.

Tabela 3 - Premissas econômicas

\begin{tabular}{lcr}
\hline Equipamento & Custo Fixo mensal & \multicolumn{1}{c}{ Custo variável } \\
\hline Rodotrem & $\mathrm{R} \$ 20.581,99$ & $\mathrm{R} \$ 2,17 / \mathrm{km}$ \\
Conj. Reboques & $\mathrm{R} \$ 7.249,81$ & $\mathrm{R} \$ 0,28 / \mathrm{km}$ \\
Cavalo-escravo & $\mathrm{R} \$ 20.581,99$ & $\mathrm{R} \$ 2,17 / \mathrm{km}$ \\
Colhedora & $\mathrm{R} \$ 26.896,82$ & $\mathrm{R} \$ 165,00 /$ hora \\
Trator reboque & $\mathrm{R} \$ 16.843,85$ & $\mathrm{R} \$ 28,00 /$ hora \\
Conjunto transbordo & $\mathrm{R} \$ 3.770,41$ & $\mathrm{R} \$ 4,70 /$ hora \\
\hline
\end{tabular}

Os salários dos motoristas e operadores de máquinas agrícolas estão inclusos no custo fixo mensal.

O custo da equipe de engatadores foi considerado apenas nos cenários em que se adotou o bate-volta na usina. O custo mensal deste item é de $\mathrm{R} \$ 13.620,96$ 
Ca pít u lo

6

\section{RESULTADOS}

\subsection{PROJETO EXPERIMENTAL}

De acordo com FREITAS FILHO (2001) é através da experimentação que se verifica como um sistema é influenciado por uma ou mais variáveis. Este autor afirma ainda que "de acordo com o jargão da estatística, as variáveis que medem o desempenho do sistema são aquelas conhecidas como respostas, ou variáveis de resposta, enquanto que aquelas que o experimentador está manipulando são conhecidas por fatores" (FREITAS FILHO, 2001, p.249). Ainda segundo o mesmo autor, denomina-se níveis os valores que um fator pode assumir.

No sistema avaliado as variáveis cujos resultados se desejam avaliar são a produção diária e o seu custo. Os fatores manipulados foram os listados no Quadro 5.

\begin{tabular}{cl}
\hline Fator & Descrição \\
\hline 1 & Quantidade de cavalos mecânicos \\
2 & Quantidade de semi-reboques reservas \\
3 & Quantidade de cavalos escravos \\
4 & Tipo de despacho \\
5 & Adoção de bate-volta e \\
6 & Carga média \\
\hline
\end{tabular}

Quadro 5 - Lista de fatores dos experimentos 
No Quadro 6 encontram-se os níveis aplicados aos fatores dos experimentos.

\begin{tabular}{ccc}
\hline Fator & Níveis & $\begin{array}{c}\text { Método de } \\
\text { Despacho }\end{array}$ \\
\hline 1 & Sim & Estático \\
2 & Sim & Dinâmico \\
3 & Sim & Estático \\
4 & Sim & Dinâmico \\
5 & Não & Estático \\
6 & Não & Dinâmico \\
\hline
\end{tabular}

Quadro 6 - Valores associados a níveis de cada fator

O fator "Método de Despacho" refere-se à forma de despacho dos caminhões, que pode ser dinâmico ou estático.

Para cada um destes experimentos foram testados vários níveis para os fatores 1,2 e 3, avaliando-se a produção obtida e o custo do CCT.

A quantidade de colhedoras e de tratores de transbordo foi mantida inalterada entre os cenários, assim como a distância média de cada frente.

\subsection{CENÁRIO BASE}

O cenário base da simulação é o cenário com despacho estático e sem adoção de bate-volta. Para a configuração desse cenário foi elaborada a quantificação determinística da frota de caminhões necessária para atender à demanda de produção. O tamanho da frota ${ }^{2}$ é dado pela equação empírica descrita a seguir.

$$
\text { Frota }=\frac{\mathrm{Mp}}{\mathrm{Ct}}
$$

\footnotetext{
${ }^{2} \mathrm{O}$ termo frota, deste ponto em diante refere-se ao conjunto cavalo-mecânico e dois semi-reboques, formando uma composição do tipo rodotrem.
} 
Onde:

Frota $=$ frota de caminhões

$\mathrm{Mp}=$ meta de produção

$\mathrm{Ct}$ = capacidade diária de transporte de cada caminhão

A capacidade diária de transporte de cada caminhão, por sua vez, é obtida pela equação 11.

$$
\mathrm{Ct}=\frac{\mathrm{Td}}{\mathrm{Tch}} * \mathrm{Pm}
$$

Onde:

$$
\begin{aligned}
& \text { Td = tempo disponível } \\
& \text { Tch }=\text { tempo de ciclo do caminhão } \\
& \text { Pm = peso médio da carga do caminhão }
\end{aligned}
$$

Na equação 11 o tempo disponível é igual a 1.230 minutos, sendo equivalente à parcela de tempo de um dia trabalho que o caminhão está disponível para transporte, descontando-se as paradas para troca de turno, para refeição dos motoristas e para reparos mecânicos.

Para obter-se o tempo de ciclo aplica-se a equação 12

$$
\mathrm{Tch}=\frac{\text { Dist }}{\mathrm{Vvz}_{\mathrm{v}}}+\mathrm{Tcp}+\frac{\mathrm{Dist}}{\mathrm{Vch}}+\mathrm{Tu}+\mathrm{Tm}
$$

Onde:

Tch $=$ tempo de ciclo do caminhão

Dist $=$ distância média da frente de corte até a usina

$\mathrm{Vvz}=$ velocidade do caminhão vazio

Tcp $=$ tempo de permanência no campo 


$$
\begin{aligned}
& \text { Vch = velocidade do caminhão cheio } \\
& \text { Tu = tempo de usina } \\
& \text { Tm = tempo de manutenção }
\end{aligned}
$$

Atribuindo-se valores às equações 10 a 12, tomando como exemplo a Frente de Corte 1, obtém-se:

$$
\mathrm{Tch}=\frac{27}{37,85}+5,7+\frac{27}{29,41}+15,1+11,9=130,6 \mathrm{~min}
$$

Substituindo os valores de Tch, Td e Pm na equação 11, temos:

$$
\mathrm{Ct}=\frac{1230}{130,6} * 62 \cong 584 \mathrm{t} / \mathrm{dia}
$$

Voltando à equação 10 e substituindo os valores de suas variáveis obtemos a quantificação da frota para a Frente 1:

$$
\text { Frota }=\frac{3.900}{584} \cong 7 \text { caminhões }
$$

Então, a quantificação da frota para o cenário base é a que está representada no Quadro 7.

\begin{tabular}{cc}
\hline Frente de corte & Frota \\
\hline 1 & 7 \\
2 & 8 \\
3 & 4 \\
4 & 5 \\
5 & 3 \\
\hline
\end{tabular}

Quadro 7 - Frota de caminhões do cenário base 
Para o cenário base não foi considerada a frota de reboques-reserva da lavoura.

O resultado deste cenário foi uma produção de 16.245 t/dia, não atingindo a meta de produção.

\subsection{AVALIAÇÃO DE CENÁRIOS SEM ADOÇÃO DE BATE-VOLTA}

A partir do cenário base a frota de caminhões foram geradas diversas séries de cenários. Na primeira fase da análise foram avaliados cenários sem adoção de bate-volta na usina.

\subsubsection{Série 1 - 27 a 46 rodotrens, sem reboque reserva ${ }^{3}$ na lavoura, despacho estático}

$\mathrm{Na}$ primeira série foram analisados quatro cenários, todos sem bate-volta e com despacho estático; para calcular a nova configuração de quantidade de caminhões de cada novo cenário aplicou-se regra de três simples, à razão direta da produtividade.

Os resultados da primeira série, exibidos na Tabela 4, indicaram que aumentando somente a frota de caminhões não é possível atender à demanda. O Gráfico 2 mostra que o tempo de permanência no campo aumentou significantemente a cada aumento da frota de caminhões, indicando um gargalo na capacidade de corte e carregamento. Observa-se que do cenário 42 para o 46 o aumento da frota não reflete em aumento da produção, mas reflete no aumento do custo. Embora não seja o objetivo deste trabalho, o modelo também poderia ser utilizado para eliminar gargalos, como por exemplo, testando o aumento do número de colhedoras ou a troca deste recurso por outro de maior capacidade.

\footnotetext{
${ }^{3}$ A partir deste ponto quando se utilizar o termo reboque reserva estará se referindo a um conjunto formado por dois semi-reboques conectados por um dolly. Este conjunto de semi-reboques acoplados ao cavalo-mecânico forma a composição do tipo rodotrem
} 
Tabela 4 - Série 1: 27 rodotrens sem reboque reserva na lavoura, despacho estático

\begin{tabular}{cccccc}
\hline & & Produção & \multicolumn{2}{c}{ Custo operação } & Tempo de \\
Cenário & Frota & (t/dia) & Safra $(\mathbf{x}$ 1000) & $\mathrm{R} \$ / \mathbf{t}$ & (min) \\
\hline 1 & 27 & 16.245 & $\mathrm{R} \$ 37.335$ & $\mathrm{R} \$ 11,27$ & 30 \\
2 & 32 & 17.836 & $\mathrm{R} \$ 40.150$ & $\mathrm{R} \$ 11,03$ & 40 \\
3 & 37 & 18.677 & $\mathrm{R} \$ 42.062$ & $\mathrm{R} \$ 11,04$ & 56 \\
4 & 42 & 18.974 & $\mathrm{R} \$ 43.458$ & $\mathrm{R} \$ 11,23$ & 74 \\
5 & 46 & 19.116 & $\mathrm{R} \$ 44.323$ & $\mathrm{R} \$ 11,37$ & 85 \\
\hline
\end{tabular}

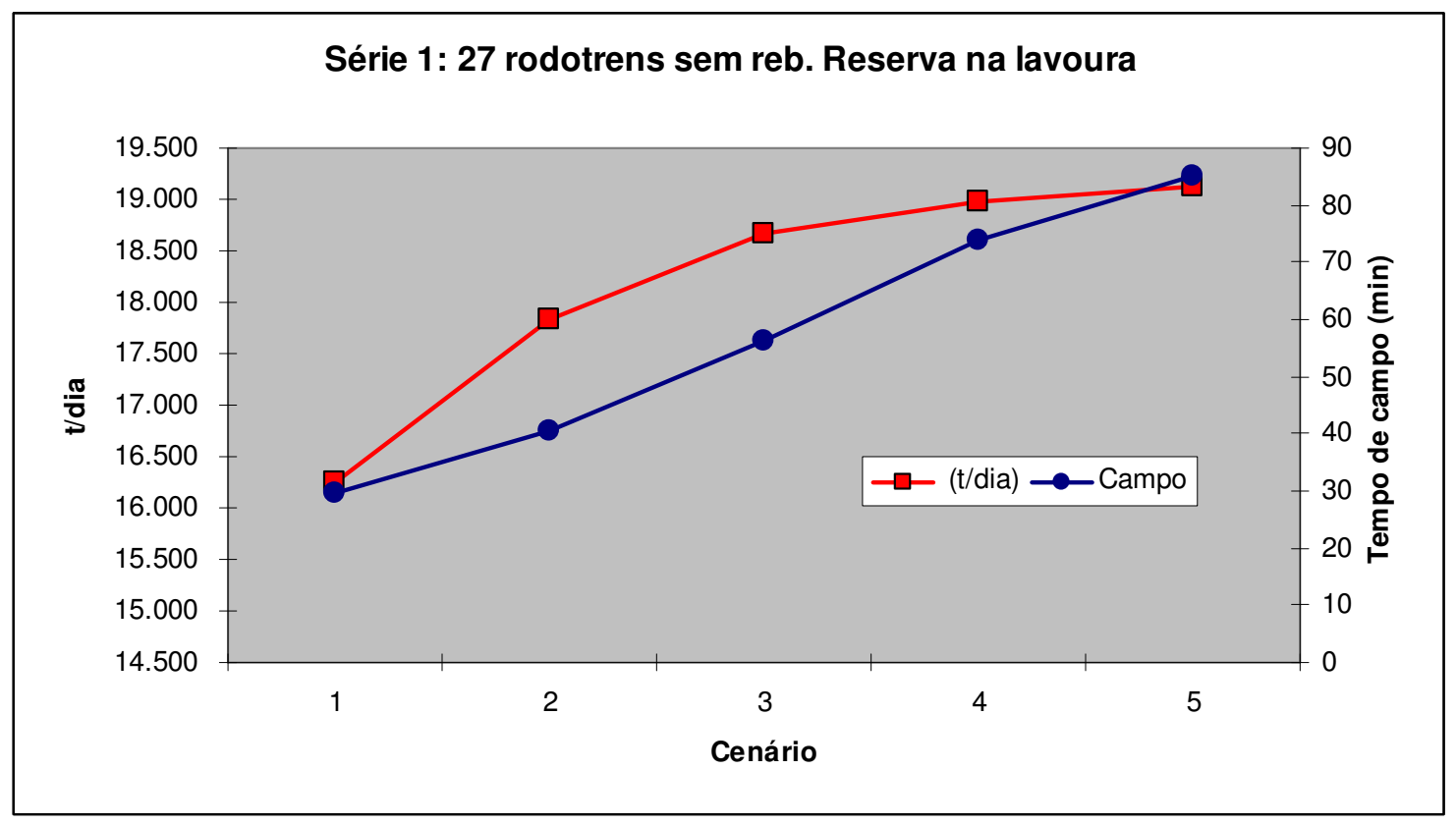

Gráfico 2- Série 1:Produção e tempo de campo

\subsubsection{Série $2-27$ rodotrens, com reboque reserva na lavoura, despacho estático}

Considerando que se encontrou o limite máximo de produção sem adoção de reboques reserva na lavoura, elaborou-se a segunda série de cenários, na qual foram adicionados equipamentos desta classe à frota.

Os resultados desta série, exibidos na Tabela 5, mostram que o uso de reboques reserva na lavoura contribuem de maneira decisiva para a melhoria da produtividade dos 
caminhões. Este aumento de produtividade está evidente quando se compara o cenário $1 \mathrm{com}$ o 6, notando-se um acréscimo de 1.962 t na produção diária, ou 12\% de incremento. Observase ainda na Tabela 5 que o tempo de permanência no campo reduziu-se quase pela metade, de 30 minutos no cenário 1 , para 16 minutos no cenário 6.

Analisando ainda na série 2 os cenários de número 7 em diante, verifica-se que incrementos de reboque reserva além da quantidade de 10 unidades não trazem benefício à produção diária e que o tempo de campo também se estabiliza. Além destas observações, nota-se que o custo de produção aumenta.

Os resultados mostram também que a frota de 27 rodotrens não é suficiente para atender a demanda prevista.

Tabela 5 - Série 2 - 27 rodotrens, com reboque reserva na lavoura, despacho estático

\begin{tabular}{|c|c|c|c|c|c|c|}
\hline \multirow[b]{2}{*}{ Cenário } & \multicolumn{2}{|c|}{ Frota } & \multirow{2}{*}{$\begin{array}{c}\text { Produção } \\
\text { (t/dia) }\end{array}$} & \multicolumn{2}{|c|}{ Custo operação } & \multirow{2}{*}{$\begin{array}{c}\text { Tempo de } \\
\text { campo (min) }\end{array}$} \\
\hline & Caminhões & $\begin{array}{c}\text { Reb. reserva } \\
\text { na lavoura }\end{array}$ & & Safra (x 1000) & $\mathbf{R} \$ / \mathbf{t}$ & \\
\hline 1 & 27 & 0 & 16.245 & $\mathrm{R} \$ 37.335$ & $\mathrm{R} \$ 11,27$ & 30 \\
\hline 6 & 27 & 5 & 18.207 & $\mathrm{R} \$ 36.172$ & $\mathrm{R} \$ 9,74$ & 16 \\
\hline 7 & 27 & 10 & 18.891 & $\mathrm{R} \$ 36.173$ & $\mathrm{R} \$ 9,39$ & 11 \\
\hline 8 & 27 & 15 & 18.900 & $\mathrm{R} \$ 36.451$ & $\mathrm{R} \$ 9,45$ & 10 \\
\hline 9 & 27 & 20 & 18.974 & $\mathrm{R} \$ 36.650$ & $\mathrm{R} \$ 9,47$ & 9 \\
\hline 10 & 27 & 25 & 19.030 & $\mathrm{R} \$ 36.954$ & $\mathrm{R} \$ 9,52$ & 9 \\
\hline 11 & 27 & 30 & 19.030 & $\mathrm{R} \$ 37.212$ & $\mathrm{R} \$ 9,59$ & 9 \\
\hline 12 & 27 & 35 & 19.158 & $\mathrm{R} \$ 37.518$ & $\mathrm{R} \$ 9,60$ & 9 \\
\hline 13 & 27 & 40 & 19.139 & $\mathrm{R} \$ 37.761$ & $\mathrm{R} \$ 9,67$ & 9 \\
\hline 14 & 27 & 45 & 19.122 & $\mathrm{R} \$ 38.050$ & $\mathrm{R} \$ 9,75$ & 9 \\
\hline 15 & 27 & 50 & 19.059 & $\mathrm{R} \$ 38.219$ & $\mathrm{R} \$ 9,83$ & 9 \\
\hline
\end{tabular}

Nota-se que a partir do cenário 9 o tempo de campo se estabiliza, Cabe ressaltar que do cenário 10 ao 15 ocorre uma flutuação nos valores de produção. Uma análise estatística da média obtida em cada cenário, utilizando o Minitab, demonstrou que não se pode rejeitar a igualdade desses valores. 


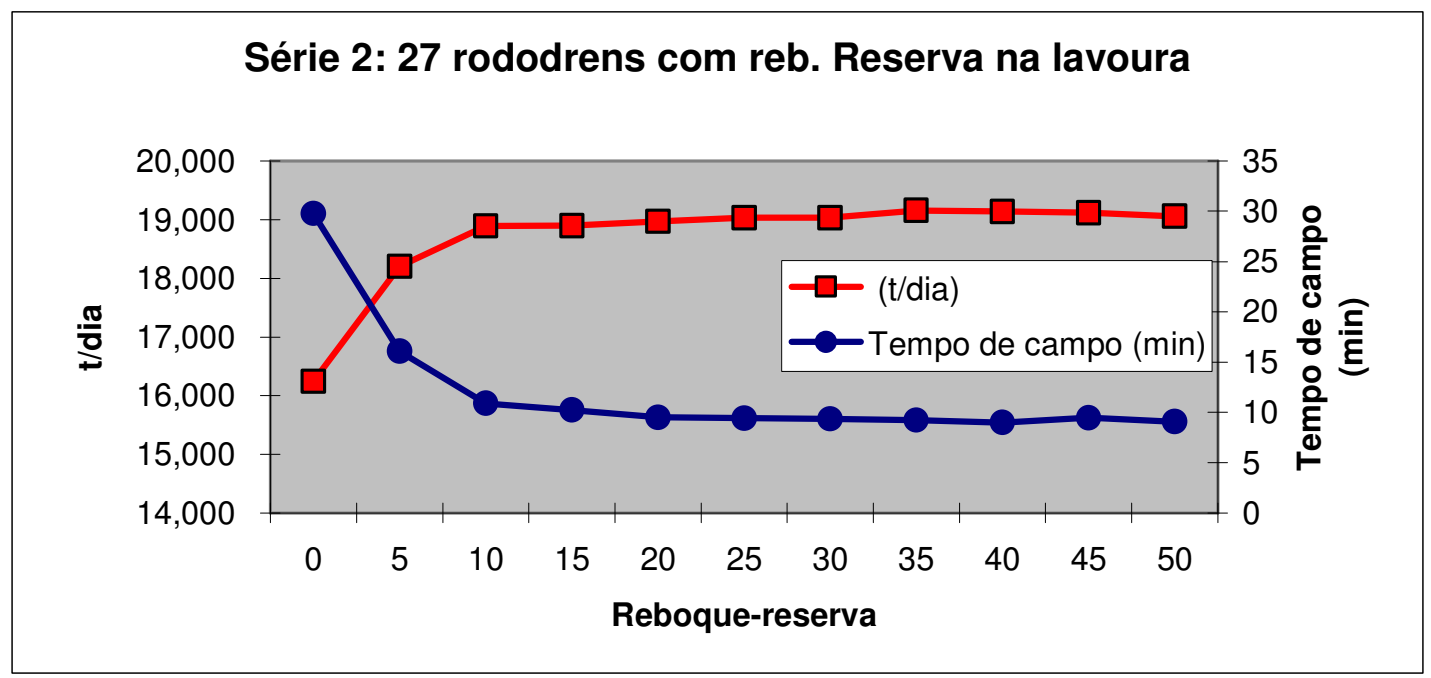

Gráfico 3 - Série 2: 27 rodotrens com reboque reserva na lavoura

\subsubsection{Série 3 - 32 rodotrens, com reboque reserva na lavoura, despacho estático}

Constatando-se que a frota de 27 caminhões não é suficiente para atender à demanda diária de produção, elaborou-se a série 3, para a qual foram adotados 32 caminhões com reboques reserva na lavoura, variando-se a quantidade destes últimos equipamentos de 5 a 50 unidades por cenário, com incremento de cinco unidades entre cada um.

Pelos resultados desta série, relacionados na Tabela 6, nota-se que a meta de produção foi atingida e a um custo de $\mathrm{R} \$ 9,51 / \mathrm{t}$ - cenário 18 , tendo sido utilizados quinze conjuntos de reboque reserva na lavoura. A produção deste cenário é $20 \%$ maior que a produção do cenário base.

É importante observar também que o tempo de campo para os caminhões é de onze minutos neste cenário 18, o que indica que há uma pequena formação de fila na lavoura, com duração e torno de 5,3 minutos, quando se compara com tempo de campo previsto de 5,7 minutos por composição (equação 12). 
Tabela 6 - Série 3: 32 rodotrens, com reboque reserva na lavoura, despacho estático

\begin{tabular}{|c|c|c|c|c|c|c|}
\hline \multirow[b]{2}{*}{ Cenário } & \multicolumn{2}{|c|}{ Frota } & \multirow[b]{2}{*}{ (t/dia) } & \multicolumn{2}{|c|}{ Custo operação } & \multirow[b]{2}{*}{$\begin{array}{c}\text { Tempo de } \\
\text { campo }(\mathrm{min})\end{array}$} \\
\hline & Caminhões & $\begin{array}{c}\text { Reb.reserva } \\
\text { na lavoura }\end{array}$ & & $\begin{array}{c}\text { Safra } \\
(x \text { 1000) }\end{array}$ & $\mathbf{R} \$ / \mathbf{t}$ & \\
\hline 1 & 27 & 0 & 16.245 & $\mathrm{R} \$ 37.335$ & $\mathrm{R} \$ 11,27$ & 30 \\
\hline 6 & 32 & 5 & 19.301 & $\mathrm{R} \$ 39.112$ & $\mathrm{R} \$ 9,93$ & 25 \\
\hline 7 & 32 & 10 & 19.459 & $\mathrm{R} \$ 37.911$ & $\mathrm{R} \$ 9,55$ & 15 \\
\hline 18 & 32 & 15 & 19.560 & $\mathrm{R} \$ 37.956$ & $\mathrm{R} \$ 9,51$ & 11 \\
\hline 19 & 32 & 20 & 19.581 & $\mathrm{R} \$ 38.246$ & $\mathrm{R} \$ 9,57$ & 12 \\
\hline 20 & 32 & 25 & 19.519 & $\mathrm{R} \$ 38.419$ & $\mathrm{R} \$ 9,65$ & 11 \\
\hline 21 & 32 & 30 & 19.524 & $\mathrm{R} \$ 38.551$ & $\mathrm{R} \$ 9,68$ & 11 \\
\hline 22 & 32 & 35 & 19.591 & $\mathrm{R} \$ 38.847$ & $\mathrm{R} \$ 9,72$ & 10 \\
\hline 23 & 32 & 40 & 19.565 & $\mathrm{R} \$ 39.180$ & $\mathrm{R} \$ 9,82$ & 10 \\
\hline 24 & 32 & 45 & 19.599 & $\mathrm{R} \$ 39.419$ & $\mathrm{R} \$ 9,86$ & 10 \\
\hline 25 & 32 & 50 & 19.632 & $\mathrm{R} \$ 39.640$ & $\mathrm{R} \$ 9,90$ & 10 \\
\hline
\end{tabular}

Os comentários da Tabela 5 também se aplicam aos resultados da Tabela 6

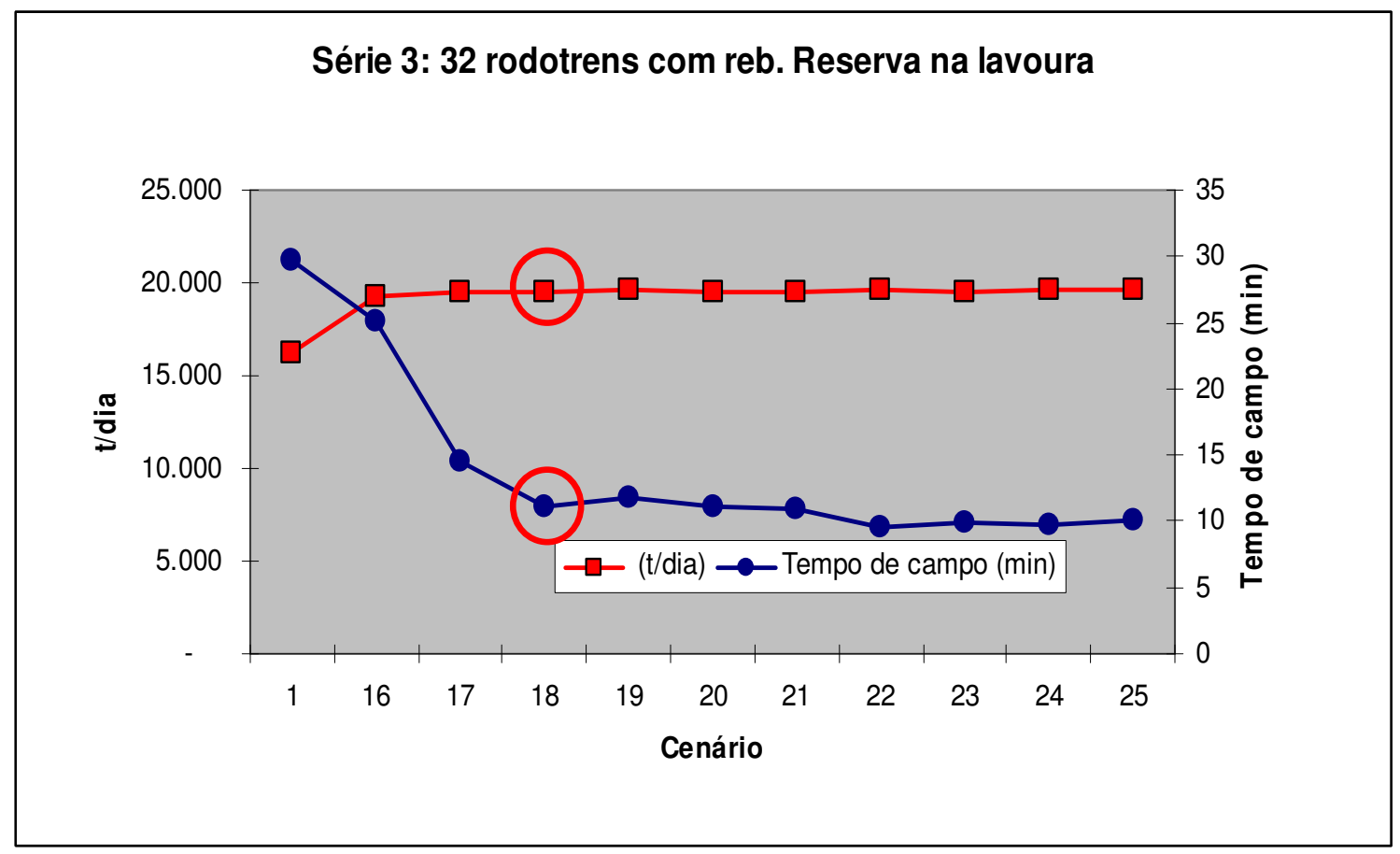

Gráfico 4- Série 3: 32 rodotrens com reboque reserva na lavoura

\subsubsection{Série 4 - 27 a 46 rodotrens, sem reboque reserva na lavoura, despacho dinâmico}

$\mathrm{Na}$ quarta série de cenários iniciam-se os testes para verificar a melhoria do desempenho da frota com o despacho dinâmico. 
Foram repetidas as séries 1 a 3, alterando apenas o critério de despacho.

Na série 4, que se compara com a série 1, foram utilizados 27 rodotrens, sem reboque reserva na lavoura. Assim como na série 1, não foi possível atingir a meta de produção. Como a produção obtida na série 1 estava muito abaixo da meta não se esperava que o despacho dinâmico, por si só, fosse capaz de reverter este quadro.

Os resultados desta série estão representados na Tabela 7 e no Gráfico 5, e são muito parecidos com os resultados da Série 1 .

Tabela 7 - Série 4: 27 rodotrens sem reboque reserva na lavoura, despacho dinâmico

\begin{tabular}{cccccc}
\hline & \multicolumn{2}{c}{$\begin{array}{c}\text { Frota } \\
\text { Reb. reserva na } \\
\text { lavoura }\end{array}$} & $\begin{array}{c}\text { Produção } \\
(\mathbf{t} / \text { dia) }\end{array}$ & $\begin{array}{c}\text { Custo operação } \\
\text { Safra (x } \\
\mathbf{1 0 0 0})\end{array}$ & $\mathrm{R} \$ / \mathbf{t}$ \\
\hline 26 & 27 & 0 & 16.425 & $\mathrm{R} \$ 37.516$ & $\mathrm{R} \$ 11,20$ \\
27 & 32 & 0 & 17.656 & $\mathrm{R} \$ 39.934$ & $\mathrm{R} \$ 11,09$ \\
28 & 37 & 0 & 18.471 & $\mathrm{R} \$ 41.873$ & $\mathrm{R} \$ 11,11$ \\
29 & 42 & 0 & 18.792 & $\mathrm{R} \$ 43.185$ & $\mathrm{R} \$ 11,26$ \\
30 & 46 & 0 & 19.014 & $\mathrm{R} \$ 44.171$ & $\mathrm{R} \$ 11,39$ \\
\hline
\end{tabular}

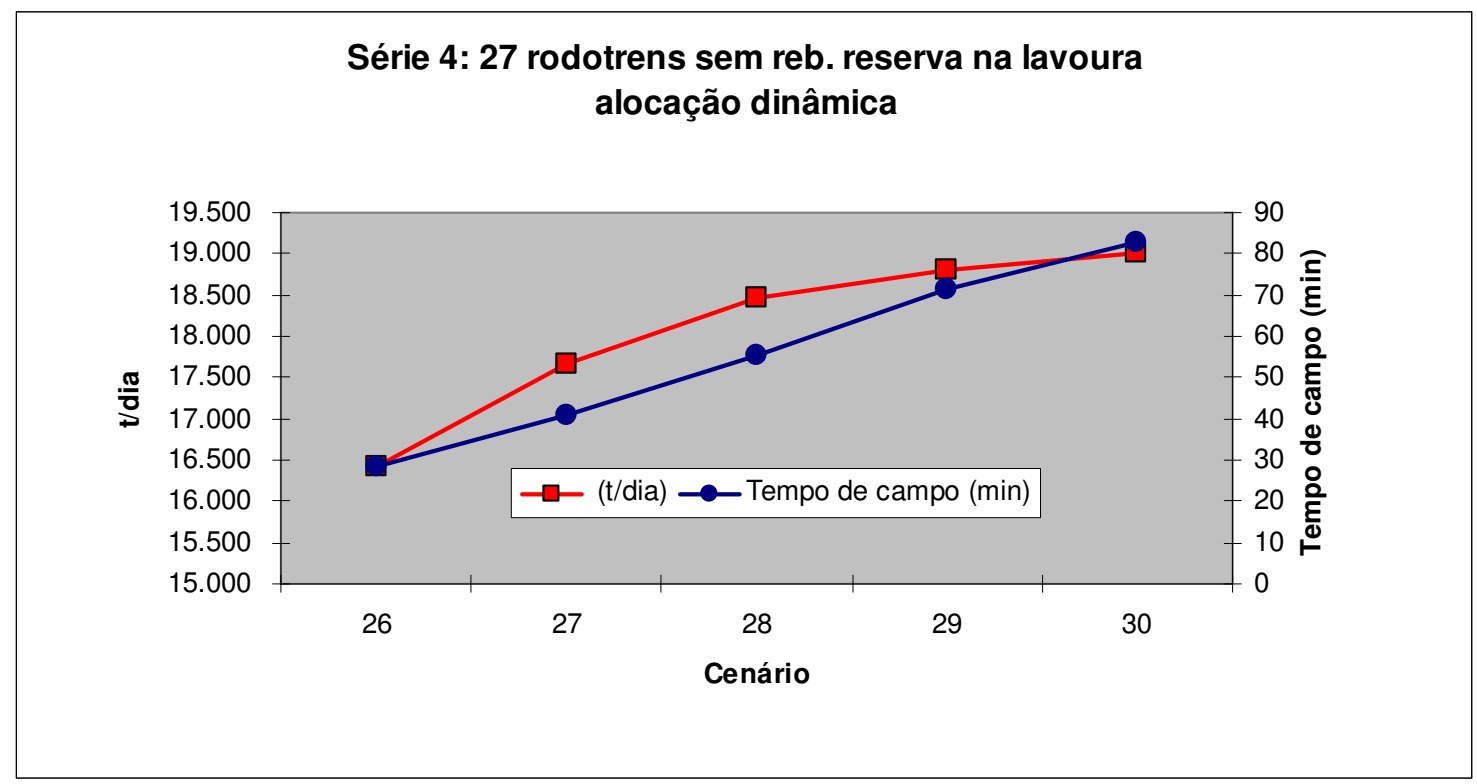

Gráfico 5 - Série 4: 27 rodotrens sem reboque reserva na lavoura, despacho dinâmico 


\subsubsection{Série 5 - 27 rodotrens, com reboque reserva na lavoura, despacho dinâmico}

Na quinta série de cenários foram adicionados reboques reserva na lavoura.

Na Tabela 8 verifica-se que nesta série também, como já havia ocorrido com a Série 2, não foi possível atingir a meta de produção mesmo com a adoção de despacho dinâmico.

Comparando os resultados, o custo da produção é menor que aquele obtido na Série

2, mostrado na Tabela 5, indicando que a despacho dinâmico traz algum benefício à operação.

Tabela 8 - Série 5: 27 rodotrens com reboque reserva na lavoura, despacho dinâmico

\begin{tabular}{|c|c|c|c|c|c|c|}
\hline \multirow[b]{2}{*}{ Cenário } & \multicolumn{2}{|c|}{ Frota } & \multirow{2}{*}{$\begin{array}{c}\text { Produção } \\
\text { (t/dia) }\end{array}$} & \multicolumn{2}{|c|}{ Custo operação } & \multirow{2}{*}{$\begin{array}{l}\text { Tempo de } \\
\text { campo (min) }\end{array}$} \\
\hline & Caminhões & $\begin{array}{c}\text { Reb. reserva } \\
\text { na lavoura }\end{array}$ & & Safra (x 1000) & $\mathbf{R} \$ / \mathbf{t}$ & \\
\hline 31 & 27 & 5 & 18.524 & $\mathrm{R} \$ 36.375$ & $\mathrm{R} \$ 9,63$ & 13 \\
\hline 32 & 27 & 10 & 19.184 & $\mathrm{R} \$ 36.393$ & $\mathrm{R} \$ 9,30$ & 9 \\
\hline 33 & 27 & 15 & 19.235 & $\mathrm{R} \$ 36.540$ & $R \$ 9,31$ & 8 \\
\hline 34 & 27 & 20 & 19.216 & $\mathrm{R} \$ 36.746$ & $\mathrm{R} \$ 9,37$ & 8 \\
\hline 35 & 27 & 25 & 19.193 & $\mathrm{R} \$ 36.985$ & $\mathrm{R} \$ 9,45$ & 8 \\
\hline 36 & 27 & 30 & 19.411 & $\mathrm{R} \$ 37.434$ & $\mathrm{R} \$ 9,45$ & 8 \\
\hline 37 & 27 & 35 & 19.091 & $\mathrm{R} \$ 37.351$ & $\mathrm{R} \$ 9,59$ & 8 \\
\hline 38 & 27 & 40 & 19.263 & $\mathrm{R} \$ 37.810$ & $\mathrm{R} \$ 9,62$ & 8 \\
\hline 39 & 27 & 45 & 19.241 & $\mathrm{R} \$ 38.046$ & $\mathrm{R} \$ 9,69$ & 8 \\
\hline 40 & 27 & 50 & 19.085 & $\mathrm{R} \$ 38.208$ & $R \$ 9,81$ & 8 \\
\hline
\end{tabular}




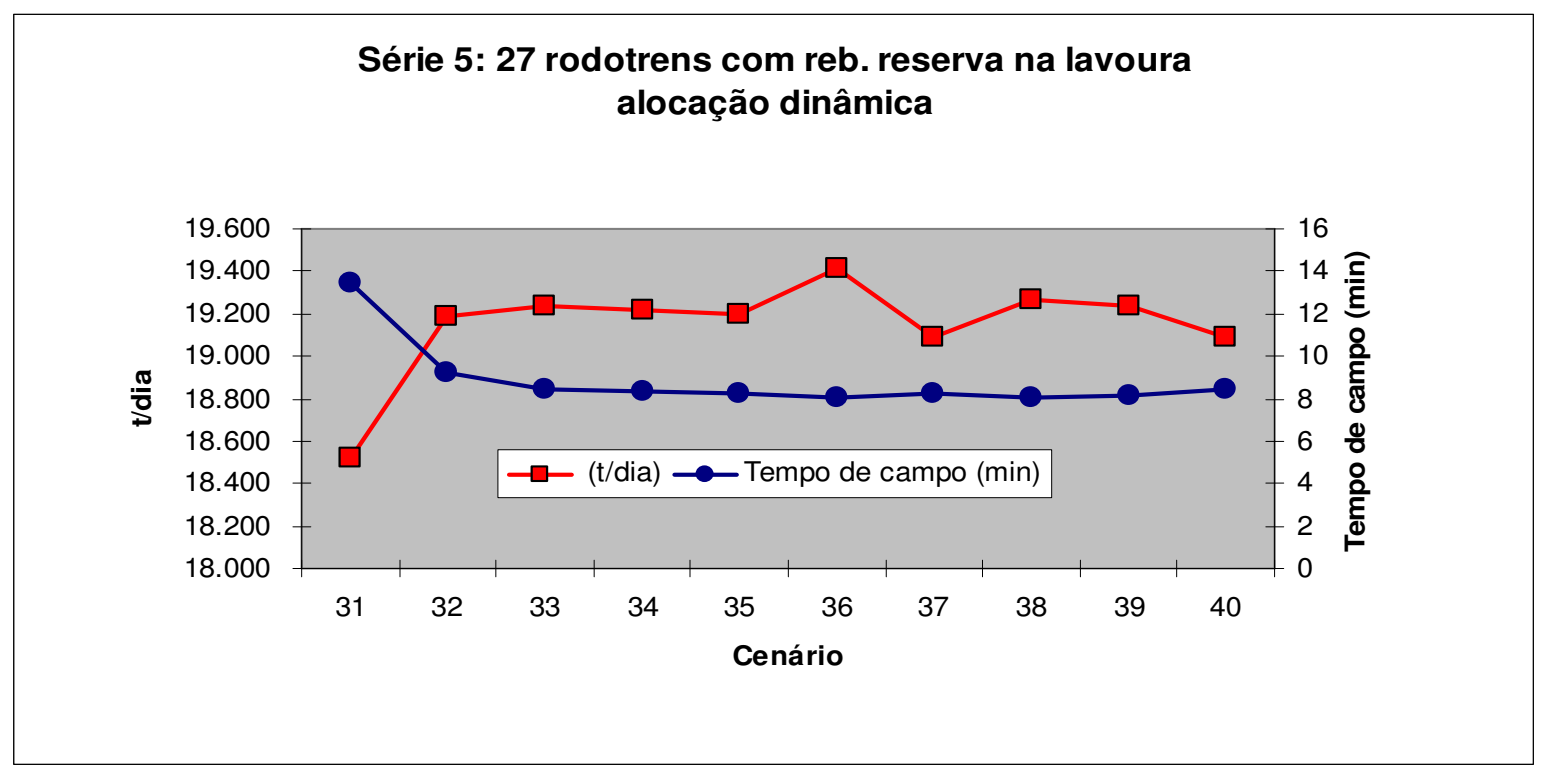

Gráfico 6 - Série 5: 27 rodotrens com reboque reserva na lavoura, despacho dinâmico

\subsubsection{Série 6 - 32 rodotrens, com reboque reserva na lavoura, despacho dinâmico}

A sexta série de cenários foi elaborada para verificar como o despacho dinâmico da frota contribui para a melhoria da produção, e para a redução dos custos, em relação à série 3, que foi a primeira série em que se atingiu a meta de produção.

Os resultados da Tabela 9 mostram que houve sucesso na adoção do despacho dinâmico, uma vez que se obteve resultado (cenário 42) com custo de produção melhor que o custo do cenário 18 , até então o cenário mais barato (dentre aqueles em que a meta de produção foi atingida).

No cenário 42 o custo de produção é de $R$ \$9,45/t, enquanto que o cenário 18 tem custo de $\mathrm{R} \$$ 9,51/t, para a mesma produção diária. Este diferença de custos equivale à economia de $\mathrm{R} \$ 266$ mil na safra.

Em relação à frota, no cenário 42 foram alocados 10 conjuntos de reboque reserva na lavoura, enquanto que no cenário 18 foram utilizados 15 conjuntos. 
Ao comparar os resultados do cenário 16, da Tabela 6, com o cenário 41, da Tabela 9, nota-se que a meta de produção é atingida sem que se altere a capacidade da colheita e da recepção. Os resultados destas duas tabelas (6 e 9) indicam também que a frota de 32 rodotrens com 5 conjuntos de reboques-reservas na lavoura operam bem no transporte, mas são restritas pela capacidade de colheita e/ou recepção.

Tabela 9 - Série 6: 32 rodotrens com reboque reserva na lavoura, despacho dinâmico

\begin{tabular}{|c|c|c|c|c|c|}
\hline \multirow[b]{2}{*}{ Cenário } & \multicolumn{2}{|c|}{ Frota } & \multirow{2}{*}{$\begin{array}{c}\text { Produção } \\
\text { (t/dia) }\end{array}$} & \multicolumn{2}{|c|}{ Custo operação } \\
\hline & Caminhões & $\begin{array}{c}\text { Reb. reserva na } \\
\text { lavoura }\end{array}$ & & Safra (x 1000) & $\mathbf{R} \$ / \mathbf{t}$ \\
\hline 41 & 32 & 5 & 19.524 & $\mathrm{R} \$ 38.933$ & $\mathrm{R} \$ 9,78$ \\
\hline 42 & 32 & 10 & 19.551 & $\mathrm{R} \$ 37.690$ & $\mathrm{R} \$ 9,45$ \\
\hline 43 & 32 & 15 & 19.562 & $\mathrm{R} \$ 37.822$ & $\mathrm{R} \$ 9,48$ \\
\hline 44 & 32 & 20 & 19.596 & $\mathrm{R} \$ 38.101$ & $\mathrm{R} \$ 9,53$ \\
\hline 45 & 32 & 25 & 19.601 & $\mathrm{R} \$ 38.348$ & $\mathrm{R} \$ 9,59$ \\
\hline 46 & 32 & 30 & 19.616 & $\mathrm{R} \$ 38.587$ & $\mathrm{R} \$ 9,64$ \\
\hline 47 & 32 & 35 & 19.618 & $\mathrm{R} \$ 38.835$ & $\mathrm{R} \$ 9,70$ \\
\hline 48 & 32 & 40 & 19.637 & $\mathrm{R} \$ 39.048$ & $\mathrm{R} \$ 9,75$ \\
\hline 49 & 32 & 45 & 19.643 & $\mathrm{R} \$ 39.249$ & $\mathrm{R} \$ 9,79$ \\
\hline 50 & 32 & 50 & 19.659 & $\mathrm{R} \$ 39.568$ & $\mathrm{R} \$ 9,87$ \\
\hline
\end{tabular}

Série 6: 32 rodotrens com reb. reserva na lavoura alocação dinâmica

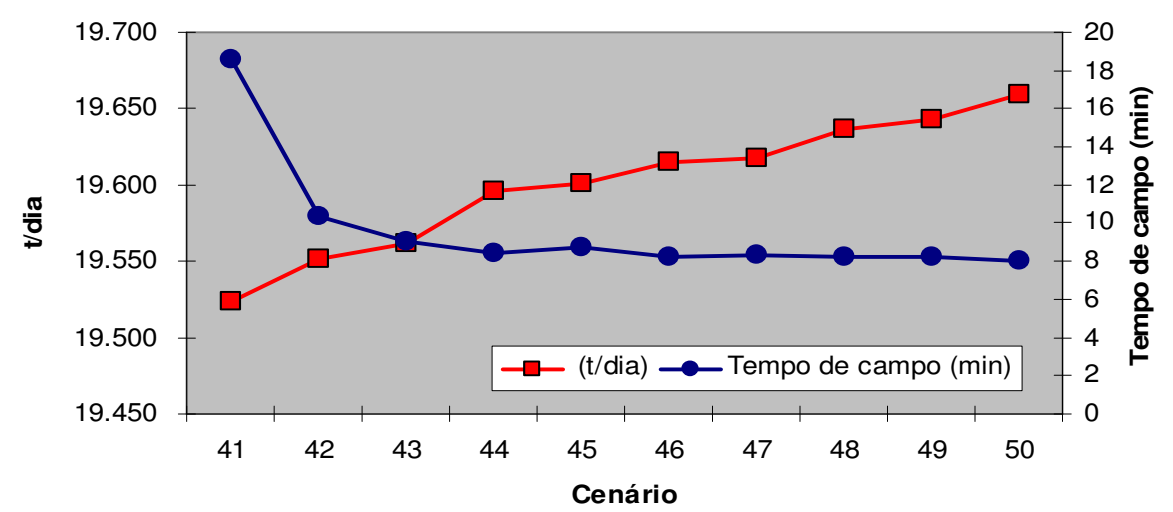

Gráfico 7 - Série 6: 32 rodotrens com reboque reserva na lavoura, despacho dinâmico 


\subsubsection{Série 7 - 27 a 31 rodotrens, com reboque reserva na lavoura, despacho dinâmico}

Ao contrário do despacho estático, em que se aloca uma determinada quantidade de caminhões para cada frente, no despacho dinâmico há um bloco de caminhões que ficam livres para serem alocados para qualquer frente de corte, conforme definido no capítulo 3.

No despacho estático, como cada grupo de caminhões é despachado para a frente de corte para a qual foi inicialmente designado, reduzir um caminhão de uma determinada frente de corte pode comprometer o resultado da produção daquela frente e, quando a frota já está no limite de sua capacidade, os resultados para a produção global são danosos. Esta situação (redução de um equipamento da frota) já não acontece com o despacho dinâmico; pelo menos não é tão sensível como no despacho estático, uma vez que esta técnica consegue distribuir melhor os equipamentos, prevenindo a formação de filas, principalmente. no campo.

A fim de avaliar qual a menor frota possível para atender a demanda de produção, utilizando o despacho dinâmico e reboques reserva na lavoura, criou-se a sétima série de cenários, cujos resultados estão listados Tabela 10. Nesta série foram avaliados quarenta cenários, utilizando os fatores frota de caminhões e frota de reboques reserva e adotando-se os níveis descritos no Quadro 8.

\begin{tabular}{ccc}
\hline Fator & Níveis & $\begin{array}{c}\text { Intervalo de variação dos } \\
\text { níveis }\end{array}$ \\
\hline Frota de caminhões & 28 a 31 & unidade \\
Frota de reb. Reserve na lavoura & 5 a 50 & cinco \\
\hline
\end{tabular}

Quadro 8 - Fatores e níveis da série 7 de cenários

Como era esperado, encontrou-se uma configuração de frota menor que todos os cenários analisados, atendendo a demanda prevista e com o menor custo dentre todos os cenários analisados até então. Estes resultados foram obtidos com a configuração do cenário 
56, em que se utilizou uma frota de 29 rodotrens e 10 reboques reserva. O custo deste cenário é de $\mathrm{R} \$ 9,30$ / t, custo este 2,3\% menor que o do cenário 18 , representando uma economia de R\$ 920,87 mil na safra.

Tabela 10 - Série 7: 28 a 31 rodotrens, com reboque reserva e despacho dinâmico

\begin{tabular}{|c|c|c|c|c|c|}
\hline \multirow[b]{2}{*}{ Cenário } & \multicolumn{2}{|c|}{ Frota } & \multirow{2}{*}{$\begin{array}{c}\text { Produção } \\
\text { (t/dia) }\end{array}$} & \multicolumn{2}{|c|}{ Custo operação } \\
\hline & Caminhões & $\begin{array}{l}\text { Reb.reserva na } \\
\text { lavoura }\end{array}$ & & Safra (x 1000) & $\mathbf{R} \$ / \mathbf{t}$ \\
\hline 51 & 28 & 5 & 19.147 & $\mathrm{R} \$ 37.421$ & $\mathrm{R} \$ 9,58$ \\
\hline 52 & 29 & 5 & 19.301 & $\mathrm{R} \$ 37.899$ & $\mathrm{R} \$ 9,63$ \\
\hline 53 & 30 & 5 & 19.437 & $\mathrm{R} \$ 38.265$ & $\mathrm{R} \$ 9,65$ \\
\hline 54 & 31 & 5 & 19.478 & $\mathrm{R} \$ 38.627$ & $\mathrm{R} \$ 9,72$ \\
\hline 55 & 28 & 10 & 19.392 & $\mathrm{R} \$ 36.712$ & $\mathrm{R} \$ 9,28$ \\
\hline 56 & 29 & 10 & 19.525 & $\mathrm{R} \$ 37.035$ & $\mathrm{R} \$ 9,30$ \\
\hline 57 & 30 & 10 & 19.542 & $\mathrm{R} \$ 37.233$ & $\mathrm{R} \$ 9,34$ \\
\hline 58 & 31 & 10 & 19.571 & $\mathrm{R} \$ 37.449$ & $\mathrm{R} \$ 9,38$ \\
\hline 59 & 28 & 15 & 19.442 & $\mathrm{R} \$ 36.956$ & $\mathrm{R} \$ 9,32$ \\
\hline 60 & 29 & 15 & 19.550 & $\mathrm{R} \$ 37.187$ & $\mathrm{R} \$ 9,32$ \\
\hline 61 & 30 & 15 & 19.568 & $\mathrm{R} \$ 37.432$ & $\mathrm{R} \$ 9,38$ \\
\hline 62 & 31 & 15 & 19.601 & $\mathrm{R} \$ 37.627$ & $\mathrm{R} \$ 9,41$ \\
\hline 63 & 28 & 20 & 19.551 & $\mathrm{R} \$ 37.303$ & $\mathrm{R} \$ 9,35$ \\
\hline 64 & 29 & 20 & 19.550 & $\mathrm{R} \$ 37.459$ & $\mathrm{R} \$ 9,39$ \\
\hline 65 & 30 & 20 & 19.596 & $\mathrm{R} \$ 37.721$ & $\mathrm{R} \$ 9,44$ \\
\hline 66 & 31 & 20 & 19.566 & $\mathrm{R} \$ 37.925$ & $\mathrm{R} \$ 9,50$ \\
\hline 67 & 28 & 25 & 19.511 & $\mathrm{R} \$ 37.552$ & $\mathrm{R} \$ 9,43$ \\
\hline 68 & 29 & 25 & 19.590 & $\mathrm{R} \$ 37.750$ & $\mathrm{R} \$ 9,45$ \\
\hline 69 & 30 & 25 & 19.590 & $\mathrm{R} \$ 37.928$ & $\mathrm{R} \$ 9,49$ \\
\hline 70 & 31 & 25 & 19.570 & $\mathrm{R} \$ 38.170$ & $\mathrm{R} \$ 9,56$ \\
\hline 71 & 28 & 30 & 19.545 & $\mathrm{R} \$ 37.763$ & $\mathrm{R} \$ 9,47$ \\
\hline 72 & 29 & 30 & 19.544 & $\mathrm{R} \$ 37.953$ & $\mathrm{R} \$ 9,52$ \\
\hline 73 & 30 & 30 & 19.590 & $\mathrm{R} \$ 38.207$ & $\mathrm{R} \$ 9,56$ \\
\hline 74 & 31 & 30 & 19.607 & $\mathrm{R} \$ 38.386$ & $\mathrm{R} \$ 9,60$ \\
\hline 75 & 28 & 35 & 19.614 & $\mathrm{R} \$ 38.077$ & $R \$ 9,52$ \\
\hline 76 & 29 & 35 & 19.540 & $\mathrm{R} \$ 38.240$ & $\mathrm{R} \$ 9,59$ \\
\hline 77 & 30 & 35 & 19.588 & $\mathrm{R} \$ 38.450$ & $\mathrm{R} \$ 9,62$ \\
\hline 78 & 31 & 35 & 19.619 & $\mathrm{R} \$ 38.663$ & $\mathrm{R} \$ 9,66$ \\
\hline 79 & 28 & 40 & 19.550 & $\mathrm{R} \$ 38.240$ & $\mathrm{R} \$ 9,59$ \\
\hline 80 & 29 & 40 & $\begin{array}{l}19.586 \\
\text { tinua - }\end{array}$ & $\mathrm{R} \$ 38.495$ & $\mathrm{R} \$ 9,63$ \\
\hline
\end{tabular}


- continuação -

\begin{tabular}{ccccccc}
\hline & & \multicolumn{2}{c}{$\begin{array}{c}\text { Frota } \\
\text { Reb.reserva na } \\
\text { lavoura }\end{array}$} & $\begin{array}{c}\text { Produção } \\
\text { (t/dia) }\end{array}$ & Custo operação \\
\hline & & & & & \\
81 & 30 & 40 & 19.604 & $\mathrm{R} \$ 38.636$ & $\mathrm{R} \$ 9,66$ \\
82 & 31 & 40 & 19.635 & $\mathrm{R} \$ 38.924$ & $\mathrm{R} \$ 9,72$ \\
83 & 28 & 45 & 19.581 & $\mathrm{R} \$ 38.538$ & $\mathrm{R} \$ 9,65$ \\
84 & 29 & 45 & 19.577 & $\mathrm{R} \$ 38.721$ & $\mathrm{R} \$ 9,70$ \\
85 & 30 & 45 & 19.618 & $\mathrm{R} \$ 38.873$ & $\mathrm{R} \$ 9,71$ \\
86 & 31 & 45 & 19.648 & $\mathrm{R} \$ 39.082$ & $\mathrm{R} \$ 9,75$ \\
87 & 28 & 50 & 19.557 & $\mathrm{R} \$ 38.763$ & $\mathrm{R} \$ 9,72$ \\
88 & 29 & 50 & 19.617 & $\mathrm{R} \$ 39.026$ & $\mathrm{R} \$ 9,75$ \\
89 & 30 & 50 & 19.643 & $\mathrm{R} \$ 39.219$ & $\mathrm{R} \$ 9,79$ \\
90 & 31 & 50 & 19.647 & $\mathrm{R} \$ 39.401$ & $\mathrm{R} \$ 9,83$ \\
\hline
\end{tabular}

A fim de facilitar a visualização dos resultados utilizou-se o gráfico de contorno (Gráficos 8 e 9). Este tipo de gráfico é empregado quando se deseja avaliar o relacionamento entre três variáveis, que neste caso foram custo de produção, a frota de rodotrem e a frota de reboques reserva. O gráfico apresenta, a partir de duas das três variáveis selecionadas, uma região de respostas viáveis para a combinação dessas duas variáveis. Para interpretar este tipo de gráfico utilizam-se duas retas perpendiculares entre si. Cada uma dessas retas cruza um dos eixos do gráfico, também perpendiculares ao eixo em que tocam. No cruzamento entre as duas retas encontra-se a terceira dimensão, ou o resultado procurado. Nos Gráficos 8 e 9 as duas retas vermelhas foram desenhadas para exemplificar a interpretação dos resultados; neste exemplo uma frota de 30 caminhões e 30 reboques reserva produz entre 19.500 e 19.600 t/dia e o custo da operação está entre $R \$ 9,50$ e $R \$ 9,60 /$. Para se chegar a estes dois valores é preciso correlacionar a cor da região onde as retas se cruzam com a legenda do gráfico. 


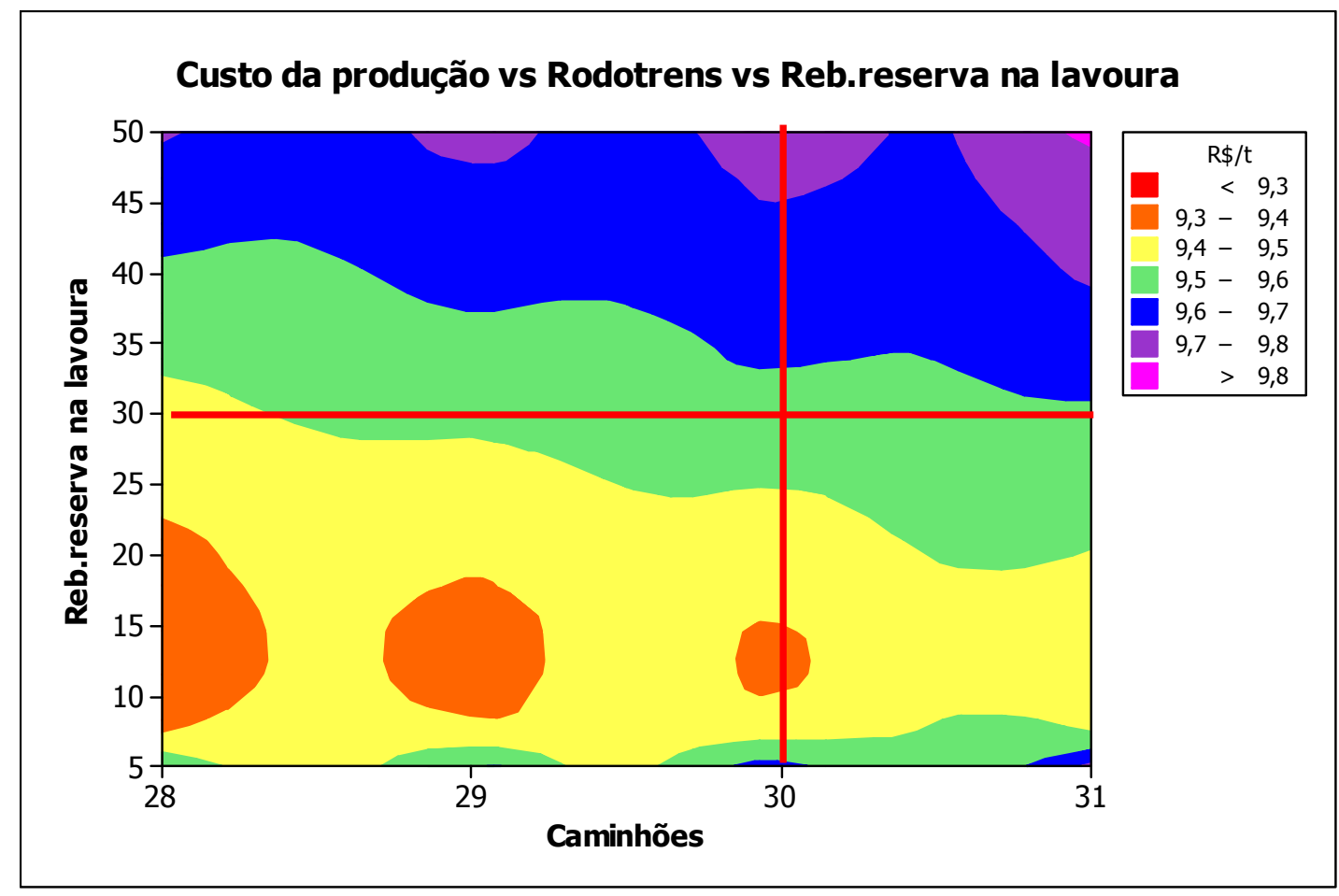

Gráfico 8 -Série 7: custo da produção vs frota de caminhões vs frota de reboques reserva

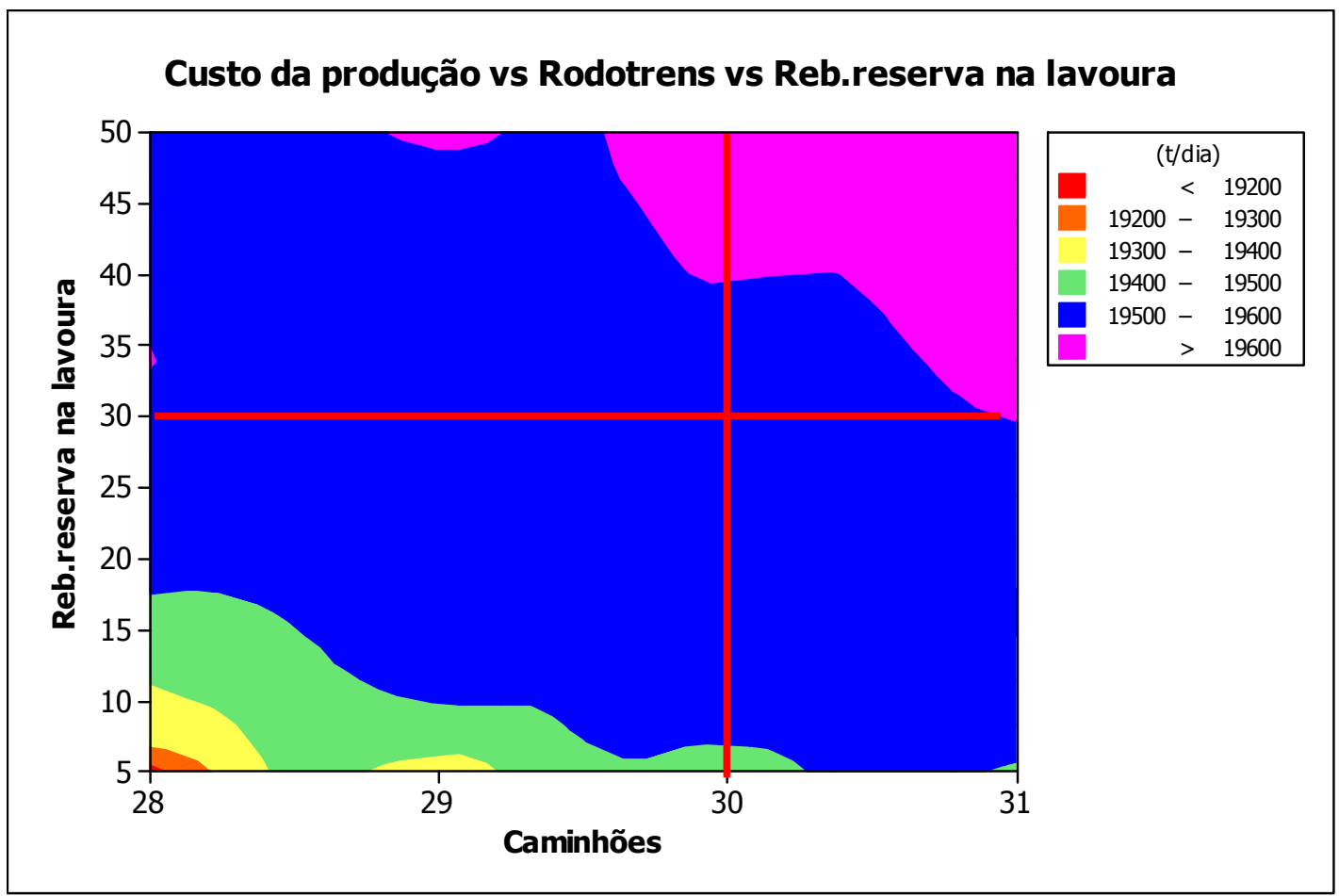

Gráfico 9 - Série 7: produção diária vs frota de caminhões vs frota de reboques reserva 


\subsubsection{Comparação dos cenários sem bate-volta na usina}

$\mathrm{Na}$ Tabela 11 encontram agrupados o melhor resultado de cada uma das séries analisadas, tendo sido considerados somente cenários em que se atingiu a meta de produção.

Tabela 11 - Melhores resultados de cada série sem bate-volta na usina

\begin{tabular}{ccccccccc}
\hline & Série & \multicolumn{2}{c}{ Frota } & Produção & \multicolumn{2}{c}{ Custo } & Despacho \\
Cenário & & Caminhões & $\begin{array}{c}\text { Reb.reserva } \\
\text { na lavoura }\end{array}$ & (t/dia) & $\mathbf{R} \$ / \mathbf{t}$ & $\begin{array}{c}\text { Safra }(\mathbf{x} \\
\text { 1000) }\end{array}$ & \\
\hline 1 & Base & 27 & 0 & 16.245 & $\mathrm{R} \$ 11,27$ & $\mathrm{R} \$ 37.334$ & Estático \\
18 & 3 & 32 & 15 & 19.559 & $\mathrm{R} \$ 9,51$ & $\mathrm{R} \$ 37.955$ & Estático \\
42 & 6 & 32 & 10 & 19.551 & $\mathrm{R} \$ 9,45$ & $\mathrm{R} \$ 37.689$ & Dinâmico \\
56 & 7 & 29 & 10 & 19.525 & $\mathrm{R} \$ 9,30$ & $\mathrm{R} \$ 37.034$ & Dinâmico \\
\hline
\end{tabular}

É importante notar na Tabela 11 que das sete séries analisadas em apenas três se conseguiu atender a demanda de produção (o cenário base foi listado apenas para comparação). Outra observação que chama a atenção é o fato de que só constam cenários com reboque reserva.

É prática corrente para a quantificação da frota aplicar um percentual de acréscimo à frota calculada deterministicamente; este percentual normalmente é de $30 \%$, atribuído ao tempo de manutenção. Além deste percentual para "tempo de manutenção", costuma-se calcular a quantidade de reboque reserva como sendo equivalente a $30 \%$ da frota estimada. Assim, a partir do cenário base, aplicando estes dois fatores, a frota alocada teria 32 rodotrens e 10 conjuntos reserva. Esta frota corresponde ao cenário 42. Comparando o cenário 42 com o cenário 56, o de menor custo, verifica-se que o custo de produção seria $R \$ 0,15 / t$ mais caro, o que representaria um dispêndio de $\mathrm{R}$ \$654,67 mil na safra.

Confrontando o despacho estático versus despacho dinâmico, cenários 18 e 56, respectivamente, a diferença de custos é ainda mais significativa, atingindo $\mathrm{R} \$ 920,87$ mil na safra. 


\subsubsection{Comparação dos cenários sem bate-volta na usina, com relaxação da meta de produção diária}

Considerando uma margem de tolerância de 5\% para a produção diária, quando o limite mínimo passa a ser de 18.525 t/dia, elaborou-se uma nova lista com sete cenários, selecionando-se o cenário de menor custo de cada série (Tabela 12). O cenário 56, embora não seja o de menor custo na série 7 , neste novo agrupamento de resultados, foi mantido na tabela para facilitar a comparação.

É importante frisar que a perda de receita provocada pela menor quantidade de cana moída não foi computada em nenhum cenário, por não fazer parte do escopo desta dissertação.

Tabela 12 - Melhores resultados de cada série sem bate-volta na usina

\begin{tabular}{cccccccc}
\hline$\cdot$ & $\cdot$ & \multicolumn{2}{c}{ Frota } & Produção & \multicolumn{2}{c}{ Custo } & Despacho \\
Cenário & Série & Caminhões & $\begin{array}{c}\text { Reb.reserva } \\
\text { na lavoura }\end{array}$ & (t/dia) & $\mathbf{R} \$ / \mathbf{t}$ & $\begin{array}{c}\text { Safra }(\mathbf{x} \\
\mathbf{1 0 0 0})\end{array}$ & \\
\hline 1 & Base & 27 & 0 & 16.245 & $\mathrm{R} \$ 11,27$ & $\mathrm{R} \$ 37.335$ & Estático \\
4 & 1 & 42 & 0 & 18.974 & $\mathrm{R} \$ 11,23$ & $\mathrm{R} \$ 43.458$ & Estático \\
7 & 2 & 27 & 10 & 18.891 & $\mathrm{R} \$ 9,39$ & $\mathrm{R} \$ 36.173$ & Estático \\
18 & 3 & 32 & 15 & 19.560 & $\mathrm{R} \$ 9,51$ & $\mathrm{R} \$ 37.956$ & Estático \\
29 & 4 & 42 & 0 & 18.792 & $\mathrm{R} \$ 11,26$ & $\mathrm{R} \$ 43.185$ & Dinâmico \\
32 & 5 & 27 & 10 & 19.184 & $\mathrm{R} \$ 9,30$ & $\mathrm{R} \$ 36.393$ & Dinâmico \\
42 & 6 & 32 & 10 & 19.551 & $\mathrm{R} \$ 9,45$ & $\mathrm{R} \$ 37.690$ & Dinâmico \\
55 & 7 & 28 & 10 & 19.392 & $\mathrm{R} \$ 9,28$ & $\mathrm{R} \$ 36.712$ & Dinâmico \\
56 & 7 & 29 & 10 & 19.525 & $\mathrm{R} \$ 9,30$ & $\mathrm{R} \$ 37.035$ & Dinâmico \\
\hline
\end{tabular}

Os resultados da Tabela 12, com exceção cenário 1, indicam que, relaxando a meta de produção em 5\%, é possível transportar a cota diária de cana sem adotar despacho dinâmico e sem utilizar reboques reserva (cenários 1, 2 e 3), porém, o custo do CCT pode ser até $17,5 \%$ maior que no cenário 56 e a frota tem até 13 rodotrens a mais, o que certamente será mais trabalhoso para administrar. Ao custo adicional do CCT devem ser somados ainda a 
receita perdida com os produtos que deixarão de ser fabricados com as $101.854 \mathrm{t}$ de cana que não serão transportadas.

Com esta nova regra, ou este novo limitador de produção, o cenário de menor custo passa a ser o 55 , com custo de produção de $\mathrm{R} \$ 9,28 / \mathrm{t}$, ou $0,9 \%$ menor que o custo do cenário 56. Neste novo melhor cenário, entretanto, transportam-se 133 t/dia a menos que no cenário 56. Considerando-se 204 dias úteis de safra, a quantidade de cana não transportada é equivalente a $24.546 \mathrm{t}$, ou 1,26 dias de moagem.

Na comparação do cenário 55, de menor custo, com o cenário 4, o de maior custo, verifica-se a diferença de $\mathrm{R} \$ 7.285$ mil na safra, para uma produção equivalente.

\subsection{AVALIAÇÃO DE CENÁRIOS COM ADOÇÃO DE BATE-VOLTA}

Após avaliar as respostas ao dimensionamento sem adoção de bate-volta na usina, uma nova seqüência de cenários foi desenvolvida a fim de verificar se há algum ganho operacional e/ou econômico com o desengate das composições na usina.

\subsubsection{Série 8 - cenário base com bate-volta}

O primeiro cenário avaliado nesta nova série foi configurado a partir do cenário base, em que se adotou o despacho estático e não foram utilizados reboques reserva na lavoura. Pelos resultados listados na Tabela 13, verifica-se que somente a adoção de bate-volta na usina não foi capaz de melhor a produtividade dos rodotrens, ocorrendo apenas o aumento do custo de produção uma vez que novos equipamentos foram agregados à frota.

A quantidade de cavalos escravos e reboques reserva da usina foram propositalmente configuradas para 10 equipamentos. O propósito desta escolha foi o de facilitar a geração dos cenários, pois se constatasse que, com esta quantidade exagerada de equipamentos, mantidos 
os demais parâmetros de configuração, não fosse possível transportar a cana necessária outros cenários com quantidades menores de equipamentos não precisariam ser analisados, como de fato ocorreu.

\subsubsection{Série 9 - 32 rodotrens com bate-volta e despacho estático}

Na seqüência foram avaliados os cenários com 32 rodotrens. Esta quantidade de rodotrens foi escolhida por ter sido a configuração do cenário 18, que foi o de menor custo dentre os cenários com despacho estático. Conforme se verifica pelos resultados listados na Tabela 14, para a configuração com 32 rodotrens também não foi possível reduzir o custo de produção adotando-se o bate-volta na usina.

\subsubsection{Série 10 - 27 rodotrens com bate-volta e despacho dinâmico}

Constatado pela série 8 que uma frota de 27 rodotrens, sem reboque reserva na lavoura, não é suficiente para transportar a produção necessária, foi elaborada uma nova série com 96 cenários. Nesta série a quantidade de cavalos escravo variou entre 5 e 12 e a quantidade de reboques reserva entre 2 e 10. Foram testados os dois métodos de despacho.

Pelos resultados listados na tabela 15 verifica-se que nenhum dos cenários apresentou custo menor que aquele obtido no cenário 56, concluindo-se que, para esta configuração de usina, a adoção de bate-volta na usina não é economicamente viável.

No Gráfico 10 está ilustrado o relacionamento entre tempo de usina versus quantidade de cavalos escravo versus quantidade de reboques reserva na usina. 
Tabela 13 - Série 8: 27 cenário base com bate-volta na usina

\begin{tabular}{|c|c|c|c|c|c|c|c|c|c|}
\hline \multirow[b]{2}{*}{ Cenário } & \multirow{2}{*}{$\begin{array}{c}\cdot \\
\text { Série }\end{array}$} & \multicolumn{4}{|c|}{ Frota } & \multirow{2}{*}{$\begin{array}{c}\text { Produção } \\
\text { (t/dia) }\end{array}$} & \multirow{2}{*}{$\begin{array}{c}\text { Custo } \\
\text { operação } \\
\mathbf{R} \$ / \mathbf{t}\end{array}$} & \multirow{2}{*}{$\begin{array}{l}\text { Custo da } \\
\text { safra } \\
\text { (x 1000) }\end{array}$} & \multirow[t]{2}{*}{ Despacho } \\
\hline & & Caminhões & $\begin{array}{c}\text { Reb.reserva } \\
\text { na lavoura }\end{array}$ & Escravo & Reb. Usina & & & & \\
\hline 1 & 8 & 27 & 0 & 0 & 0 & 16.245 & $\mathrm{R} \$ 11,27$ & $\mathrm{R} \$ 37.335$ & Estático \\
\hline 91 & 8 & 27 & 0 & 10 & 10 & 16.245 & $\mathrm{R} \$ 11,84$ & $\mathrm{R} \$ 39.227$ & Dinâmico \\
\hline
\end{tabular}

Tabela 14 - Série 9: 32 rodotrens com e bate-volta na usina

\begin{tabular}{|c|c|c|c|c|c|c|c|c|c|}
\hline \multirow[b]{2}{*}{ Cenário } & \multirow{2}{*}{ Série } & \multicolumn{4}{|c|}{ Frota } & \multirow{2}{*}{$\begin{array}{c}\text { Produção } \\
\text { (t/dia) }\end{array}$} & \multirow{2}{*}{$\begin{array}{c}\text { Custo } \\
\text { operação } \\
\mathbf{R} \$ / \mathbf{t}\end{array}$} & \multirow{2}{*}{$\begin{array}{c}\text { Custo da } \\
\text { safra } \\
\text { R\$ }\end{array}$} & \multirow[t]{2}{*}{ Despacho } \\
\hline & & Caminhões & $\begin{array}{c}\text { Reb.reserva } \\
\text { na lavoura }\end{array}$ & Escravo & Reb. Usina & & & & \\
\hline 18 & 8 & 32 & 15 & 0 & 0 & 19.560 & $\mathrm{R} \$ 9,51$ & $\mathrm{R} \$ 37.956$ & Estático \\
\hline 92 & 8 & 32 & 0 & 10 & 10 & 18.877 & $\mathrm{R} \$ 11,31$ & $\mathrm{R} \$ 43.544$ & Estático \\
\hline 93 & 8 & 32 & 5 & 10 & 10 & 19.308 & $\mathrm{R} \$ 10,57$ & $\mathrm{R} \$ 41.639$ & Estático \\
\hline 94 & 8 & 32 & 10 & 10 & 10 & 19.544 & $\mathrm{R} \$ 10,04$ & $\mathrm{R} \$ 40.042$ & Estático \\
\hline 95 & 8 & 32 & 15 & 10 & 10 & 19.451 & $\mathrm{R} \$ 10,12$ & $\mathrm{R} \$ 40.136$ & Estático \\
\hline 96 & 8 & 32 & 20 & 10 & 10 & 19.597 & $\mathrm{R} \$ 10,12$ & $\mathrm{R} \$ 40.464$ & Estático \\
\hline 97 & 8 & 32 & 25 & 10 & 10 & 19.549 & $\mathrm{R} \$ 10,21$ & $\mathrm{R} \$ 40.706$ & Estático \\
\hline
\end{tabular}


Tabela 15 - Cenários com 27 rodotrens e diferentes quantidades de cavalo-escravo e reb. reserva na usina

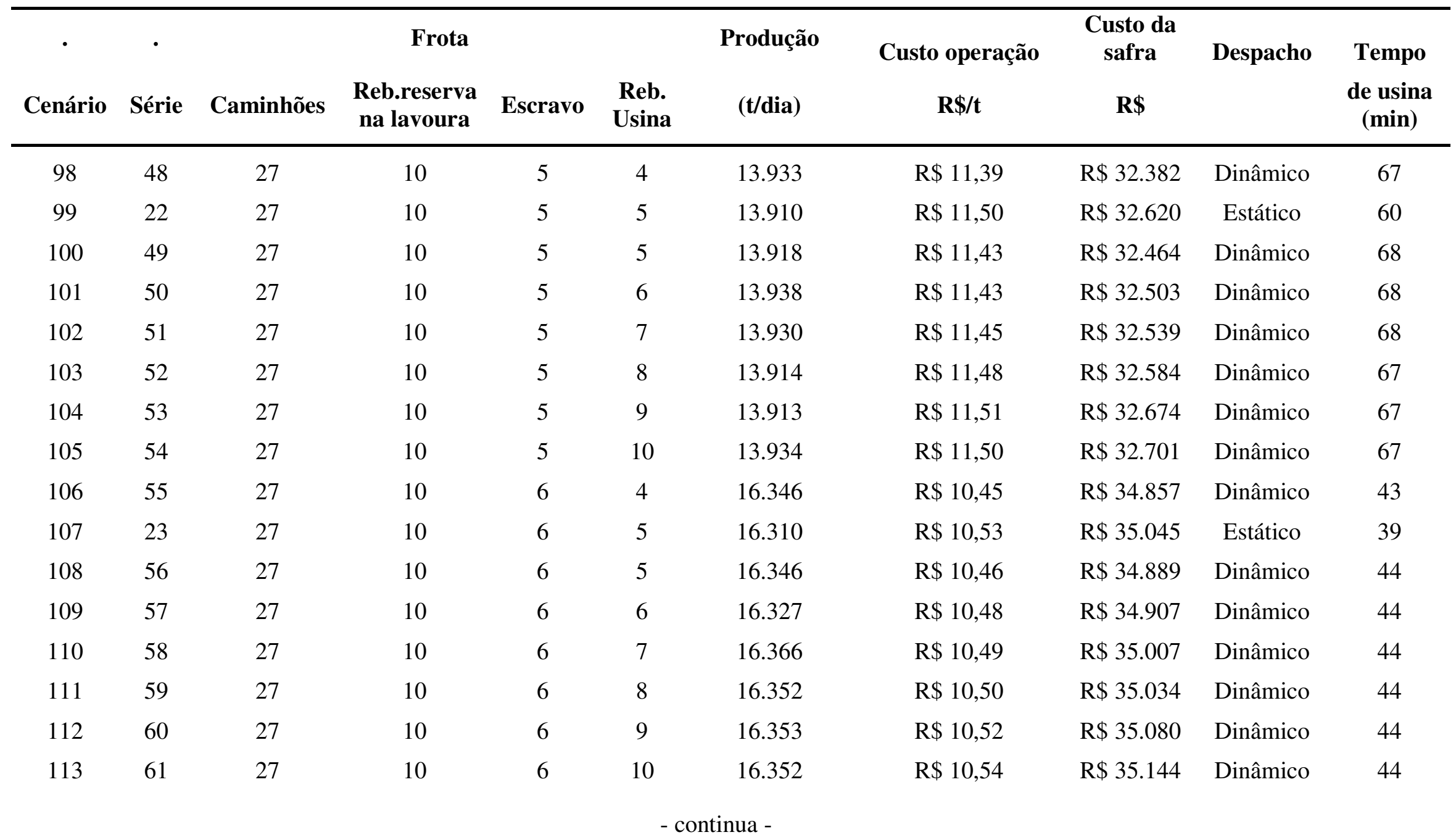


- continuação -

\begin{tabular}{|c|c|c|c|c|c|c|c|c|c|c|}
\hline Cenário & Série & Caminhões & $\begin{array}{c}\text { Frota } \\
\text { Reb.reserva } \\
\text { na lavoura }\end{array}$ & Escravo & $\begin{array}{c}\text { Reb. } \\
\text { Usina }\end{array}$ & $\begin{array}{c}\text { Produção } \\
\text { (t/dia) }\end{array}$ & $\begin{array}{c}\text { Custo operação } \\
\mathbf{R} \$ / \mathbf{t}\end{array}$ & $\begin{array}{c}\text { Custo da } \\
\text { safra } \\
\text { R\$ }\end{array}$ & Despacho & $\begin{array}{c}\text { Tempo } \\
\text { de usina } \\
\text { (min) }\end{array}$ \\
\hline 114 & 62 & 27 & 10 & 7 & 4 & 18.431 & $\mathrm{R} \$ 9,86$ & $\mathrm{R} \$ 37.090$ & Dinâmico & 28 \\
\hline 115 & 24 & 27 & 10 & 7 & 5 & 18.429 & $\mathrm{R} \$ 9,92$ & $\mathrm{R} \$ 37.302$ & Estático & 23 \\
\hline 118 & 65 & 27 & 10 & 7 & 7 & 18.503 & $\mathrm{R} \$ 9,87$ & $\mathrm{R} \$ 37.242$ & Dinâmico & 28 \\
\hline 119 & 66 & 27 & 10 & 7 & 8 & 18.527 & $\mathrm{R} \$ 9,89$ & $\mathrm{R} \$ 37.366$ & Dinâmico & 28 \\
\hline 120 & 67 & 27 & 10 & 7 & 9 & 18.519 & $\mathrm{R} \$ 9,89$ & $\mathrm{R} \$ 37.352$ & Dinâmico & 28 \\
\hline 121 & 68 & 27 & 10 & 7 & 10 & 18.506 & $\mathrm{R} \$ 9,92$ & $\mathrm{R} \$ 37.438$ & Dinâmico & 27 \\
\hline 125 & 28 & 27 & 10 & 8 & 5 & 19.550 & $\mathrm{R} \$ 9,61$ & $\mathrm{R} \$ 38.320$ & Dinâmico & 21 \\
\hline 126 & 30 & 27 & 10 & 8 & 5 & 19.550 & $\mathrm{R} \$ 9,61$ & $\mathrm{R} \$ 38.320$ & Dinâmico & 21 \\
\hline 127 & 70 & 27 & 10 & 8 & 5 & 19.550 & $\mathrm{R} \$ 9,61$ & $\mathrm{R} \$ 38.320$ & Dinâmico & 21 \\
\hline 128 & 31 & 27 & 10 & 8 & 6 & 19.545 & $\mathrm{R} \$ 9,64$ & $\mathrm{R} \$ 38.454$ & Dinâmico & 21 \\
\hline 129 & 71 & 27 & 10 & 8 & 6 & 19.545 & $\mathrm{R} \$ 9,64$ & $\mathrm{R} \$ 38.454$ & Dinâmico & 21 \\
\hline 130 & 32 & 27 & 10 & 8 & 7 & 19.546 & $\mathrm{R} \$ 9,63$ & $\mathrm{R} \$ 38.418$ & Dinâmico & 21 \\
\hline
\end{tabular}


- continuação -

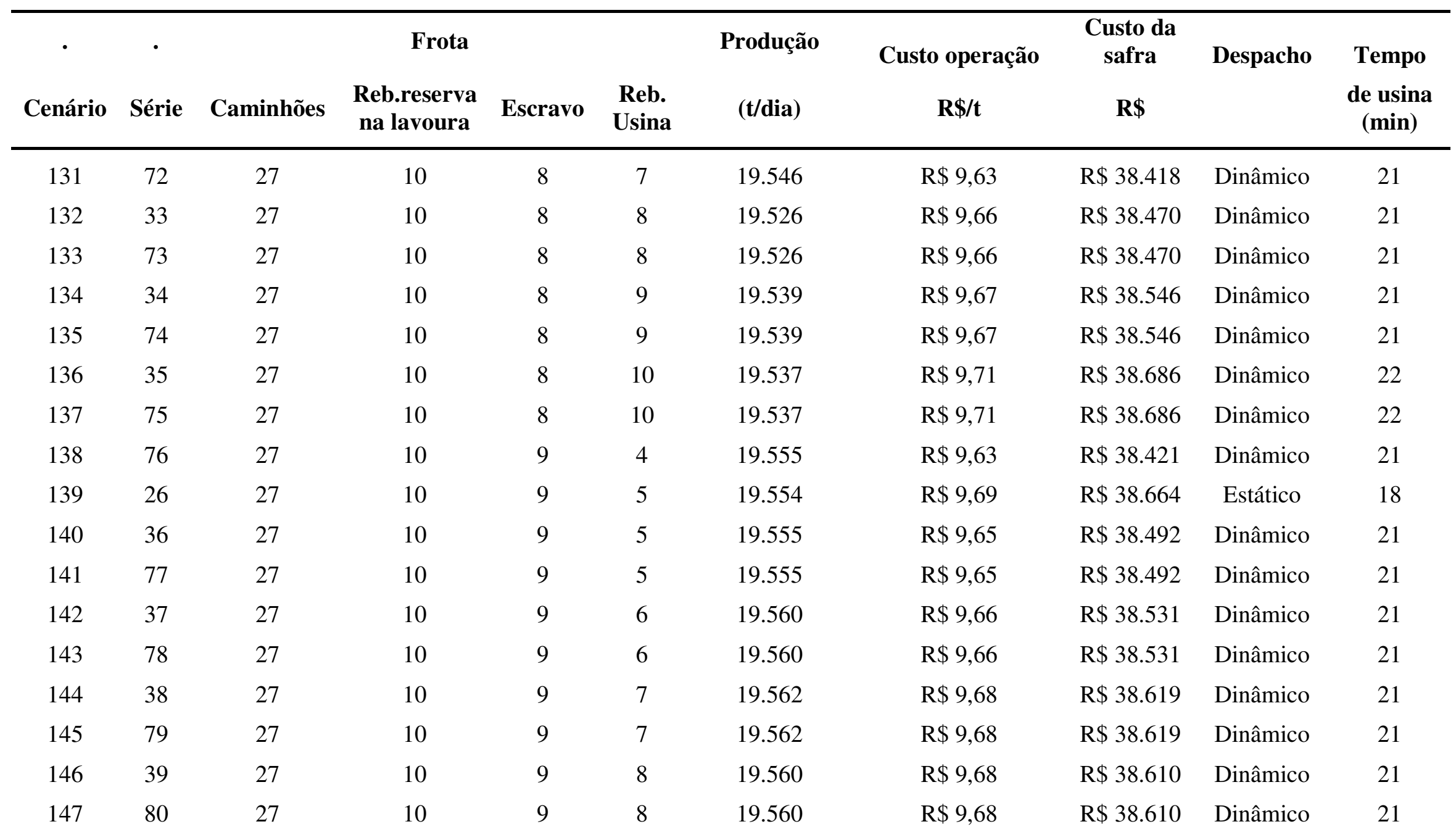


- continuação -

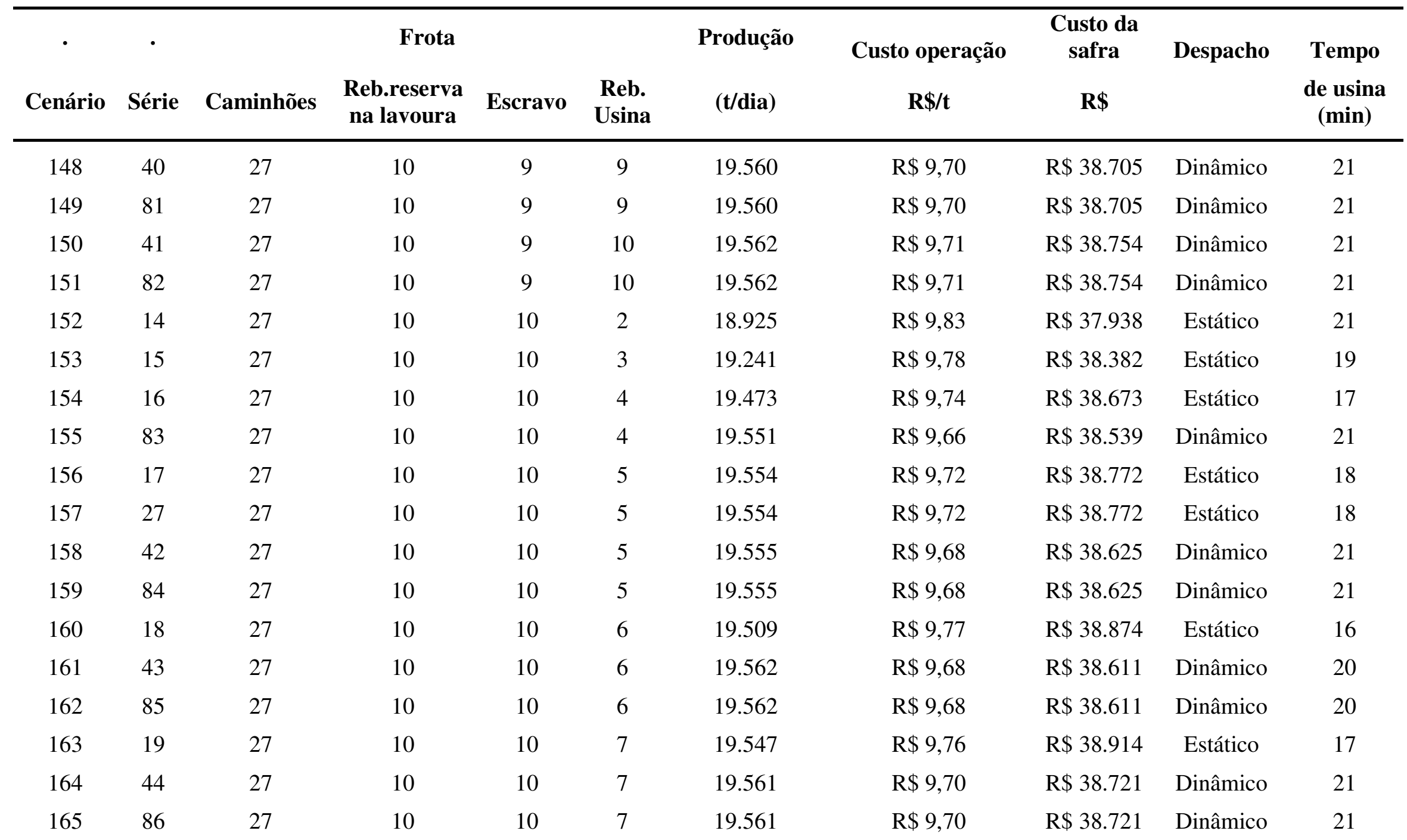


- continuação -

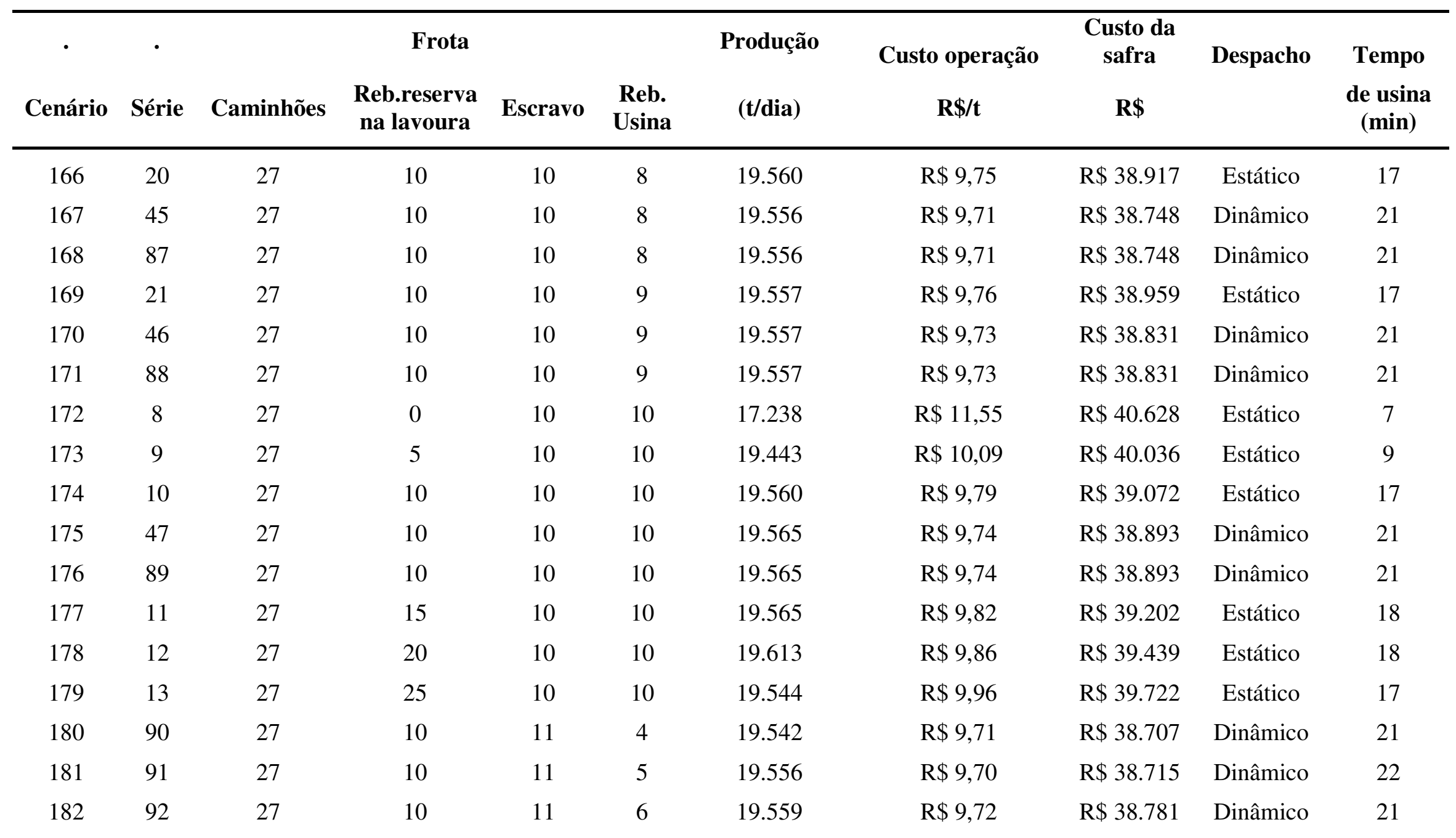


- continuação -

\begin{tabular}{|c|c|c|c|c|c|c|c|c|c|c|}
\hline Cenário & Série & Caminhões & $\begin{array}{c}\text { Reb.reserva } \\
\text { na lavoura }\end{array}$ & Escravo & $\begin{array}{l}\text { Reb. } \\
\text { Usina }\end{array}$ & $\begin{array}{c}\text { Produção } \\
\text { (t/dia) }\end{array}$ & $\begin{array}{c}\text { Custo operação } \\
\mathbf{R} \$ / \mathbf{t}\end{array}$ & $\begin{array}{c}\text { Custo da } \\
\text { safra } \\
\text { R\$ }\end{array}$ & Despacho & $\begin{array}{c}\text { Tempo } \\
\text { de usina } \\
\text { (min) }\end{array}$ \\
\hline 183 & 93 & 27 & 10 & 11 & 7 & 19.559 & $\mathrm{R} \$ 9,73$ & $\mathrm{R} \$ 38.803$ & Dinâmico & 20 \\
\hline 184 & 94 & 27 & 10 & 11 & 8 & 19.563 & $\mathrm{R} \$ 9,76$ & $\mathrm{R} \$ 38.935$ & Dinâmico & 20 \\
\hline 187 & 97 & 27 & 10 & 12 & 4 & 19.545 & $\mathrm{R} \$ 9,73$ & $\mathrm{R} \$ 38.806$ & Dinâmico & 21 \\
\hline 188 & 98 & 27 & 10 & 12 & 5 & 19.550 & $\mathrm{R} \$ 9,75$ & $\mathrm{R} \$ 38.891$ & Dinâmico & 21 \\
\hline 189 & 99 & 27 & 10 & 12 & 6 & 19.557 & $\mathrm{R} \$ 9,77$ & $\mathrm{R} \$ 38.974$ & Dinâmico & 21 \\
\hline 190 & 100 & 27 & 10 & 12 & 7 & 19.566 & $\mathrm{R} \$ 9,76$ & $\mathrm{R} \$ 38.940$ & Dinâmico & 21 \\
\hline
\end{tabular}




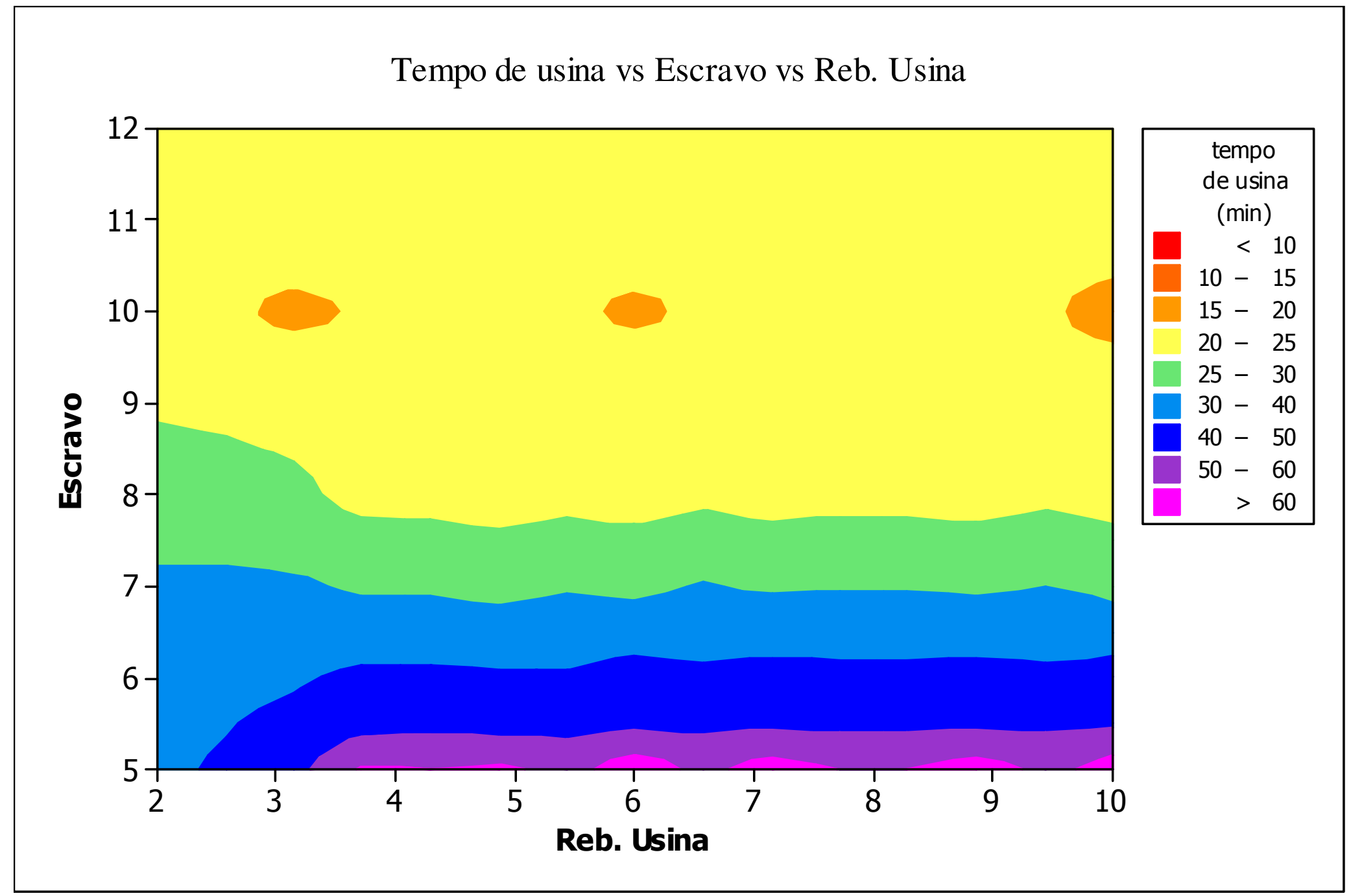

Gráfico 10 - Tempo de usina vs Escravo vs Reb. Usina 


\section{Ca pít u lo}

\section{CONCLUSÕES}

A dissertação atingiu o objetivo de desenvolver uma ferramenta computacional, baseada em simulação estocástica, que fosse capaz de representar a despacho de caminhões para o transporte de cana-de-açúcar, tanto pelo método dinâmico como pelo método estático e que permitisse, também, avaliar a adoção de sistema de drop and hook das composições na usina.

O modelo permitiu ainda avaliar como a produção e seu custo operacional são afetados pelo tamanho da frota de caminhões e de semi-reboques.

As respostas à adoção de reboques reserva, e de despacho dinâmico não seriam possíveis de serem obtidas por métodos determinísticos, uma vez que por este método de quantificação não é possível saber, a priori, como estas duas variáveis afetam o desempenho da frota, ou, como se comportam os tempos de permanência no campo e na usina.

Verificou-se que, para uma usina com as condições e custos operacionais como as consideradas neste trabalho, a opção de menor custo para o CCT é aquela em que se adota o despacho dinâmico, com descarregamento direto das composições rodoviárias, ou seja, sem adoção de drop and hook. 


\subsection{RECOMENDAÇÕES}

Recomenda-se a adoção da simulação para análises de sistemas em que estejam presentes interações entre processos, entre recursos, e entre estes dois componentes simultaneamente.

A simulação é indicada como ferramenta de apoio à tomada de decisão, principalmente em planejamentos estratégicos e para a análise de sistemas, especialmente aqueles ainda não implementados.

Como o custo de um estudo de simulação é relativamente alto, pois requer a presença de especialistas e um longo tempo de desenvolvimento, desde a decisão pela análise do problema até a obtenção dos resultados finais, recomenda-se que durante a fase de definição dos sistema seja dada atenção ao uso futuro do modelo, de forma a prolongar a sua vida útil, diluindo assim o investimento.

Por outro lado, como lembra SILVA (2006), é importante que se mantenha o foco no propósito do estudo, sob pena de se desviar do objetivo inicial traçado.

Este trabalho só foi possível de ser realizado, em grande parte, em função da experiência do autor com as atividades de CCT, bem como com o desenvolvimento de sistemas computacionais, em especial um sistema para despacho de caminhões. Ainda assim foi necessário, e recomenda-se, que haja uma forte participação de técnicos que vivenciam o dia-a-dia do sistema em análise. 


\section{T.2 SUGESTÕES PARA TRABALHOS FUTUROS}

Neste trabalho avaliou-se a política de despacho de caminhões e a adoção de sistema drop and hook, considerando-se somente um tipo de sistema de colheita - cana picada.

Com base no modelo desenvolvido, outros estudos podem ser conduzidos, como por exemplo a avaliação de outros tipos de composição, frentes de corte de cana inteira interagindo com frentes de corte de cana picada, análise do impacto da variação das características agronômicas da cana-de-açúcar ao longo da safra (variação dos teores de açúcar e fibra), entre outros fatores.

No campo da avaliação econômica, outras abordagens podem também ser avaliadas, como a terceirização da frota, quando parte dos custos são suportados pela usina e parte por empresas prestadoras de serviços.

Ainda no âmbito da avaliação econômica pode-se avaliar o custo da falta de cana, buscando não a minimização do custo, mas a maximização do lucro. 


\section{REFERÊNCIAS BIBLIOGRÁFICAS}

ARCE, J.E, CARNIEIRI, C., MENDES, J.B Un sistema de programación del transporte forestal principal objetivando la minimización de costos. Investigación Operativa, Brasil, v. 8 , n. 1,2 y 3 , p. 51-61, 1999.

CAIXETA FILHO, JOSÉ VICENTE. Estrutura de modelagem para programação de colheita de laranja. São Paulo, 1993. (Tese de Doutorado) - Escola Politécnica, Universidade de São Paulo.

CASE IH, folheto promocional de produtos, 2008.

CHWIF, L.; MEDINA, A. C. Modelagem e simulação de eventos discretos: Teoria e Aplicações. 1. ed. São Paulo: Bravarte, 2006. v. 1. 255 p.

COCHRAN, B.J. \& WHITNEY, R.W. A technique for designing transport systems for sugarcane. In: International Society of Sugar Cane Technologists Congress, 16. São Paulo, 1977. Anais. São Paulo, ISSCT, 1977. p. 2069-79.

FREITAS FILHO, P. J. Introdução à modelagem e simulação de sistemas com aplicações em Arena, Visual Books, 2001.

GAUCHER, S., LE GAL, P. Y. , SOLER, G. Modelling supply chain management in the sugar industry, in Annual Congress - South African Sugar Technologists' Association, 2003 (No. 77) 542-554.

GUALDA, N.D. F. Terminais de transporte: contribuição ao Planejamento e ao Dimensionamento Operacional. Tese apresentada para a Escola Politécnica da USP para o Concurso de Livre Docência. São Paulo, 1995

HAHN, M. H. SISTEC: Simulador de sistema de transporte da cana-de-açúcar. Dissertação (Mestrado em Eng. Elétrica) - Faculdade de Engenharia Elétrica e Computação, Universidade Estadual de Campinas, Campinas, 1994.

IANNONI, A. P. Análise do sistema logístico de descarga de cana-de-açúcar: Um Estudo de Caso em uma Grande Usina na Região de Ribeirão Preto. Dissertação (Mestrado em Eng. Produção) - Departamento de Eng. de Produção, Universidade Federal de São Carlos, São Carlos, 2000.

KELTON, W.D.; SADOWSKI, R. P.; SADOWSKY, D. A. Simulation with Arena. Mc Graw-Hill, New York, 1998.

LOPES M. B. Simulação de um sistema de carregamento e transporte de cana-deaçúcar. Dissertação (Mestrado em Eng. Agrícola) - Escola Superior de Agricultura "Luiz de Queiroz", Universidade de São Paulo, Piracicaba, 1995.

PEGDEN, C. D., SHANNON, R. E., SADOWSKI, R. P.: Introduction to simulation using SIMAN. 2.ed. McGraw-Hill, New York, 1995. 
RAICU, R. ,TAYLOR, M. A. P. Computerised decision support system for the operational management of transportation of sugar cane. In Taylor, M A P (ed). Transportation and Traffic Theory in the 21st Century. (Elsevier-Pergamon: Oxford), pp.197$218,2002$.

SADOWSKY, D. A.; GRABAU, M. R. Tips for successful practice of simulation. Proceedings of the 1999 Winter Simulation Conference, 1999.

SALIBY, E. Repensando a simulação: a amostragem descritiva. São Paulo; 1989, Editora da UFRJ.

SEIXAS, F. \& WIDMER, J.A. Seleção e dimensionamento da frota de veículos rodoviários para o transporte principal de madeira utilizando-se programação linear não inteira, $I P E F$, n. 46, p. 107-118, 1993.

SILVA, J. E. A. R. Desenvolvimento de um modelo de simulação para auxiliar o gerenciamento de sistemas de corte, carregamento e transporte de cana-de-açúcar. São Paulo. Dissertação (Mestrado), Universidade Federal de São Carlos, 2006.

SLACK, N. et alli Administração da produção. Editora Atlas. São Paulo, 1997.

TRACAN <http://www.tracan.com.br/produtos.htm> visitado em 08/02/2009

ÚNICA <http://www.unica.com.br/userFiles/estatisticas/produção\%20Brasil\%203.xls> visitado em 03/02/2008.

WIDMER, J.A. A influência de técnicas de despacho e processamento de caminhões na formação de filas no transporte agrícola, VI Congresso Panamericano de Ingeneria de Tránsito e Transporte, p. 107 - 119, 1990.

YOSHIZAKI, H. T. Y. Análise de Desempenho Operacional de Sistemas Logísticos e de Transportes: Aplicações de Redes de Filas. São Paulo. Dissertação (Mestrado em Eng. Produção) - Escola Politécnica, Universidade de São Paulo, 1989. 


\section{APÊNDICES}

APÊNDICE A - Distribuições estatísticas dos tempos de manutenção dos caminhões

\begin{tabular}{|c|c|c|c|c|c|}
\hline Evento & $\begin{array}{c}\text { Tamanho } \\
\text { da } \\
\text { amostra }\end{array}$ & Mínimo & Média & Máximo & Ajuste \\
\hline Abastecimento - intervalo & - & - & 450 & - & - \\
\hline $\begin{array}{c}\text { Abastecimento - } \\
\text { duração }\end{array}$ & 262 & 9.1 & 14.8 & 22.7 & $9+14$ * BETA(0.976, 1.33) \\
\hline Borracharia - intervalo & 452 & 18 & 5430 & 43200 & $18+$ WEIB(4.82e+003, \\
\hline Borracharia - duração & 516 & 8 & 165 & 176 & $8+$ WEIB(141, 1.09) \\
\hline Eétrica - intervalo & 777 & 10 & 3570 & 59500 & $10+$ EXPO(3.56e+003) \\
\hline Elétrica - duração & 805 & 3 & 95 & 490 & $3+$ LOGN(100, 163) \\
\hline Funilaria - intervalo & 509 & 28 & 4630 & 40900 & $28+$ WEIB(4e+003, 0.92) \\
\hline Funilaria - duração & 560 & 9 & 143 & 999 & $9+$ LOGN(165, 365) \\
\hline Geral - intervalo & 623 & 131 & 4490 & 18900 & $100+$ GAMM(3.13e+003, \\
\hline Geral - duração & 696 & 6 & 257 & 1880 & $6+$ EXPO(251) \\
\hline Motor - intervalo & 617 & 11 & 4450 & 53400 & $11+$ EXPO(4.44e+003) \\
\hline Motor - duração & 687 & 5 & 192 & 1760 & $5+$ LOGN(235, 633) \\
\hline
\end{tabular}


APÊNDICE B - Distribuições estatísticas dos tempos de manutenção dos tratores de transbordo

\begin{tabular}{|c|c|c|c|c|c|}
\hline Evento & $\begin{array}{l}\text { Tamanho } \\
\text { da } \\
\text { amostra }\end{array}$ & Mínimo & Média & Máximo & Ajuste \\
\hline Abastecimento - intervalo & 115 & 120 & 360 & 1440 & $\begin{array}{c}120+1.2 \mathrm{e}+003^{*} \operatorname{beta}(0.713 \\
2.89)\end{array}$ \\
\hline Abastecimento - duração & 165 & 5 & 13 & 50 & $4+\operatorname{expo}(9.09)$ \\
\hline Manut. Lavoura - intervalo & 87 & - & 1656 & - & $\begin{array}{c}\text { Disc(0.17,200,0.37,500,0.69,1 } \\
200,0.86,2000,1.00,5700)\end{array}$ \\
\hline Manut. Lavoura - duração & 87 & 300 & 801 & 2850 & $300+$ weib $(480,0.908)$ \\
\hline Rep. Mecânico - intervalo & 208 & - & 705 & - & $\begin{array}{c}\operatorname{Disc}(0.12,50,0.28,180,0.50,45 \\
0,0.66,650,0.81,900,0.93,150 \\
0,1.00,2174)\end{array}$ \\
\hline Rep. Mecânico - duração & 197 & 11 & 118 & 300 & $11+\operatorname{gamm}(76.3,1.4)$ \\
\hline
\end{tabular}


APÊNDICE C - Distribuições Estatísticas dos tempos operacionais na usina

\begin{tabular}{|l|c|c|c|c|c|}
\hline \multicolumn{1}{|c|}{ EVENTO } & $\begin{array}{c}\text { Tamanho } \\
\text { da } \\
\text { amostra }\end{array}$ & Mínimo & Médio & Máximo & Ajuste \\
\hline Pesagem vazio & 92 & 0,725 & 1,5 & 2,3 & $0.7+1.6 * \operatorname{Beta}(1.94,1.93)$ \\
\hline Pesagem carregado & 82 & 0,725 & 1,5 & 2,3 & $0.7+1.6 * \operatorname{Beta}(1.94,1.93)$ \\
\hline Deslocamento p/ sonda & 96 & 0,668 & 1,77 & 2,78 & $0.45+2.55 * \operatorname{Beta}(9.07,8.43)$ \\
\hline $\begin{array}{l}\text { Sonda-tempo de 1 amostragem* } \\
(30 \%)\end{array}$ & 92 & 0,5 & 0,901 & 1,48 & Norm $(0.901,0.17)$ \\
\hline Deslocamento sonda-descarga & 88 & 2,11 & 3,86 & 4,59 & $2.1+2.5 * \operatorname{Beta}(4.05,1.68)$ \\
\hline Deslocamento pesagem-descarga & 75 & 3,35 & 4,99 & 6,09 & Norm(4.99,0.485) \\
\hline Descarga & 94 & 4,1 & 4,7 & 5,71 & Norm(4.7,0.309) \\
\hline Deslocamento descarga-balança & 91 & 1,3 & 1,9 & 2,54 & Norm $(1.9,0.205)$ \\
\hline
\end{tabular}

- $\quad$ Multiplicar pelo número de amostragens realizadas. 
APÊNDICE D - Distribuições Estatísticas dos tempos de manutenção das colhedoras

\begin{tabular}{|c|c|c|c|c|c|}
\hline EVENTO & $\begin{array}{c}\text { Tamanho } \\
\text { da } \\
\text { amostra }\end{array}$ & Mínimo & Média & Máximo & Ajuste \\
\hline \multirow[t]{2}{*}{ ABASTECIMENTO E LUBRIFICAÇÃO } & 3142 & 10 & 23 & 96 & $10+\mathrm{WEIB}(8.89,0.582)$ \\
\hline & 3279 & 120 & 463 & 899 & $120+780 * \operatorname{BETA}(1.15,1.46)$ \\
\hline \multirow[t]{2}{*}{ REPARO ELÉTRICO NA MÁQUINA } & 94 & 10 & 25 & 50 & $10+\mathrm{EXPO}(15)$ \\
\hline & 68 & 110 & 3100 & 7800 & $109+7.89 \mathrm{E}+003 * \operatorname{BETA}(0.507,0.816)$ \\
\hline \multirow[t]{2}{*}{ LAVAGEM MÁQUINA/IMPLEMENTO } & 202 & 15 & 42 & 100 & $15+\mathrm{EXPO}(27.7)$ \\
\hline & 176 & 1240 & 11500 & 40100 & $1.25 \mathrm{E}+003+\mathrm{WEIB}(6.65 \mathrm{E}+003,0.484)$ \\
\hline \multirow{2}{*}{$\begin{array}{l}\text { REPARO MECÂNICO MÁQUINA } \\
\text { CAMPO }\end{array}$} & 285 & 5 & 104 & 650 & 4+LOGN(105,145) \\
\hline & 287 & 15 & 628 & 3550 & $15+3.53 \mathrm{E}+003 * \operatorname{BETA}(0.782,3.73)$ \\
\hline
\end{tabular}




\section{APÊNDICE G - Código fonte em linguagem SIMAN, da rotina de despacho de caminhões, gerado pelo software Arena}

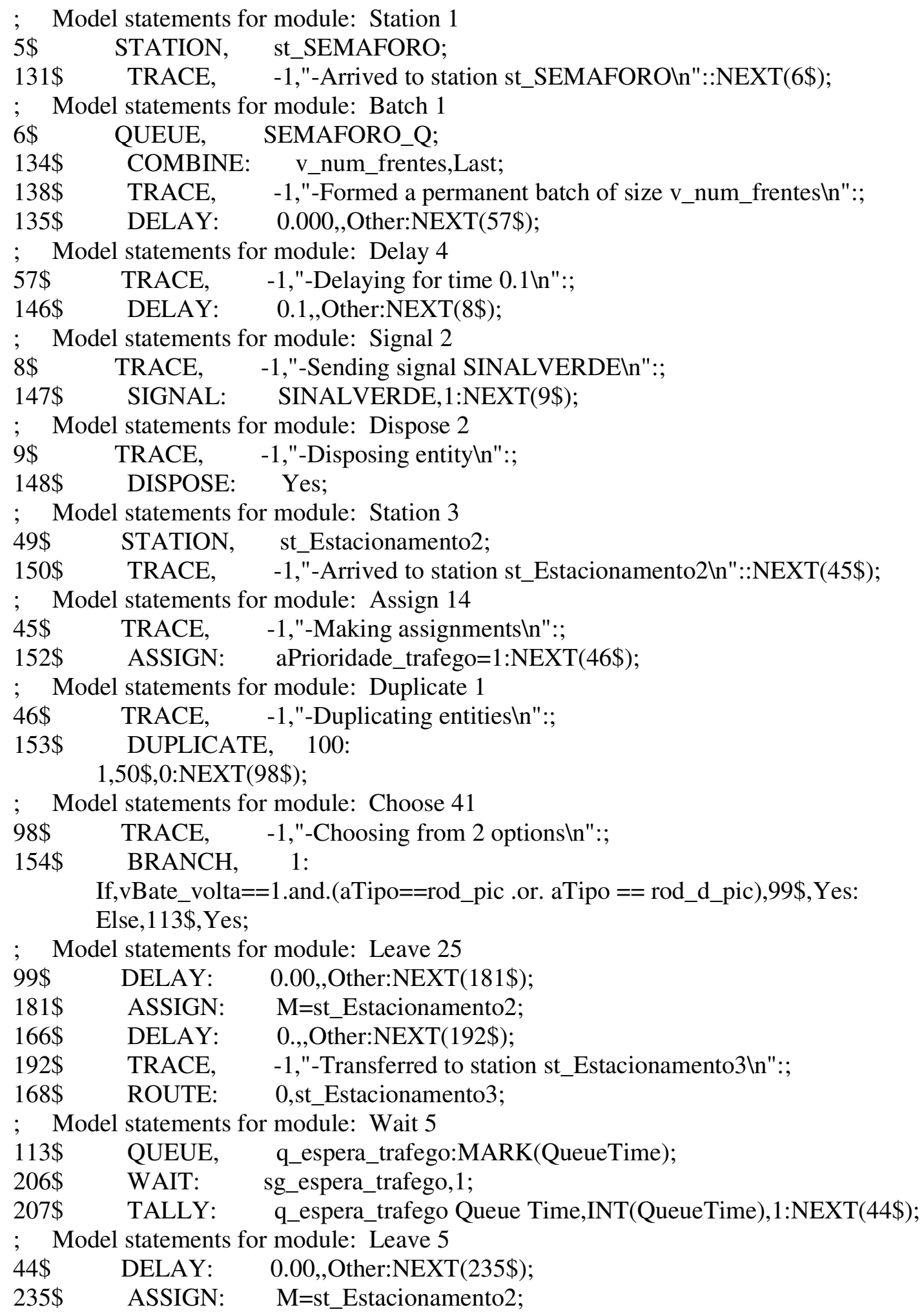


$220 \$$ DELAY: $\quad 0 .$, Other:NEXT(246\$);

246\$ TRACE, -1,"-Transferred to station st_trafego3 $\backslash n "$ :;

222\$ ROUTE: 0.2 ,st_trafego3;

; Model statements for module: Signal 5

50\$ TRACE, $\quad-1$, ,-Sending signal DECISAOTOMADAln":;

260\$ SIGNAL: DECISAOTOMADA:NEXT(51\$);

; Model statements for module: Delay 3

51\$ TRACE, $\quad-1$, "-Delaying for time $0.5 \backslash n ": ;$

261\$ DELAY: $\quad 0.5$, ,Other:NEXT(47\$);

; Model statements for module: Release 3

47\$ TRACE, -1,"-Releasing resources $\backslash n "$ :;

$262 \$$ RELEASE: r_CONTROLEDETRAFEGO,1:NEXT(48\$);

; Model statements for module: Dispose 3

$48 \$ \quad$ TRACE, $\quad-1$, ,-Disposing entityln":;

263\$ DISPOSE: Yes;

; Model statements for module: Station 4

$58 \$$ STATION, st_inicio_trafego:MARK(achega_na_usina_s);

$265 \$ \quad$ TRACE, -1,"-Arrived to station st_inicio_trafegoln"::NEXT(13\$);

; Model statements for module: Station 2

$13 \$$ STATION, st_Trafego:MARK(ch_controle);

$268 \$ \quad$ TRACE, $\quad-1$, "-Arrived to station st_Trafegoln"::NEXT(119\$);

; Model statements for module: Assign 49

$119 \$ \quad$ TRACE, $\quad$-1,"-Making assignments $\backslash n ": ;$

$270 \$$ ASSIGN: aEstacao $=\mathrm{m}$ :

$\mathrm{aDESTINO}=22$ :NEXT $(111 \$)$;

; Model statements for module: Choose 46

$111 \$ \quad$ TRACE, $\quad-1$, ,-Choosing from 2 options $\backslash n " ;$

271\$ BRANCH, 1:

If,nq(q_espera_trafego) $>=1,118 \$$,Yes:

Else, $110 \$$, Yes;

; Model statements for module: Assign 48

$118 \$ \quad$ TRACE, $\quad-1$, ,-Making assignments $\backslash n ": ;$

$272 \$$ ASSIGN: aEstacao $=\mathrm{m}$ :

aDESTINO=22:NEXT $(126 \$)$;

; Model statements for module: Signal 18

$126 \$$ TRACE, -1,"-Sending signal sg_espera_trafegoln":;

$273 \$$ SIGNAL: sg_espera_trafego,1:NEXT(112\$);

; Model statements for module: Leave 26

$112 \$$ DELAY: 0.00, ,Other:NEXT(300\$);

300\$ ASSIGN: M=st_Trafego;

285\$ DELAY: 0.,,Other:NEXT(311\$);

311\$ TRACE, $\quad-1$, ,-Transferred to station st_Estacionamento4 $\backslash n " ;$

287\$ ROUTE: 0,st_Estacionamento4;

; Model statements for module: Station 8

$110 \$$ STATION, st_trafego2;

$326 \$$ TRACE, $\quad-1$, --Arrived to station st_trafego2 $\backslash n ":: N E X T(43 \$)$;

; Model statements for module: Choose 14

$43 \$ \quad$ TRACE, $\quad-1$, "-Choosing from 4 options $\backslash n " ;$

$328 \$$ BRANCH, 1 :

If,aFrente $==0,56 \$$, Yes: 
If, $v$ Controle_trafego $==0,52 \$$, Yes:

If,nr(r_CONTROLEDETRAFEGO) $>=1$.or. ne(st_trafego3) $>=1,121 \$$, Yes:

Else, $12 \$, Y e s ;$

; Model statements for module: Assign 22

$56 \$ \quad$ TRACE, $\quad-1, "-M a k i n g$ assignments $\backslash n ": ;$

329 ASSIGN: vErroVetor=800:NEXT(59\$);

; Model statements for module: Dispose 4

59\$ TRACE, -1,"-Disposing entity $\backslash n "$ :;

330\$ DISPOSE: Yes;

; Model statements for module: Leave 12

52\$ DELAY: 0.00, ,Other:NEXT(357\$);

$357 \$$ ASSIGN: M=st_trafego2;

$342 \$$ DELAY: 0.,,Other:NEXT(368\$);

$368 \$$ TRACE, $\quad-1$, ,-Transferred to station st_SEGUE_USINAIn":;

344\$ ROUTE: 0,st_SEGUE_USINA;

; Model statements for module: Leave 27

$121 \$$ DELAY: 0.00, ,Other:NEXT(408\$);

408\$ ASSIGN: M=st_Trafego;

393\$ DELAY: 0.,Other:NEXT(419\$);

419\$ TRACE, -1,"-Transferred to station st_Estacionamento4\n":;

395\$ ROUTE: 0,st_Estacionamento4;

; Model statements for module: Assign 4

$12 \$$ TRACE, $\quad-1$, ,-Making assignments $\backslash n " ; ;$

433\$ ASSIGN: aHaDestino $=0$ :

aPrioridade_trafego $=0$ :

aRetorna_trafego $=0$ :

aJa_passou_ordena $=0$ :

aFrente $=20$ :

aDESTINO=0:NEXT $(2 \$)$;

; Model statements for module: Seize 1

$2 \$$ QUEUE, q_TRAFEGO:MARK(QueueTime);

434\$ SEIZE, ,Other:

r_CONTROLEDETRAFEGO,1:NEXT(439\$);

439\$ ASSIGN: $\mathrm{j}=\mathrm{j}$;

435\$ TALLY: q_TRAFEGO Queue Time,INT(QueueTime), 1:NEXT(122\$);

; Model statements for module: Choose 48

$122 \$$ TRACE, $\quad-1$, ,-Choosing from 2 options $\backslash n ": ;$

$440 \$$ BRANCH, 1:

If,vBate_volta==1.and.(aTipo==rod_pic .or. aTipo $==$ rod_d_pic),123\$,Yes:

Else, $0 \$$, Yes;

; Model statements for module: Choose 49

$123 \$ \quad$ TRACE, $\quad$-1,"-Choosing from 3 options $\backslash n " ; ;$

$441 \$$ BRANCH, 1 :

If,nq(q_cj_vz_u) $>=1,0 \$, Y e s:$

If,nq(q_semi_vz_u) $>=1$.and.nq(q_reb_vz_u $)>=1,0 \$, Y e s:$

Else, $124 \$, Y e s ;$

; Model statements for module: Signal 1

0\$ TRACE, $\quad-1$, ,-Sending signal saidadecaminhaoln":;

442\$ SIGNAL: saidadecaminhao:NEXT(10\$);

; Model statements for module: Wait 1 
$\begin{array}{lcc}10 \$ & \text { QUEUE, } & \text { q_SINALVERDE; } \\ 443 \$ & \text { WAIT: } & \text { SINALVERDE, } 1 ; \\ 445 \$ & \text { DELAY: } & \text { 0.000,,Other:NEXT }(4 \$) ; \\ 4 \$ & \text { FINDJ, } & \text { 1,v_num_frentes:MAX }(v \operatorname{vazao}(J, 1)): \operatorname{NEXT}(1 \$) ;\end{array}$

; Model statements for module: Assign 3

$1 \$ \quad$ TRACE, -1,"-Making assignments $\backslash n " ;$

446\$ ASSIGN: aJa_passou_ordena=0:

aDESTINO=J+6:

aVazaodestino $=\mathrm{vCc}(\mathrm{aDESTINO}, 22)$ :

aPrioridade_trafego $=1$ :

aPassada $=1$ :

aDESTINADO $=0$ :

vTemp5=aDestino:NEXT(89\$);

; Model statements for module: Choose 40

$89 \$ \quad$ TRACE, $\quad-1$, ,-Choosing from 2 options $\backslash n "$;

$447 \$$ BRANCH, 1:

If,vBate_volta $==1$.and.(aTipo==rod_pic. or. aTipo $==$ rod_d_pic),lbRodotrem,Yes:

Else, $14 \$$, Yes;

; $\quad$ Model statements for module: Choose 33

lbRodotrem TRACE, -1,"-Choosing from 2 options $\backslash n "$ :;

448\$ BRANCH, 1:

If,aVazaodestino $>=1,75 \$$,Yes:

Else, $100 \$$, Yes;

; Model statements for module: Assign 44

$75 \$ \quad$ TRACE, $\quad-1, "-M a k i n g$ assignments $\backslash n " ;$

449\$ ASSIGN: aHaDestino=1:NEXT(60\$);

; Model statements for module: Choose 34

$60 \$ \quad$ TRACE, $\quad-1$, "-Choosing from 3 options $\backslash n "$ :;

$450 \$$ BRANCH, 1:

If, $\mathrm{vPrioriza}(\mathrm{aDestino}, 7)==1$. and $. \mathrm{aRestricao}==0,76 \$$,Yes:

If,vPrioriza (aDestino,7)==1,67\$,Yes:

Else, 70\$,Yes;

; Model statements for module: Choose 38

$76 \$ \quad$ TRACE, $\quad-1$, ,-Choosing from 3 options $\backslash n "$;;

$451 \$ \quad$ BRANCH, 1 :

If,nq(q_cj_vz_u) $>=1,80 \$$,Yes:

If,nq(q_semi_vz_u) $>=1$.and. nq(q_reb_vz_u $)>=1,79 \$$,Yes:

Else, $94 \$$, Yes;

$80 \$ \quad$ REMOVE: 1,q_cj_vz_u,Match_cj L2:NEXT(108\$);

; Model statements for module: Choose 45

$108 \$ \quad$ TRACE, -1,"-Choosing from 2 options $\backslash n "$ :;

$452 \$ \quad$ BRANCH, 1:

If, $\mathrm{vCc}(7,22)>=1$.or.vCc $(8,22)>=1$.or.vCc $(9,22)>=1$.or.vCc $(10,22)>=1,109 \$$, Yes:

Else, 64\$,Yes;

; Model statements for module: Signal 16

$109 \$ \quad$ TRACE, -1,"-Sending signal sg_espera_trafegoln":;

453\$ SIGNAL: sg_espera_trafego,1:NEXT(64\$);

; $\quad$ Model statements for module: Signal 11

$64 \$ \quad$ TRACE, $\quad-1, "-S e n d i n g$ signal DECISAOTOMADAln":;

454\$ SIGNAL: DECISAOTOMADA:NEXT(66\$); 
; $\quad$ Model statements for module: Delay 9

$66 \$ \quad$ TRACE, $\quad-1$, "-Delaying for time $0.1 \backslash \mathrm{n} "$ :;

455\$ DELAY: 0.1,,Other:NEXT(63\$);

; Model statements for module: Release 7

$63 \$ \quad$ TRACE, $\quad-1$, ,-Releasing resources $\backslash n ": ;$

456\$ RELEASE: r_CONTROLEDETRAFEGO,1:NEXT(65\$);

; Model statements for module: Leave 18

65\$ DELAY: 0.00, ,Other:NEXT(483\$);

483\$ ASSIGN: M=st_trafego2;

468\$ DELAY: 0.,,Other:NEXT(494\$);

494\$ TRACE, -1,"-Transferred to station st_SEGUE_cavaloln":;

$470 \$$ ROUTE: 0,st_SEGUE_cavalo;

$79 \$ \quad$ REMOVE: 1,q_semi_vz_u,78\$;

81\$ REMOVE: 1,q_reb_vz_u,78\$:NEXT(108\$);

; Model statements for module: Batch 3

$78 \$ \quad$ TRACE, $\quad-1$, ,-Waiting for batch size of $2 \backslash \mathrm{ln} "$;

509\$ COMBINE: 2,Last;

513\$ TRACE, $\quad-1$, ,-Formed a permanent batch of size $2 \backslash n " ;$

510\$ DELAY: 0.000, ,Other:NEXT(Match_cj L2);

; Model statements for module: Leave 23

94\$ DELAY: 0.00, ,Other:NEXT(547\$);

547\$ ASSIGN: M=st_trafego2;

532\$ DELAY: 0.,Other:NEXT(558\$);

558\$ TRACE, -1,"-Transferred to station st_Estacionamento2 $\backslash n "$ ";

534\$ ROUTE: 0,st_Estacionamento2;

; Model statements for module: Choose 36

67\$ TRACE, -1,"-Choosing from 5 options $\backslash n ": ;$

572\$ BRANCH, 1:

If,TDIA $>=v H R s t(1,1)$.AND.TDIA $<=v H R s t(1,2), 82 \$$, Yes:

If,TDIA $>=v H R s t(2,1) . A N D . T D I A<=v H R s t(2,2), 82 \$$, Yes:

If,(TDIA+tavg(tl_rod_vz(aDestino $)))>=v H r s t(1,1)$.and.TDIA $<=v H r s t(1,2), 82 \$$, Yes:

If,(TDIA+tavg(tl_rod_vz(aDestino $)))>=v H r s t(2,1)$.and.TDIA $<=v H r s t(2,2), 82 \$$, Yes:

Else, 76\$,Yes;

; $\quad$ Model statements for module: Choose 39

$82 \$ \quad$ TRACE, $\quad-1$, ,-Choosing from 3 options $\backslash n "$ :;

573\$ BRANCH, 1:

If,nq(q_semi_vz_u) $>=1,83 \$$,Yes:

If,nq(q_cj_vz_u) $>=1,88 \$$,Yes:

Else, $97 \$$,Yes;

83\$ REMOVE: 1,q_semi_vz_u,Match_cjd L2:NEXT(106\$);

; Model statements for module: Choose 44

$106 \$ \quad$ TRACE, $\quad-1$, ,-Choosing from 2 options $\mid n ": ;$

$574 \$ \quad$ BRANCH, 1:

If, $\mathrm{vCc}(7,22)>=1$.or.vCc $(8,22)>=1$.or.vCc $(9,22)>=1$.or. $\mathrm{vCc}(10,22)>=1,107 \$$, Yes:

Else, $85 \$, Y e s ;$

; Model statements for module: Signal 15

$107 \$ \quad$ TRACE, $\quad-1$, ,-Sending signal sg_espera_trafegoln":;

$575 \$ \quad$ SIGNAL: sg_espera_trafego,1:NEXT $(85 \$)$;

; Model statements for module: Signal 12

$85 \$ \quad$ TRACE, $\quad-1, "-$ Sending signal DECISAOTOMADAln":; 


\section{6\$ SIGNAL: DECISAOTOMADA:NEXT(87\$);}

; Model statements for module: Delay 10

$87 \$ \quad$ TRACE, $\quad-1$, "-Delaying for time $0.1 \backslash \mathrm{n} "$ :;

577\$ DELAY: 0.1,,Other:NEXT(84\$);

; Model statements for module: Release 8

$84 \$ \quad$ TRACE, $\quad-1$, ,-Releasing resources $\backslash n ": ;$

578\$ RELEASE: r_CONTROLEDETRAFEGO,1:NEXT(86\$);

; Model statements for module: Leave 21

86\$ DELAY: 0.00,,Other:NEXT(605\$);

605\$ ASSIGN: M=st_trafego2;

590\$ DELAY: 0.,Other:NEXT(616\$);

$616 \$$ TRACE, -1,"-Transferred to station st_SEGUE_cavalo_d $\backslash n$ ":;

592\$ ROUTE: 0,st_SEGUE_cavalo_d;

$88 \$ \quad$ REMOVE: 1,q_cj_vz_u,Match_cjd2 L2:NEXT(104\$);

; Model statements for module: Choose 43

$104 \$ \quad$ TRACE, $\quad-1$,"-Choosing from 2 options $\backslash n ": ;$

630\$ BRANCH, 1:

If, $\mathrm{vCc}(7,22)>=1$.or.vCc $(8,22)>=1$.or.vCc $(9,22)>=1$.or.vCc $(10,22)>=1,105 \$$, Yes:

Else,91\$,Yes;

; Model statements for module: Signal 14

$105 \$ \quad$ TRACE, -1,"-Sending signal sg_espera_trafegoln":;

631\$ SIGNAL: sg_espera_trafego,1:NEXT(91\$);

; Model statements for module: Signal 13

$91 \$ \quad$ TRACE, $\quad-1, "-$ Sending signal DECISAOTOMADAln":;

632\$ SIGNAL: DECISAOTOMADA:NEXT(93\$);

; Model statements for module: Delay 11

93\$ TRACE, -1,"-Delaying for time $0.1 \backslash n ": ;$

633\$ DELAY: 0.1,,Other:NEXT(90\$);

; Model statements for module: Release 9

90\$ TRACE, -1,"-Releasing resources $\backslash n "$ :;

634\$ RELEASE: r_CONTROLEDETRAFEGO,1:NEXT(92\$);

; Model statements for module: Leave 22

$92 \$$ DELAY: 0.00, ,Other:NEXT(661\$);

661\$ ASSIGN: M=st_trafego2;

646\$ DELAY: 0.,,Other:NEXT(672\$);

$672 \$$ TRACE, -1,"-Transferred to station st_SEGUE_cavalo_d2 2 n":;

648\$ ROUTE: 0,st_SEGUE_cavalo_d2;

; Model statements for module: Leave 24

97\$ DELAY: 0.00, Other:NEXT(712\$);

$712 \$$ ASSIGN: M=st_trafego2;

697\$ DELAY: 0.,Other:NEXT(723\$);

723\$ TRACE, -1,"-Transferred to station st_Estacionamento2\n":;

699\$ ROUTE: 0,st_Estacionamento2;

; Model statements for module: Choose 37

$70 \$ \quad$ TRACE, $\quad-1$, "-Choosing from 2 options $\backslash n " ;$

$737 \$ \quad$ BRANCH, 1:

If,aJa_passou_ordena==0,ordena_rod,Yes:

Else, 62\$,Yes;

; Model statements for module: Ordena 2

ordena_rod STATION, st_ordena_rod; 


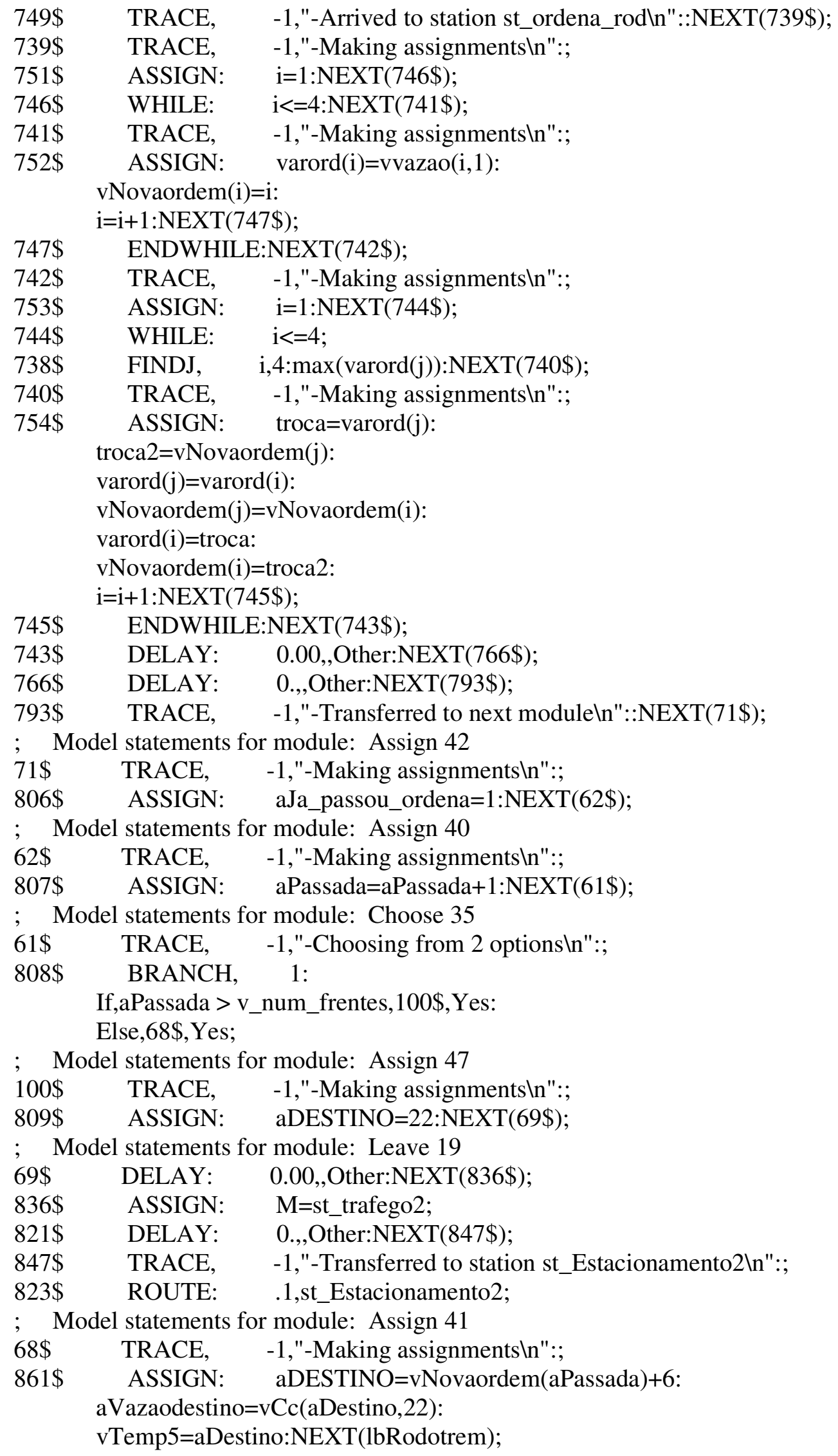


; Model statements for module: Choose 2

$14 \$ \quad$ TRACE, $\quad-1$, "-Choosing from 3 options $\backslash n " ;$

862\$ BRANCH, 1:

If,aVazaodestino $>=1,53 \$$, Yes:

If,aHadestino $==1,55 \$$,Yes:

Else, $37 \$$, Yes;

; Model statements for module: Assign 20

53\$ TRACE, -1,"-Making assignments $\backslash n "$ :;

863\$ ASSIGN: aHaDestino=1:NEXT(15\$);

; Model statements for module: Choose 3

$15 \$ \quad$ TRACE, $\quad-1$, ,-Choosing from 3 options $\backslash n "$ :;

$864 \$$ BRANCH, 1:

If, $\mathrm{vPrioriza}(\mathrm{aDestino}, \mathrm{aTipo})==1$ and $\cdot \mathrm{aRestricao}==0,115 \$$, Yes:

If,vPrioriza(aDestino,aTipo $)==1,29 \$$, Yes:

Else, $41 \$, Y e s ;$

; $\quad$ Model statements for module: Choose 47

$115 \$ \quad$ TRACE, $\quad-1$, ,-Choosing from 2 options $\backslash n "$ :;

$865 \$$ BRANCH, 1:

If, $\mathrm{vCc}(7,22)>=1$.or. $\mathrm{vCc}(8,22)>=1$.or.vCc $(9,22)>=1$.or. $\mathrm{vCc}(10,22)>=1,116 \$$, Yes:

Else, 20\$,Yes;

; Model statements for module: Signal 17

$116 \$$ TRACE, -1,"-Sending signal sg_espera_trafegoln":;

866\$ SIGNAL: sg_espera_trafego:NEXT(20\$);

; Model statements for module: Signal 3

20\$ TRACE, $\quad-1$, "-Sending signal DECISAOTOMADA $\backslash n ": ;$

867\$ SIGNAL: DECISAOTOMADA:NEXT(22\$);

; Model statements for module: Delay 1

$22 \$ \quad$ TRACE, $\quad-1$, ,-Delaying for time $0.1 \backslash \mathrm{n} ": ;$

868\$ DELAY: 0.1,,Other:NEXT(19\$);

; Model statements for module: Release 1

$19 \$ \quad$ TRACE, $\quad-1$, ,-Releasing resources $\backslash n ": ;$

$869 \$$ RELEASE: r_CONTROLEDETRAFEGO,1:NEXT(23\$);

; Model statements for module: Choose 6

23\$ TRACE, -1,"-Choosing from 10 options $\backslash n "$ :;

$870 \$$ BRANCH, 1:

If, afornec $==1,27 \$$, Yes:

If,aTipo ==truck,27\$,Yes:

If, aTipo==Rj_int,25\$,Yes:

If,aTipo==rj_pic, $25 \$$,Yes:

If,aTipo==tre_int,24\$,Yes:

If,aTipo==Tre_pic,24\$,Yes:

If,aTipo==rod_int, 28\$,Yes:

If,aTipo==rod_pic, $28 \$, Y e s:$

If,aTipo==rod_d_int,26\$,Yes:

Else, 26\$, Yes;

; Model statements for module: Assign 9

27\$ TRACE, -1,"-Making assignments $\backslash n$ ";

871\$ ASSIGN: aPassada=0:

Picture=toco_vz:NEXT $(21 \$)$;

; Model statements for module: Leave 1 
$21 \$ \quad$ DELAY: $\quad 0.00$, ,Other:NEXT $(898 \$)$;

898\$ ASSIGN: M=st_trafego2;

883\$ DELAY: 0.,Other:NEXT(909\$);

$909 \$ \quad$ TRACE, $\quad-1$, ,-Transferred to station st_SEGUE_USINAIn":;

885\$ ROUTE: 0,st_SEGUE_USINA;

; Model statements for module: Assign 7

$25 \$ \quad$ TRACE, -1,"-Making assignments $\backslash n "$;

923\$ ASSIGN: Picture=ro_ju_vz:

aPassada $=0: \operatorname{NEXT}(21 \$)$;

; Model statements for module: Assign 6

$24 \$ \quad$ TRACE, $\quad$-1,"-Making assignments $\backslash n " ;$

924\$ ASSIGN: aPassada=0:

Picture=trem_vz:NEXT $(21 \$)$;

; Model statements for module: Assign 10

$28 \$ \quad$ TRACE, $\quad$-1,"-Making assignments $\backslash n ": ;$

925\$ ASSIGN: Picture=rod_int_vz:

aPassada $=0$ :NEXT $(21 \$)$;

; Model statements for module: Assign 8

$26 \$$ TRACE, -1,"-Making assignments $\backslash n "$;

926\$ ASSIGN: Picture=rodotrem_d_int_vz:

aPassada=0:NEXT $(21 \$)$;

; Model statements for module: Choose 7

$29 \$ \quad$ TRACE, $\quad-1$, "-Choosing from 4 options $\backslash n "$;

927\$ BRANCH, 1:

If, $\mathrm{vRestricao}(\mathrm{aDestino}, 1)==0,115 \$$, Yes:

If, aTipo $==4$.or.aTipo $==5,18 \$$,Yes:

If,, Tipo $==6$.or.aTipo $==7,31 \$$,Yes:

Else, $115 \$$,Yes;

; Model statements for module: Choose 5

$18 \$ \quad$ TRACE, $\quad-1$, ,-Choosing from 5 options $\backslash n "$ :;

$928 \$$ BRANCH, 1:

If,TDIA $>=v H R s t(1,1)$. AND.TDIA $<=v H R s t(1,2), 41 \$$,Yes:

If,TDIA $>=v H R s t(2,1)$.AND.TDIA $<=v H R s t(2,2), 41 \$$, Yes:

If,(TDIA+tavg(tl_tre_vz(aDestino) $))>=v H r s t(1,1)$.and.TDIA $<=v H r s t(1,2), 41 \$$, Yes:

If,(TDIA+tavg(tl_tre_vz(aDestino $)))>=v H r s t(2,1)$.and.TDIA $<=v \operatorname{vHrst}(2,2), 41 \$$, Yes:

Else, $115 \$, Y e s ;$

; Model statements for module: Choose 13

$41 \$ \quad$ TRACE, $\quad-1$, "-Choosing from 2 options $\backslash n "$;

929\$ BRANCH, 1:

If,aJa_passou_ordena $==0$,ordena_tre,Yes:

Else, $17 \$$,Yes;

; Model statements for module: Ordena 1

ordena_tre STATION, st_ordena_tre;

941\$ TRACE, -1,"-Arrived to station st_ordena_treln"::NEXT(931\$);

931\$ TRACE, -1,"-Making assignments $\backslash n "$ :;

943\$ ASSIGN: i=1:NEXT(938\$);

938\$ WHILE: $\quad \mathrm{i}<=4$ :NEXT(933\$);

933\$ TRACE, $\quad$-1,"-Making assignments $\backslash n " ; ;$

944\$ ASSIGN: $\operatorname{varord}(\mathrm{i})=\operatorname{vvazao}(\mathrm{i}, 1)$ :

vNovaordem $(\mathrm{i})=\mathrm{i}$ : 


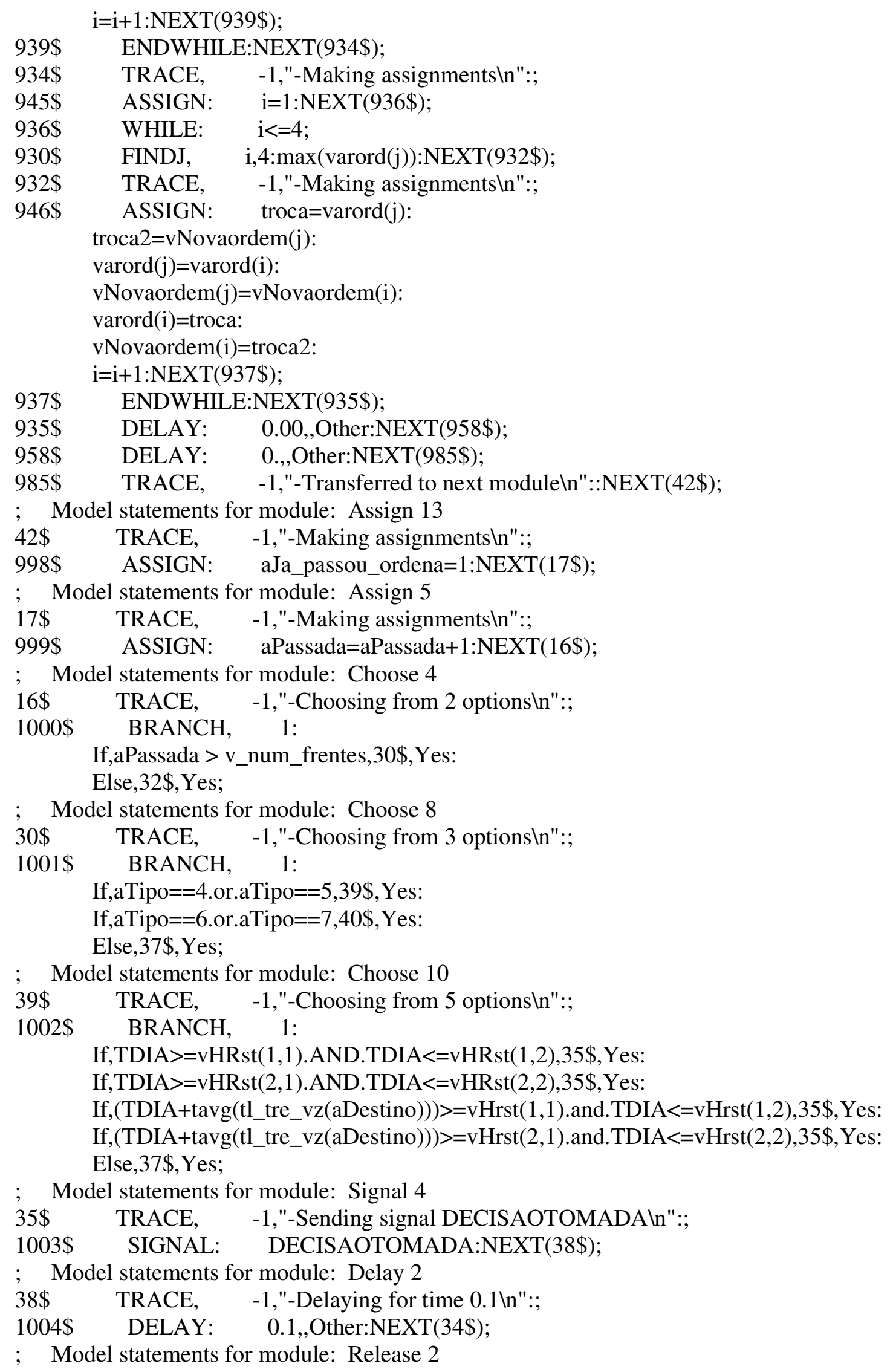




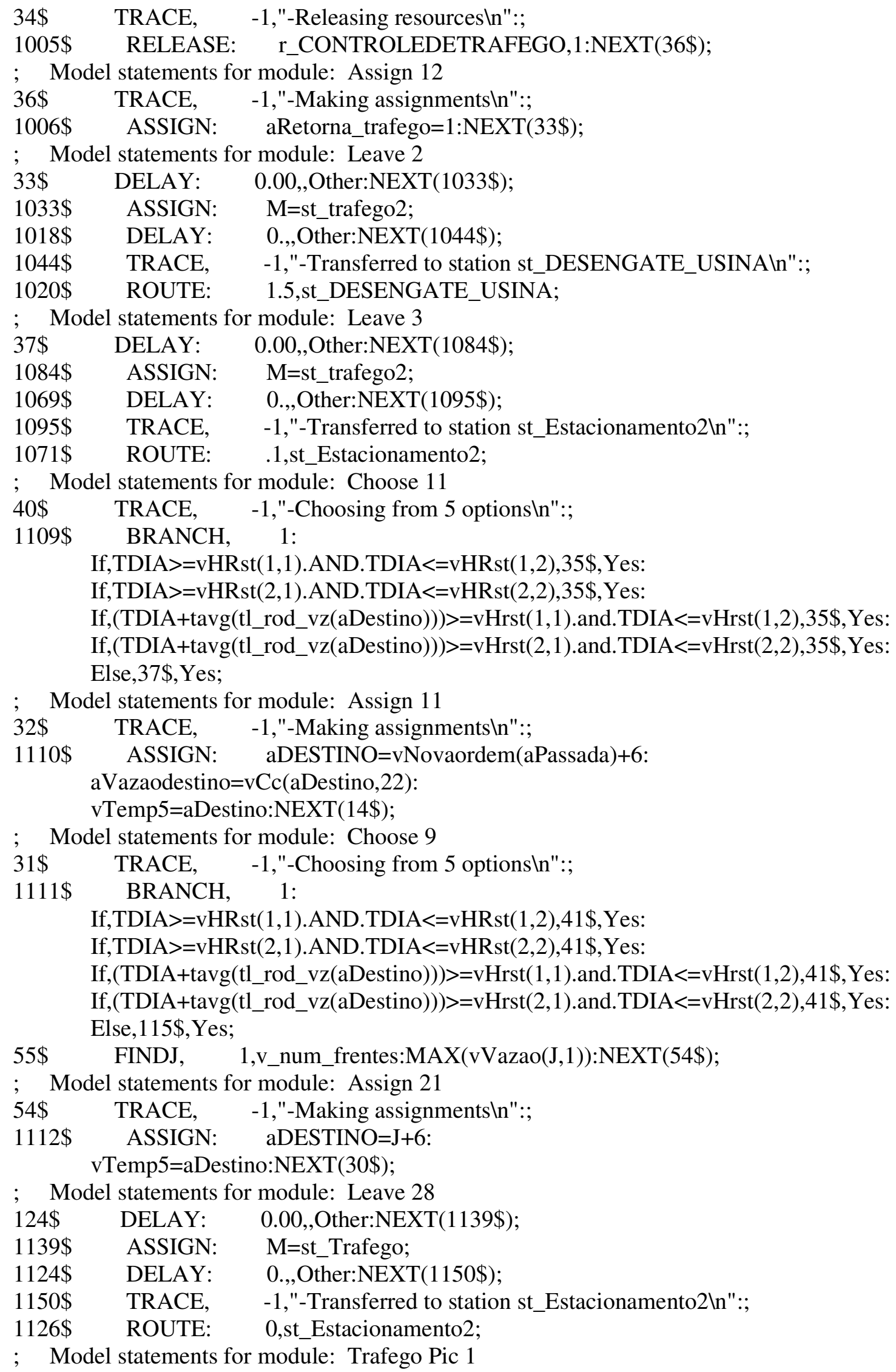




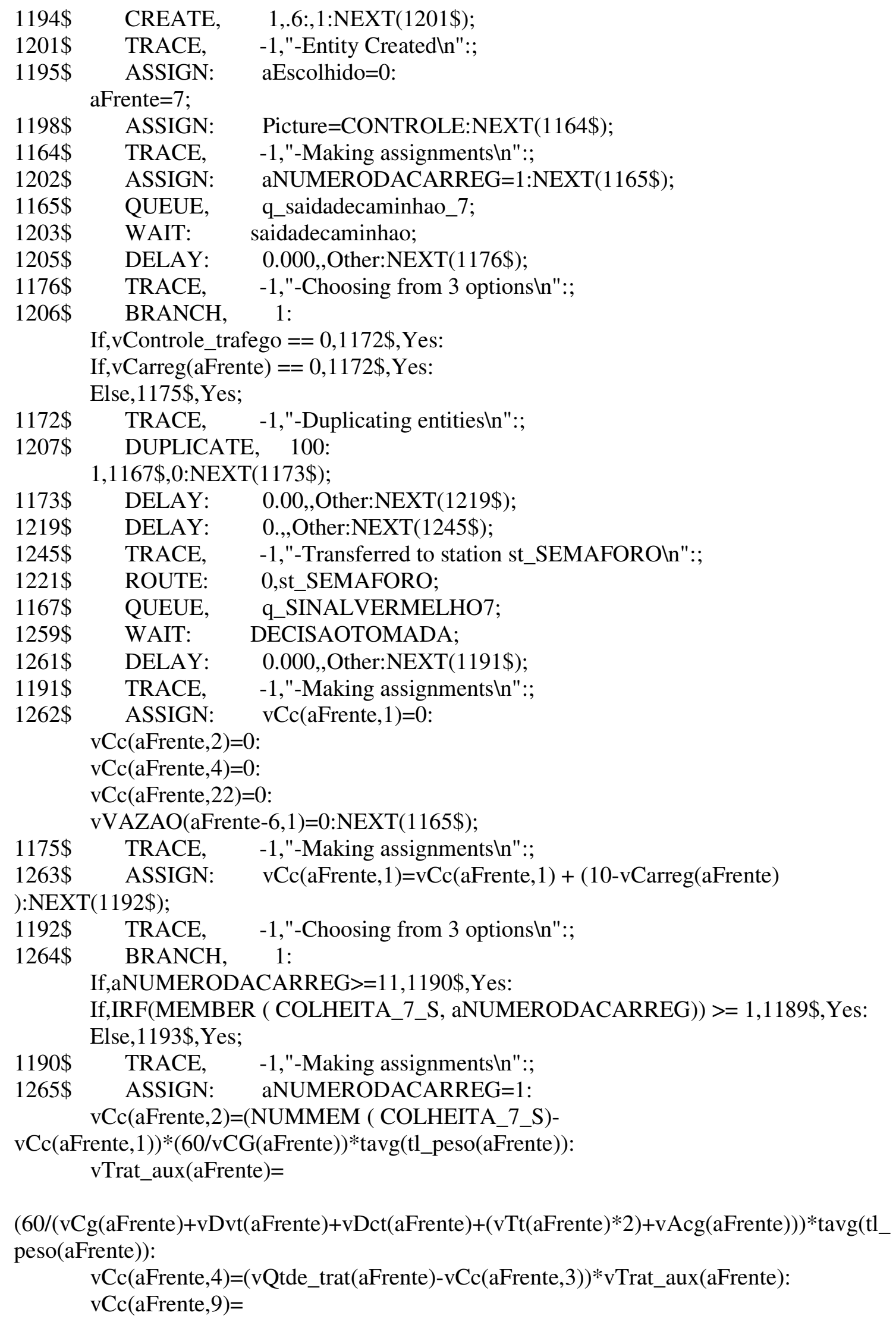


$\operatorname{tavg}\left(\mathrm{tl} \_\right.$truck_ch(aFrente $\left.)\right)+\operatorname{tavg}\left(\mathrm{tl} \_t\right.$ truck_vz(aFrente $\left.)\right)+\mathrm{vDvt}(\mathrm{aFrente})+\mathrm{vDct}(\mathrm{aFrente})+(\mathrm{vTt}(\mathrm{aF}$ rente)*2) $+v \operatorname{Acg}($ aFrente $)$ :

$\mathrm{vCc}(\mathrm{aFrente}, 10)=$

$\operatorname{tavg}\left(t \mathrm{tl} \_r j \_c h(a F r e n t e)\right)+\operatorname{tavg}\left(t \mathrm{t} \_r j \_v z(a F r e n t e)\right)+v \operatorname{Dvt}($ aFrente $)+v \operatorname{Dct}($ aFrente $)+\left(\mathrm{vTt}(\text { aFrente })^{*}\right.$ 2)+vAcg (aFrente):

$\operatorname{vCc}(\mathrm{aFrente}, 11)=$

$\operatorname{tavg}\left(\mathrm{tl} \_\right.$tre_ch(aFrente $\left.)\right)+\operatorname{tavg}\left(\mathrm{tl} \_\right.$tre_vz(aFrente) $)+v \operatorname{vvt}(\mathrm{aFrente})+\mathrm{vDct}(\mathrm{aFrente})+(\mathrm{vTt}(\mathrm{aFrente}$ )*2)+vAcg (aFrente):

$\operatorname{vCc}($ aFrente, 12$)=$

$\operatorname{tavg}\left(\mathrm{tl} \_r o d \_c h(a F r e n t e)\right)+\operatorname{tavg}\left(\mathrm{tl} \_r o d \_v z(a F r e n t e)\right)+v D v t($ aFrente $)+v D c t(a F r e n t e)+(v T t(a F r e n$

te)*2) $+v \operatorname{Acg}($ aFrente $)$

:NEXT(1177\$);

$1177 \$ \quad$ TRACE, $\quad-1$, ,-Making assignments $\backslash n ": ;$

$1266 \$$ ASSIGN:

$\mathrm{vCc}($ aFrente, 13$)=\left(\mathrm{vCc}(\right.$ aFrente, 5$) * \operatorname{tavg}\left(\mathrm{tl} \_\right.$peso_truck $($aFrente $\left.\left.)\right) * 60\right) / \mathrm{vCc}($ aFrente, 9$)$ :

vCc $($ aFrente, 14$)=(\operatorname{vCc}($ aFrente, 6$) * \operatorname{tavg}($ tl_peso_rj(aFrente $) * 60) / v C c($ aFrente, 10$)$ :

$\mathrm{vCc}(\mathrm{aFrente}, 15)=\left(\mathrm{vCc}(\mathrm{aFrente}, 7) * \operatorname{tavg}\left(\mathrm{tl} \_\right.\right.$peso_tre $\left.\left.(\mathrm{aFrente})\right) * 60\right) / \mathrm{vCc}($ aFrente, 11$)$ :

$\mathrm{vCc}(\mathrm{aFrente}, 16)=\left(\mathrm{vCc}(\mathrm{aFrente}, 8) * \operatorname{tavg}\left(\mathrm{tl} \_\right.\right.$peso_rod $($aFrente $\left.\left.)\right) * 60\right) / \mathrm{vCc}($ aFrente, 12$)$ :

$\mathrm{vCc}(\mathrm{aFrente}, 17)=\mathrm{vCc}(\mathrm{aFrente}, 13)+\mathrm{vCc}(\mathrm{aFrente}, 14)+\mathrm{vCc}($ aFrente, 15$)+\mathrm{vCc}(\mathrm{aFrente}, 16)$ :

$\mathrm{vCc}(\mathrm{aFrente}, 18)=1: \operatorname{NEXT}(1169 \$)$;

$1169 \$ \quad$ TRACE, $\quad-1$, --Choosing from 2 options $\backslash n " ;$

$1267 \$$ BRANCH, 1:

If, $(\mathrm{vCc}(\mathrm{aFrente}, 18) * \mathrm{vCc}(\mathrm{aFrente}, 2))<\mathrm{vCc}(\mathrm{aFrente}, 4), 1170 \$$, Yes:

Else, $1187 \$, Y e s ;$

$1170 \$ \quad$ TRACE, $\quad$-1,"-Making assignments $\backslash n ": ;$

$1268 \$ \quad$ ASSIGN: $\quad \mathrm{vCc}($ aFrente, 19$)=\mathrm{vCc}($ aFrente, 2$)$ :

$\operatorname{vCc}($ aFrente, 20$)=1: \operatorname{NEXT}(1180 \$)$;

$1180 \$ \quad$ TRACE, $\quad-1$, ,-Choosing from 2 options $\backslash n ": ;$

$1269 \$$ BRANCH, 1:

If, $\mathrm{vCc}(\mathrm{aFrente}, 20)==1,1181$ \$, Yes:

Else, $1184 \$$,Yes;

1181\$ TRACE, -1,"-Choosing from 2 options $\backslash n " ;$

1270\$ BRANCH, 1:

If, $\mathrm{vCc}(\mathrm{aFrente}, 2) * 1.1>\mathrm{vCc}(\mathrm{aFrente}, 17), 1182 \$$, Yes:

Else, $1183 \$$, Yes;

$1182 \$ \quad$ TRACE, $\quad-1, "-M a k i n g$ assignments $\backslash n " ; ;$

$1271 \$ \quad$ ASSIGN: $\quad \mathrm{vCc}($ aFrente, 21$)=(\mathrm{vCc}($ aFrente, 19$) * 1.1)-$

vCc(aFrente, 17):NEXT(1179\$);

$1179 \$ \quad$ TRACE, $\quad-1$,"-Choosing from 2 options $\mid n ": ;$

$1272 \$$ BRANCH, 1:

If, $\mathrm{vCc}(\mathrm{aFrente}, 17)==0,1178 \$$, Yes:

Else, $1186 \$$,Yes;

$1178 \$$ TRACE, $\quad-1$, "-Making assignments $\backslash n ": ;$

1273\$ ASSIGN: $\quad$ vCc $($ aFrente, 22$)=101$ :

vVAZAO(aFrente-6,1)=vCc(aFrente, 22):NEXT $(1172 \$)$; 


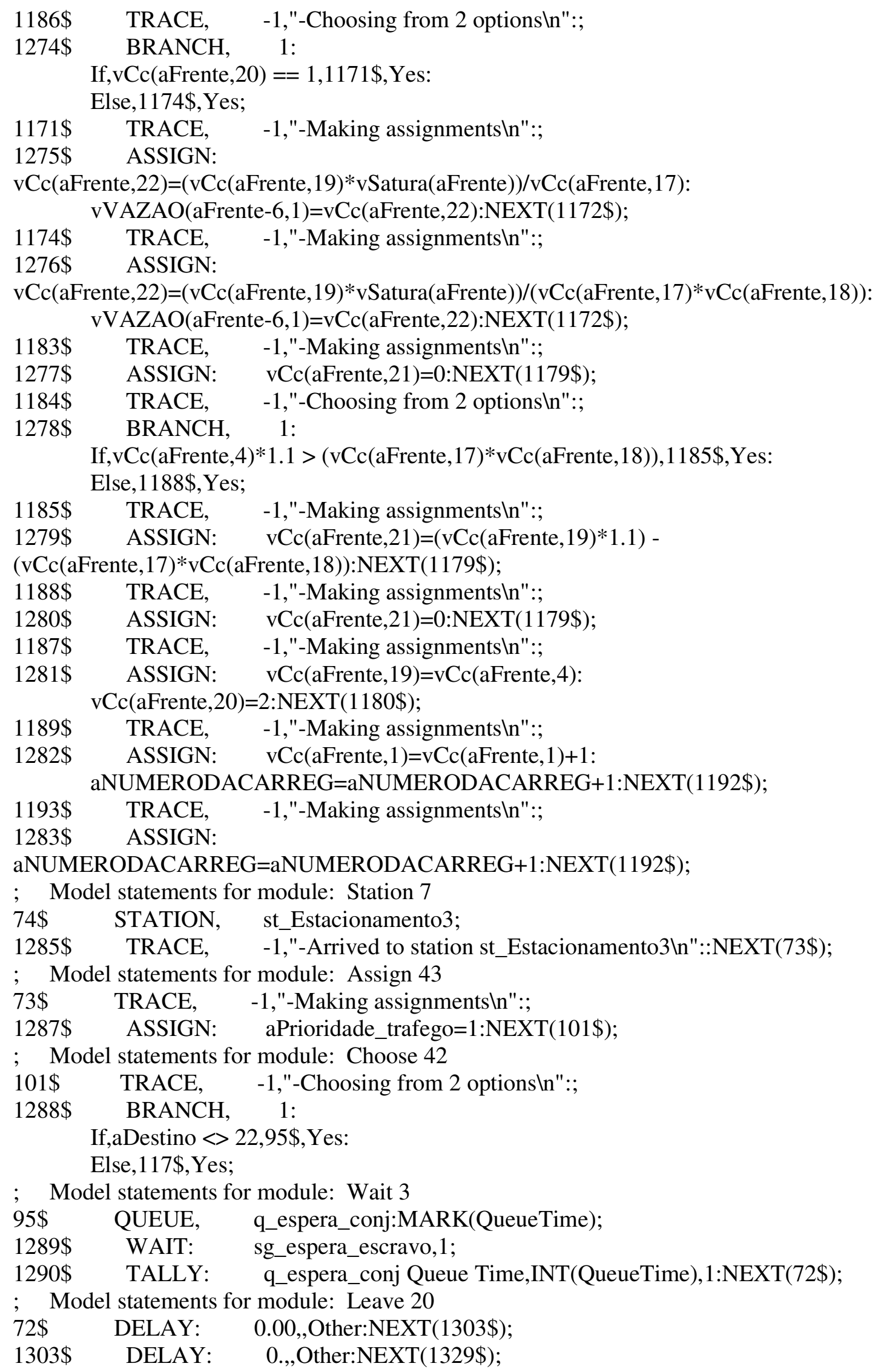




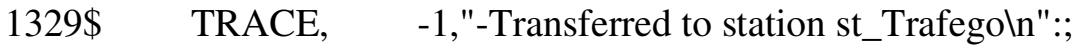

$1305 \$$ ROUTE: 1,st_Trafego;

; Model statements for module: Duplicate 5

$117 \$ \quad$ TRACE, $\quad$-1,"-Duplicating entities $\backslash n ": ;$

$1343 \$$ DUPLICATE, 100:

$1,113 \$, 0: \operatorname{NEXT}(102 \$)$;

; $\quad$ Model statements for module: Wait 4

$102 \$$ QUEUE, q_espera_vazao:MARK(QueueTime);

1344\$ WAIT: sg_espera_vazao,1;

1345\$ TALLY: q_espera_vazao Queue Time,INT(QueueTime),1:NEXT(129\$);

; $\quad$ Model statements for module: Dispose 8

$129 \$ \quad$ TRACE, $\quad-1$, "-Disposing entity $\backslash n " ;$

1347\$ DISPOSE: Yes;

; Model statements for module: Station 9

$120 \$$ STATION, st_Estacionamento4;

$1349 \$ \quad$ TRACE, $\quad-1$, --Arrived to station st_Estacionamento4ln"::NEXT(98\$);

; Model statements for module: Station 10

$128 \$$ STATION, st_trafego3;

$1352 \$$ TRACE, -1,"-Arrived to station st_trafego3 $\backslash n ":: N E X T(125 \$)$;

; Model statements for module: Choose 50

$125 \$ \quad$ TRACE, $\quad-1$, ,-Choosing from 2 options $\backslash n " ; ;$

1354\$ BRANCH, 1:

If,vBate_volta==1.and.(aTipo==rod_pic .or. aTipo $==$ rod_d_pic),127\$,Yes:

Else, $110 \$$,Yes;

; Model statements for module: Signal 19

$127 \$ \quad$ TRACE, $\quad$-1,"-Sending signal sg_espera_vazaoln":;

$1355 \$ \quad$ SIGNAL: $\quad$ sg_espera_vazao,1:NEXT(110\$); 